\title{
Propriedades Vibracionais de Defeitos de Nitrogênio em Nanotubos de Carbono
}

\author{
Leandro de Andrade Silva \\ Orientador: Prof. Dr. Antônio José Roque da Silva
}

Dissertação apresentada ao Instituto de Física para a obtenção do título de Mestre em Ciências.

Comissão Examinadora:

Prof. Dr. Antônio José Roque da Silva (IF-USP/Orientador)

Prof. Dr. Ado Jório de Vasconcelos (UFMG)

Profa. Dra. Luísa Maria Ribeiro Scolfaro (IF-USP)

São Paulo

2008 
Dedico este trabalho a todos aqueles que direta ou indiretamente contribuíram para a sua realização. 
"Há muito espaço lá embaixo"

Richard Feynman 


\section{Agradecimentos}

Agradeço à minha familia por todo o apoio, aos meus amigos, especialmente àqueles da minha sala, que através de discussões engrandeceram meus conhecimentos. Obrigado também ao Prof. Dr. Antônio José Roque da Silva, meu orientador, por me ter confiado liberdade na condução da pesquisa e resolução dos problemas e pelo necessário acompanhamento.

Também agradeço ao CNPq pelo financiamento do projeto. 


\section{Sumário}

Resumo I

Abstract III

$\begin{array}{ll}\text { Introdução } & 1\end{array}$

1 Fundamentos Teóricos $\quad 8$

1.1 Aproximação de Born-Oppenheimer . . . . . . . . . . . . 9

1.2 Cálculo da Estrutura Eletrônica . . . . . . . . . . . . . . 12

1.2.1 Aproximação de Hartree-Fock . . . . . . . . . . . . . 12

1.3 Teoria do Funcional da Densidade - DFT . . . . . . . . . . . 13

1.3.1 Equações de Kohn-Sham . . . . . . . . . . . . . 15

1.4 Dinâmica de Rede . . . . . . . . . . . . . . . . . . . . . . . . 18

1.4.1 Aproximação Harmônica ． . . . . . . . . . . . . . 20

1.5 Cálculos ab initio de fônons . . . . . . . . . . . . . . . 21

2 Espectroscopia Raman $\quad 24$

2.1 Espalhamento Raman . . . . . . . . . . . . . . . . . 24

2.2 Nanotubos de Carbono . . . . . . . . . . . . . . . . . . . . . . . . 29

2.2.1 Modo de Respiração Radial . . . . . . . . . . . . . . . . . 29

2.2 .2 Banda D . . . . . . . . . . . . . . . . . . 30

2.2 .3 Banda $G \ldots \ldots \ldots \ldots$

3 Metodologia 33

3.1 Programa Utilizado . . . . . . . . . . . . . . . . . . . . 33

3.1.1 Cálculo da Energia Total . . . . . . . . . . . . . . 35 
3.1.2 Cálculo das Forças . . . . . . . . . . . . . . . . 36

3.1.3 Cálculo da Estrutura de Equilíbrio . . . . . . . . . . 36

3.1 .4 Cálculo de Fônons . . . . . . . . . . . . . . . . . . 37

4 Resultados e Discussões 39

4.1 Sistemas Estudados . . . . . . . . . . . . . . . . . . . . . . . . 39

4.2 Posições de Equilíbrio . . . . . . . . . . . . . . . . . . . . . 39

4.3 Sistemas Puros . . . . . . . . . . . . . . . . . . . . . . . . 40

4.3.1 Nanotubo $(5,5) \ldots \ldots \ldots$. . . . . . . . . . . . . 41

4.3 .2 Nanotubo $(8,0) \ldots \ldots \ldots \ldots$

4.4 Sistemas com Defeitos . . . . . . . . . . . . . . . . . 49

4.4 .1 Nanotubo $(5,5) \ldots \ldots \ldots \ldots$

4.4.2 Nitrogênio Substitucional - $1 \mathrm{~N} \ldots \ldots$

4.4.3 Monovacância Rodeada por 3 Nitrogênios - 3NV . . . 59

4.4.4 Divacância Rodeada por 4 Nitrogênios - 4ND . . . . . . 66

4.4 .5 Nanotubo $(8,0) \quad \ldots \ldots \ldots \ldots$. . . . . . . . . . . . . . 71

4.4 .6 Nitrogênio Substitucional . . . . . . . . . . . . . . 71

4.4.7 Monovacância Rodeada por 3 Nitrogênios - 3NV _ . . . 77

4.4.8 Divacância Rodeada por 4 Nitrogênios - 4ND . . . . . 83

4.5 Resumo dos Resultados . . . . . . . . . . . . . . . . . . . 89

5 Conclusões 93

A Nanotubos de Carbono $\quad 95$

A.1 Propriedades Estruturais . . . . . . . . . . . . . . . . . . . . 95

A.2 Propriedades Energéticas _. . . . . . . . . . . . . . 100

$\begin{array}{ll}\text { Referências Bibliográficas } & 102\end{array}$ 


\section{Resumo}

O trabalho anteriormente realizado pelo nosso grupo [12], onde foram simulados defeitos de nitrogênio em nanotubos de carbono, apresentou resultados interessantes relativos às energias e propriedades eletrônicas. A interpretação dos resultados teóricos obtidos levou à proposta da Divacância rodeada por 4 Nitrogênios como estrutura mais estável para o nitrogênio tipo piridina [68], em constraste com aquela proposta pelos experimentais [14], uma Monovacância rodeada por 3 Nitrogênios. Os cálculos das propriedades eletrônicas da Divacância reproduziram as medidas experimentais na investigação de sensores de amônia. Dessa forma, como informação adicional na determinação da estrutura mais estável, o presente trabalho investigou as propriedades vibracionais daqueles sistemas que apresentaram menor energias de formação.

Foram calculadas as freqüências vibracionais dos seguintes três defeitos: Nitrogênio Substitucional (1N), Monovacância rodeada por 3 Nitrogênios (3NV) e Divacância rodeada por 4 Nitrogênios (4ND) e comparadas com os resultados para os tubos puros. Utilizou-se a aproximação de supercélula, com 140 átomos para um tubo metálico $(5,5)$ e 160 para um tubo semicondutor $(8,0)$. Como o objetivo é identificar as características de cada sistema, focalizou-se na comparação dos valores das freqüências Raman ativas mais intensas.

Os cálculos foram realizados com o código SIESTA [67], utilizando DFT com o formalismo dos pseudopotenciais e a aproximação GGA-PBE. As freqüências foram obtidas pelo Metódo Direto pelo mesmo programa.

Os resultados mostraram diferenças quanto à quebra de degenerescências, que ocorre devido à quebra da simetria do sistema puro e quanto à mudança dos valores das freqüências dos modos. Como característica geral, os defeitos fazem com que as freqüências da banda mais baixa de energia do 
espectro Raman sofram shifts negativos, ou seja, afastam os picos para energias mais baixas. O modo de freqüência intermediária sofre um shift positivo e os modos da banda $G$ voltam a apresentar valores negativos. Os splittings, bem como os valores numéricos dos shifts variam conforme o tipo de defeito e o tipo de sistema dopado (armchair ou zig-zag).

Apesar de não apresentar diferenças consideravelmente grandes para os valores de shifts e splitings entre os defeitos, o comportamento qualitativo distinto para os modos RBMs é uma boa ferramenta para a diferencição desses defeitos através de espectroscopia vibracional. 


\section{Abstract}

A previous work developed in our own group [12] on which nitrogen defects on carbon nanotubes were simulated presented very interesting results regarding the energetics and the electronic properties. The interpretation of the theoretical outcomes led us to propose the Divacancy surrounded by $4 \mathrm{ni}-$ trogen atoms as the most stable structure for a pyridine-like nitrogen [68], in contrast to the one proposed by the experimentalists, namely the Monovacancy surrounded by 3 nitrogen atoms [14]. Calculations of the electronic properties of the Divacancy have reproduced the experimental data. In this way as additional information for determining the actual most stable structure the present work investigated the vibrational properties of those systems that showed the lowest formation energies.

We performed the calculations of the vibrational frequencies for the following three defects: Substitutional nitrogen atom (1N), Monovacancy surrounded by 3 nitrogen atoms (3NV) and Divacancy surrounded by 4 nitrogen atoms (4ND). Then the frequencies were compared to those ones from the pure tubes. We used the supercell approximation with 140 atoms for a $(5,5)$ metallic tube and 160 for a $(8,0)$ semiconducting tube. Since the present work aims to identify the main features of each system we focused on the comparison of the values of the strongest Raman active modes.

All the calculations were carried out by the SIESTA code [67], using DFT with the pseudopotential formalism [22,47] and GGA approximation [27]. Then the frequencies were evaluated using the Direct Method.

The results showed differences on the degeneracy splittings, which are caused by the symmetry-breaking due to the introduction of defects, and also differences on the shifts of the numerical values of the frequencies. As general 
feature, the defects caused the low band frequencies modes of Raman spectrum to have a negative shift, i.e. they push the peaks further to lower energies. The intermediate mode shifts positively and the $G$ band modes show negative shifts again. The splittings as well as those shifts change depending on the type of the defect and the type of the doped system (armchair or zig-zag).

Although not showing significant differences for shifts and splittings between the defects, the qualitatively distinct behavior for RBMs modes is a good tool to tell them apart using vibrational spectroscopy. 


\section{Introdução}

As especulações a respeito da composição da matéria datam da época dos gregos antigos. Porém, somente no início do século passado, com investigação científica consistente pôde-se avançar nessa direção. Os átomos são os elementos fundamentais da matéria e dentre eles, merece especial atenção o carbono. Através de suas formas alotrópicas, é capaz de formar substâncias de propriedades tão distantes, como o frágil e barato grafite (Figura 1) e o duro e valioso diamante (Figura 2), além de compor a matéria orgânica. O carbono, número atômico seis, está na segunda linha da Tabela Periódica, possuindo, portanto, elétrons até a segunda camada ocupando orbitais $s$ e $p$ de energias próximas $\left(C_{6}-1 s^{2} 2 s^{2} 2 p^{2}\right)$. Tal fato possibilita ao carbono gerar uma variedade de ligações, como na Figura 3. Essa propriedade causada pela disposição espacial dos átomos chama-se hibridização.
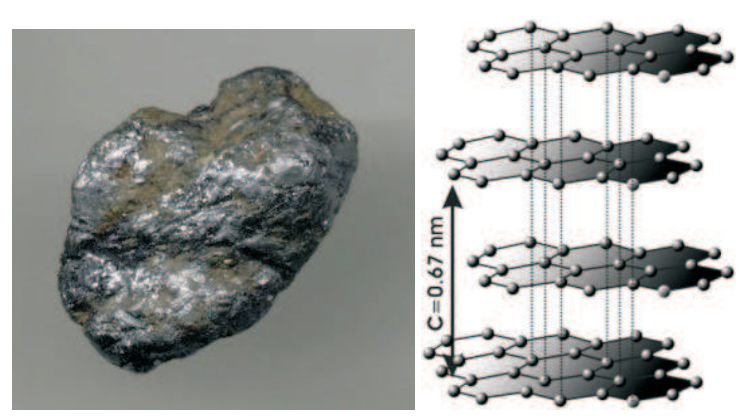

Figura 1: À esquerda: Grafite maciço. À direita: Estrutura cristalina do grafite. [1]

Em 1985 formas esféricas compostas de hexágonos planos como no grafeno e esfericidade garantida por pentágonos foram descobertos e chamados fulerenos [3] (Figura 4). Mais tarde formas cilíndricas também foram des- 
cobertas e chamadas nanotubos [4]. Posteriormente essas estruturas foram interpretadas como uma folha de grafeno devidamente dobrada(Figura 5). Essas estruturas possuem dimensões nanométricas e propriedades notáveis, constituindo grande foco do novo ramo da ciência, a Nanociência.

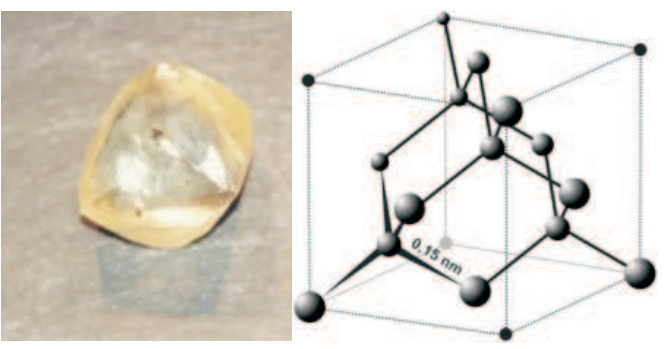

Figura 2: À esquerda: Cristal bruto de diamante. À direita: Estrutura cristalina do diamante. [2]

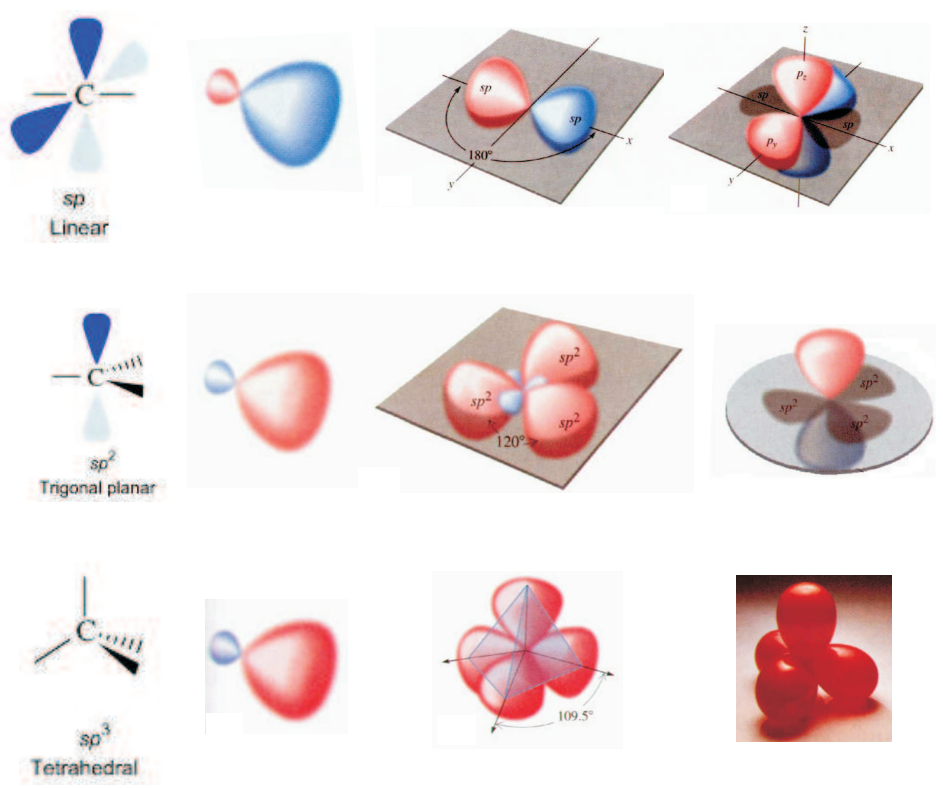

Figura 3: As três hibridizações possíveis para os orbitais do carbono (três filas). As colunas representam as várias visualizações. Na primeira a estrutura dos orbitais é mostrada, onde as linhas são os orbitais híbridos que formarão a ligação. Na segunda coluna há a representação dos orbitais híbridos isolados $s p, s p^{2}$ e $s p^{3}$. Na terceira coluna, todos os orbitais híbridos são mostrados. Finalmente, na quarta coluna, todos os orbitais são apresentados no átomo. [18] 


\section{Nanotubos}

Os nanotubos de carbono (Figura 6) possuem alta dureza e condutividade térmica, devendo sua grande importância à flexibilidade de suas propriedades eletrônicas, a saber, podem atuar como semicondutores ou metais, dependendo da forma como se pode associar o seu enrolamento da folha de grafeno. Contudo, essas propriedades podem ser modificadas e adequadamente manipuladas pela adição de defeitos. Grande interesse nesse processo consiste do armazenamento de gases [5] e da manipulação das propriedades eletrônicas, tornando possível a confecção de novos aparelhos semicondutores, como sensores [6].

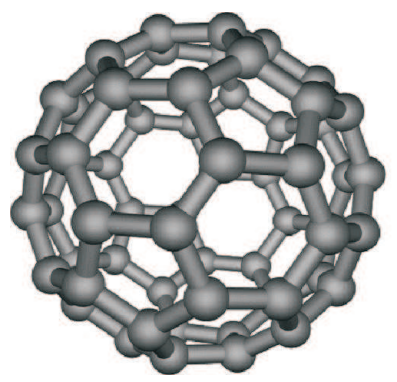

Figura 4: Fulereno $C_{60}$.

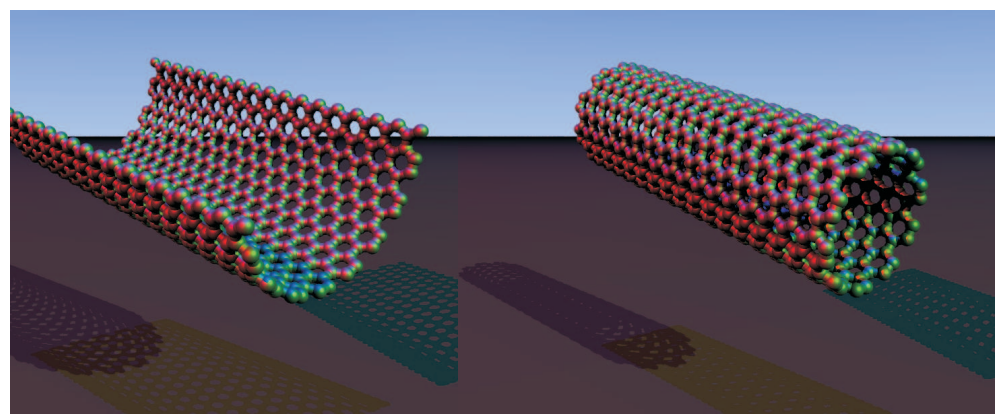

Figura 5: Nanotubo de Carbono visto como uma folha de grafeno enrolada. [7]

Recentemente, descobriu-se que compostos grafíticos como o $B N$ [8] (Figura 7), $B C_{2} N$ [9] ou $C_{3} N_{4}$ [10] também apresentam formas tubulares e foram investigados teórica e experimentalmente, o que despertou o interesse 
para estudos de defeitos em nanotubos de carbono pela introdução de seus vizinhos imediatos da tabela: B e N [11-14].
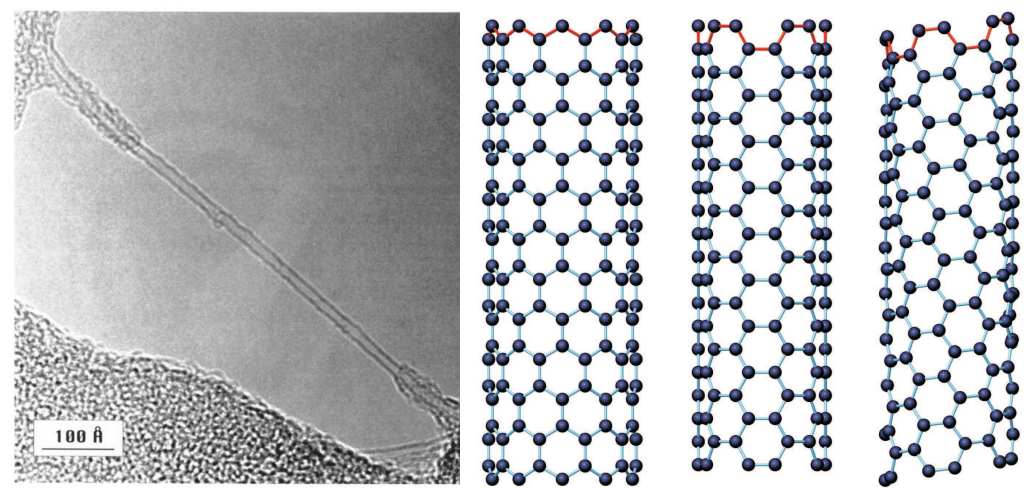

Figura 6: Imagem de Microscópio Eletrônico de Transmissão (TEM) de um Nanotubo de Carbono de parede única - SWNT (à esquerda) obtido experimentalmente e três exemplos de estruturas construídas teoricamente. [15]
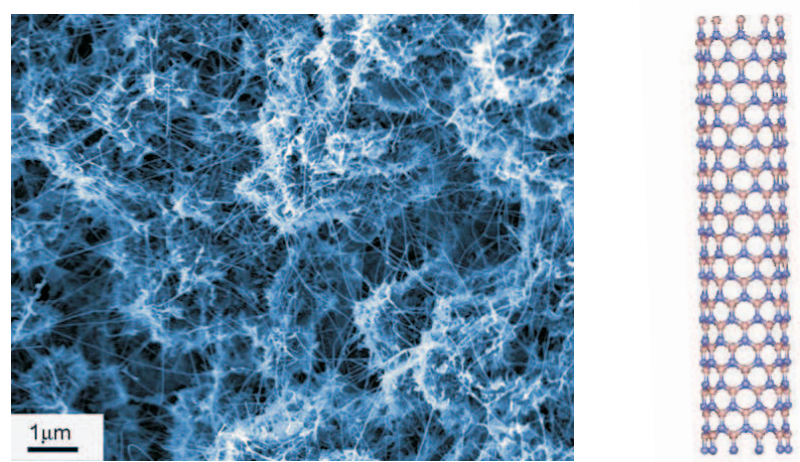

Figura 7: À esquerda: Imagem de Microsópio Eletrônico de Varredura (SEM) de Nanotubos de Nitreto de Boro. À direita: Modelo Teórico dessas estruturas. [16]

Nos nanotubos dopados com nitrogênio surgem níveis na região da energia de Fermi [14], como mostrado na Figura 8, provendo elétrons para a banda de condução. Portanto, esses nanotubos ou são metálicos ou possuem gap muito pequeno. Uma importante aplicação dessas estruturas constitui a confecção de sensores de gases, em especial, de amônia $[12,17]$. 


\section{Motivação}

Tubos dopados com nitrogênio apresentam dois tipos para as ligações: $s p^{2}$ e do tipo piridina [68]. O primeiro caso ocorre quando o nitrogênio é substitucional simples (ou seja, está simplesmente ocupando um sítio de carbono) e o segundo força o átomo de nitrogênio a estar vizinho a alguma vacância, possuindo somente 2 átomos de carbono como primeiros vizinhos. A estrutura proposta pelos experimentais como mais estável é composta por uma vacância rodeada por três nitrogênios (Figura 9) [14]. Estudos de energia de formação realizados no nosso grupo, mostraram que a estrutura mais estável numa atmosfera de amônia correspondia a uma divacância rodeada por 4 nitrogênios. Além disso, resultados relativos às propriedades eletrônicas desses sistemas apontaram reprodução daqueles experimentais para a estrutura da divacância [12].

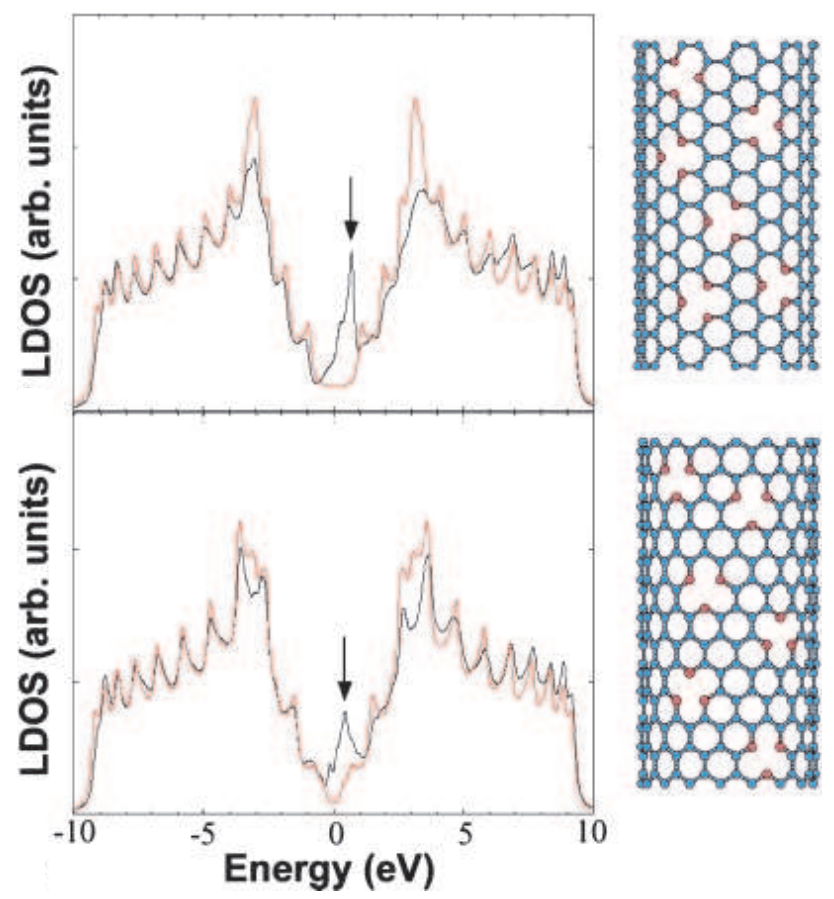

Figura 8: Acima: Densidade de Estados Local (LDOS) calculada para o nanotubo armchair $(10,10)$ para a estrutura do defeito à direita. Abaixo: Densidade de Estadois Locl (LDOS) calculada para o nanotubo zig-zag $(17,0)$ para a estrutura à direita. [14] 

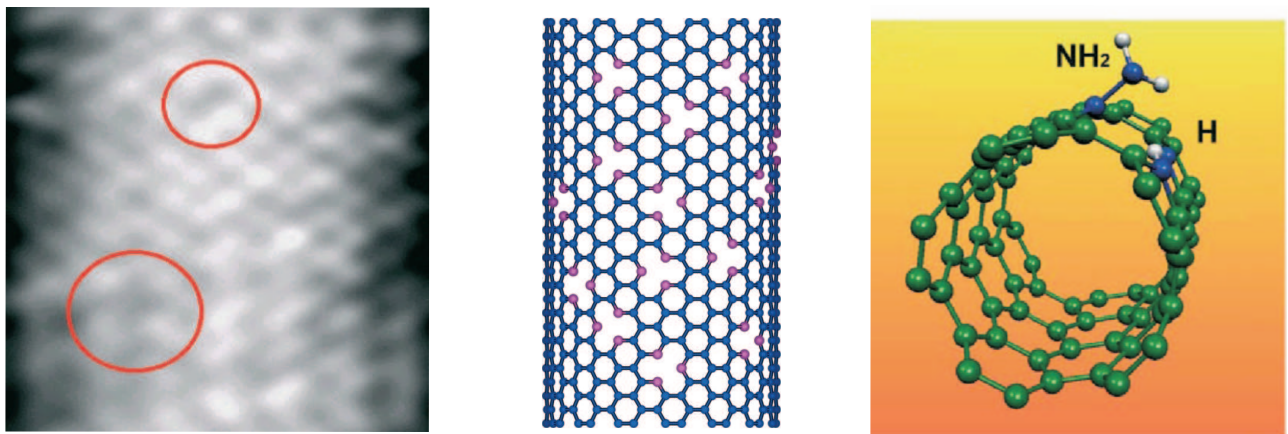

Figura 9: À esquerda: Imagem de Microscópio de Tunelamento por Varredura (STM) dos defeitos de nitrogênio. Ao centro: Geometria mais estável proposta pelos experimentais para os defeitos de nitrogênio. À direita: Geometria do defeito ligado à amônia, também segundo os experimentais. [14]

Haja vista a grande eficiência desses sistemas no monitoramento de gases tóxicos, torna-se urgente a obtenção de maiores informações sobre esses defeitos.

Constituem poderosa ferramenta para a caracterização dos sistemas moleculares, em especial estrutural, as várias espectroscopias. A espectroscopia vibracional, através da análise do espalhamento Raman, mostrou-se eficiente na caracterização das amostras de nanotubos, fornecendo dentre outras coisas, informações quanto à distribuição de diâmetros numa amostra [19], permitindo assim um controle de produção de determinados nanotubos, bem como a pureza da amostra.

O presente trabalho se propõe a extrair e analisar, através de cálculos $a b$ initio, a espectroscopia vibracional (espectro de fônons) para as geometrias mais estáveis, objetivando-se encontrar modos vibracionais que caracterizem cada defeito, em especial aqueles modos Raman ativos mais intensos. 

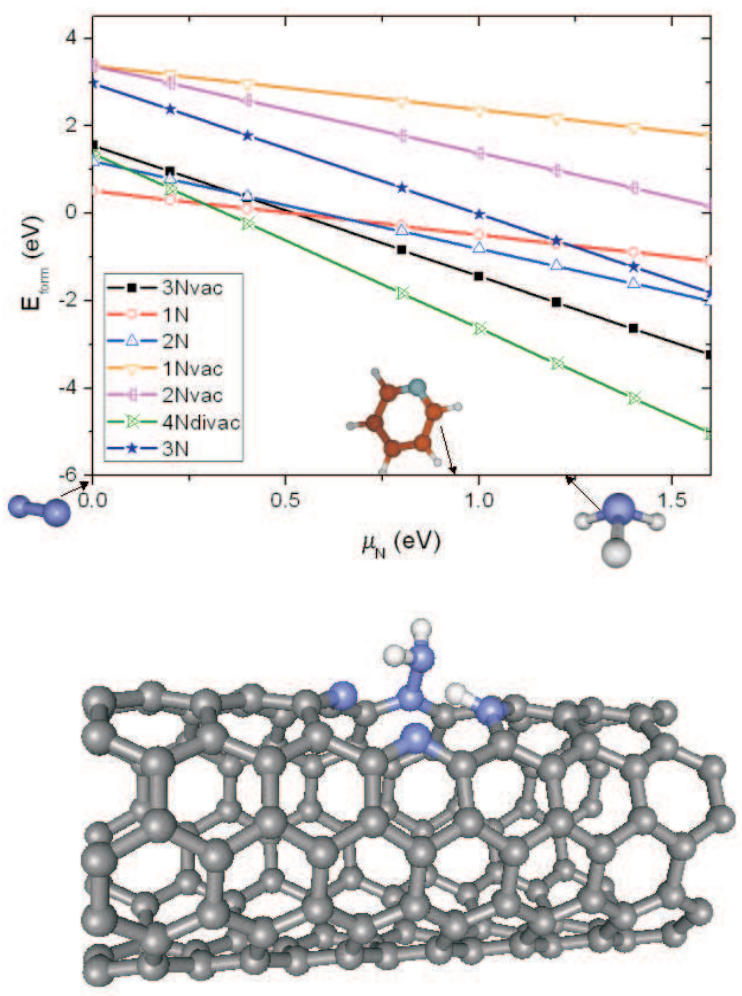

Figura 10: Acima: Energias de Formação de vários defeitos estudados, dentre eles, aquele proposto pelos experimentais (linha preta) em vários potenciais químicos do nitrogênio. Abaixo: Geometria final do defeito mais estável após interagir com amônia também calculada pelo nosso grupo (linha verde do gráfico acima). [12] 


\section{Capítulo 1}

\section{Fundamentos Teóricos}

As propriedades eletrônicas de átomos e moléculas em diversos sistemas são quanticamente descritas através da equação de Schrödinger não relativística ${ }^{1}$

$$
\hat{H} \psi=i \hbar \frac{\partial}{\partial t} \psi
$$

Geralmente o interesse maior está nas soluções estacionárias dessa equação, tornando-a um problema de autovalores. Para um sistema composto de $M$ núcleos e $N$ elétrons, a equação acima toma a forma

$$
\left[\hat{T}_{N}+\hat{T}_{e}+\hat{V}_{N N}+\hat{V}_{N e}+\hat{V}_{e e}\right] \psi\left(\vec{r}_{1}, \ldots, \vec{r}_{n}, \vec{R}_{1}, \ldots, \vec{R}_{N}\right)=E \psi\left(\vec{r}_{1}, \ldots, \vec{r}_{n}, \vec{R}_{1}, \ldots, \vec{R}_{N}\right),
$$

onde $\hat{T}_{N}$ e $\hat{T}_{e}$ são, respectivamente, os operadores energia cinética nuclear e eletrônico, $\hat{V}_{N N}, \hat{V}_{N e}$ e $\hat{V}_{e e}$ são as energias potenciais de interação internuclear, núcleo-elétron e elétron-elétron, respectivamente. Suas formas explícitas são²:

\footnotetext{
${ }^{1}$ para elementos leves (aproximadamente $\mathrm{Z}<40$ ) e elétrons de valência os efeitos relativísticos podem ser desprezados.

${ }^{2}$ tomou-se $\frac{1}{4 \pi \epsilon}=1$
} 


$$
\begin{gathered}
\hat{T}_{N}=-\sum_{i=1}^{M} \frac{\hbar^{2}}{2 M_{i}} \nabla_{R_{i}}^{2} \quad \hat{T}_{e}=-\sum_{i=1}^{N} \frac{\hbar^{2}}{2 m} \nabla_{r_{i}}^{2} \\
\hat{V}_{N N}=\frac{1}{2} \sum_{i, j=1}^{M} \frac{Z_{i} Z_{j} e^{2}}{\left|\vec{R}_{i}-\vec{R}_{j}\right|} \quad \hat{V}_{e e}=\frac{1}{2} \sum_{i, j=1}^{N} \frac{e^{2}}{\left|\vec{r}_{i}-\vec{r}_{j}\right|} \\
\hat{V}_{N e}=\frac{1}{2} \sum_{i, j=1}^{N} \frac{Z_{i} e}{\left|\vec{R}_{i}-\vec{r}_{j}\right|}
\end{gathered}
$$

Para sistemas hidrogenóides (átomos carregados que possuem somente um elétron, o átomo de hidrogênio) a solução exata é possível. Partindo-se para sistemas maiores, contudo, o método padrão de separação de variáveis tornase inviável, devido ao termo de acoplamento entre as coordenadas, advindo dos potenciais de interação. Manter o tratamento de orbitais para a função de onda exige, portanto, o uso de princípios de aproximação.

\subsection{Aproximação de Born-Oppenheimer}

A primeira aproximação refere-se ao movimento simultâneo de núcleos e elétrons. Devido a massa eletrônica ser menos de $0,1 \%$ da massa nuclear, o elétron move-se muito mais rapidamente que o núcleo, tornando possível tratar a contribuição nuclear para a função de onda apenas como uma perturbação. Deslocando-se o núcleo da posição de equilíbrio $R_{0}$, tem-se

$$
\vec{R}=\overrightarrow{R_{0}}+\delta \vec{R}=\overrightarrow{R_{0}}+\lambda \vec{u}
$$

onde a variação $\delta \vec{R}$ é colocada em termos de um parâmetro dependente das massas, que deve ser da forma $\lambda=\left(\frac{m}{M}\right)^{\frac{1}{4}}$ [20].

Escrevendo-se o Hamiltoniano total do sistema (1.2) na forma

$$
\hat{H}=\hat{H}_{e}+\hat{T}_{N}+\hat{V}_{N N}
$$

e analisando-se as propriedades do Hamiltoniano eletrônico, tem-se que o autovalor de $\hat{H}_{e}$ é simultaneamente autovalor de $\vec{R}=\overrightarrow{R_{1}}, \overrightarrow{R_{2}}, \ldots, \overrightarrow{R_{M}}$, uma vez que

$$
\left[\hat{H}_{e}, \vec{R}\right]=0
$$


Portanto, a energia eletrônica, autovalor de $\hat{H}_{e}$, também o será para uma dada configuração nuclear, ou seja, o Hamiltoniano eletrônico depende parametricamente das posições atômicas $\vec{R}$. A equação eletrônica torna-se

$$
\hat{H}_{e} \phi_{n}(\vec{r} ; \vec{R})=\epsilon(\vec{R}) \phi_{n}(\vec{r} ; \vec{R}),
$$

da mesma forma, $\vec{r}=\vec{r}_{1}, \vec{r}_{2}, \ldots, \vec{r}_{N}$.

A partir da solução geral do problema puramente eletrônico pode-se propor a solução do sistema total, tratando-se os coeficientes como uma função do parâmetro $\vec{R}$, já que a energia eletrônica também o é ${ }^{3}$ :

$$
\psi=\sum_{m} C_{m} \phi_{m}(\vec{r} ; \vec{R})=\sum_{m} C_{m}(\vec{R}) \phi_{m}(\vec{r} ; \vec{R})
$$

Essa expansão é conhecida como aproximação adiabática, assim chamada por considerar o problema eletrônico numa dada configuração nuclear. O Hamiltoniano total fica:

$$
\left[\hat{H}_{e}+\hat{T}_{N}+\hat{V}_{N N}\right] \sum_{m} C_{m}(\vec{R}) \phi_{m}(\vec{r} ; \vec{R})=E \sum_{m} C_{m}(\vec{R}) \phi_{m}(\vec{r} ; \vec{R}) .
$$

Da equação (1.7), tem-se

$$
\sum_{m}\left(\sum_{i=1}^{M}-\frac{\hbar^{2}}{2 M_{i}} \nabla_{R_{i}}^{2}+\hat{V}_{N N}+\epsilon(\vec{R})-E\right) C_{m}(\vec{R}) \phi_{m}(\vec{r} ; \vec{R})=0
$$

Multiplicando-se por $\phi_{k}^{*}(\vec{r}, \vec{R})$ e integrando-se em todo o espaço de $\vec{r}$, tem-se, por simplicidade de escrita, na notação de Dirac:

$$
\begin{array}{r}
\sum_{m}\left[\sum_{i=1}^{M}-\frac{\hbar^{2}}{2 M_{i}}\left\langle\phi_{k}(\vec{r} ; \vec{R})\left|\nabla_{R_{i}}^{2}\right| C_{m}(\vec{R}) \phi_{m}(\vec{r} ; \vec{R})\right\rangle+\left(\hat{V}_{N N}+\right.\right. \\
\left.+\epsilon(\vec{R})-E) C_{m}(\vec{R})\left\langle\phi_{k}(\vec{r} ; \vec{R}) \mid \phi_{m}(\vec{r} ; \vec{R})\right\rangle\right]=0
\end{array}
$$

o que conduz, após alguns cálculos [21] a:

\footnotetext{
${ }^{3}$ Se ela não fosse de alguma forma dependente desse parâmetro, ter-se-ia um valor unicamente dependente das coordenadas eletrônicas e degenerada para as posições atômicas. Isso implicaria que as funções eletrônicas e combinações já poderiam ser soluções gerais do sistema, o que não é verdade.
} 


$$
\begin{gathered}
\left(\sum_{i=1}^{M}-\frac{\hbar^{2}}{2 M_{i}} \nabla_{\vec{R}_{i}}^{2}+\hat{V}_{N N}+\epsilon(\vec{R})-E\right) C_{k}(\vec{R})=\sum_{m} \sum_{i=1}^{M} \frac{\hbar^{2}}{2 M_{i}} \times \\
\left(\left\langle\phi_{k}(\vec{r} ; \vec{R}) \mid \nabla_{R_{i}}^{2} \phi_{m}(\vec{r} ; \vec{R})\right\rangle+2\left\langle\phi_{k}(\vec{r} ; \vec{R}) \mid \nabla_{R_{i}} \phi_{m}(\vec{r} ; \vec{R})\right\rangle \cdot \nabla_{R i}\right) C_{m}(\vec{R}) .
\end{gathered}
$$

A aproximação de Born-Oppenheimer considera o segundo membro da equação nulo, ou seja, a dinâmica nuclear não é suficiente para misturar novos estados eletrônicos (excitados), representados pelos estados kett do segundo membro (onde se tem a "ação"de operadores nucleares tipo $\nabla$, advindos do termo cinético nuclear). Essa consideração é válida no regime da aproximação adiabática [21], anteriormente comentada, ou seja, na situação onde

$$
E_{\text {rot }} \approx \lambda^{2} E_{v i b} \approx \lambda^{4} E_{e l}
$$

Para sistemas metálicos, onde o gap é nulo, a energia de transição vibracional torna-se capaz de produzir excitação eletrônica. O elétron promovido para a banda de condução pode produzir uma deformação no arranjo nuclear a fim de reduzir a energia eletrostática da nova configuração, o que produz uma polarização. O acoplamento dessa polarização com o elétron faz surgir os pólarons [22] e caracteriza um regime não-adiabático ${ }^{4}$. Assim, na aproximação de Born-Oppenheimer, tem-se, da equação (1.12),

$$
\begin{aligned}
\left(\sum_{i=1}^{M}-\frac{\hbar^{2}}{2 M_{i}} \nabla_{\vec{R}_{i}}^{2}+V_{\text {eff }}\right) C_{m}(\vec{R}) & =E C_{m}(\vec{R}) \Rightarrow \\
\hat{H}_{N} C_{m}(\vec{R}) & =E C_{m}(\vec{R}),
\end{aligned}
$$

sendo $V_{e f f}=V_{N N}+\epsilon(\vec{R})$ o potencial efetivo sentido pelo núcleo. Finalmente, os dois sistemas podem ser resolvidos separadamente através das equações:

$$
\begin{array}{r}
\hat{H}_{e} \phi_{n}(\vec{r})=\epsilon \phi_{n}(\vec{r}) \\
\hat{H}_{N} C_{m}(\vec{R})=E C_{m}(\vec{R}) .
\end{array}
$$

${ }^{4}$ Ainda nesse caso o problema pode ser tratado "adiabaticamente"e os fenômenos nãoadiabáticos introduzidos como uma perturbação. 


\subsection{Cálculo da Estrutura Eletrônica}

A equação a ser resolvida para a estrutura eletrônica, dentro do regime adiabático, torna-se

$$
\left[\hat{T}_{e}+\hat{V}_{N e}+\hat{V}_{e e}\right] \psi=E \psi
$$

e $\psi$ é a função eletrônica total. Essa equação ainda não é trivial, devido ao potencial Coulombiano entre os elétrons, que acopla as variáveis eletrônicas $\overrightarrow{r_{i}}$ e $\overrightarrow{r_{j}}$. Novamente, o problema é resolvido por aproximações. A aproximação de Hartree $[22,23]$ considera cada elétron movendo-se num potencial efetivo de um campo médio criado pelos núcleos e uma distribuição dos elétrons restantes $\rho=-e \sum_{j \neq i}\left|\phi_{j}\right|^{2}$, sendo $\phi_{j}$ orbitais de um elétron. A função de muitos corpos ou, nesse caso, de muitos elétrons, é tomada como

$$
\psi=\prod_{i} \phi_{i}(\vec{r})
$$

Minimizando-se a energia $\langle\psi|H| \psi\rangle$ em relação aos orbitais, encontra-se as equações de um elétron [23]

$$
\left[\hat{T}_{e}^{(i)}+\left(\hat{V}_{N e}^{(i)}+e^{2} \sum_{i \neq j=1}^{N} \int \frac{\left|\phi_{j}\right|^{2}}{\left|\overrightarrow{r_{i}}-\overrightarrow{r_{j}}\right|} d \overrightarrow{r_{j}}\right)\right] \phi_{i}(\vec{r})=\epsilon_{i} \phi_{i}(\vec{r}),
$$

onde o terceiro termo é chamado termo de Hartree.

\subsubsection{Aproximação de Hartree-Fock}

A função de muitos elétrons de Hartree (Equação 1.18) despreza a antissimetria das funções de onda eletrônica. A introdução do princípio de Pauli faz surgir uma função de onda total como uma combinação, na forma de um determinante de Slater, de produtos funções de um elétron [22, 24]. Através de nova minimização, tem-se as equações de Hartree-Fock, que diferem das de Hartree pelo surgimento do termo operador exchange, ou operador de troca

$$
-\sum_{j} \int \frac{e^{2} d \vec{r}_{j}}{\left|\overrightarrow{r_{i}}-\vec{r}_{j}\right|} \phi_{j}^{*}\left(\vec{r}_{j}\right) \phi_{j}\left(\vec{r}_{i}\right) \phi_{i}\left(\vec{r}_{j}\right)
$$


que não é facilmente tratável por não ser da forma $\left.\left[\int F\left(\vec{r}^{\prime}\right) d \vec{r}^{\prime}\right)\right](\vec{r}) \psi(\vec{r})$, mas $\int F(\vec{r}) \times \psi(\vec{r}) d \vec{r}$, ou seja, a função $\psi$ está dentro da integral.

Apesar de tais aproximações cancelarem os efeitos de auto-interação automaticamente (no caso de Hartree o somatório de $\rho$ compreende somente os $j \neq i$ elétrons restantes. Em Hartree-Fock, o autoexchange cancela a autointeração Coulombiana), elas desprezam completamente os efeitos de correlações instantâneas, tomando-se valores médios, ou seja, o fato de elétron estar numa determinada posição $\vec{r}_{i}$ influenciar as possíveis posições dos demais (possíveis configurações) instantaneamente, devido à repulsão eletrônica mútua.

Esses efeitos de correlação podem ser incluídos ao se considerar várias configurações possíveis, adicionando-se orbitais virtuais excitados, fazendo surgir novos determinantes de Slater. A função de onda total torna-se então, uma combinação linear desses determinantes. Esse é o método de interação de configuração (CI) [25]. Outros esquemas, como a teoria de perturbação de MфllerPlesset, que aplica a teoria de perturbação ao Hamiltoniano de Hartree-Fock, ou o método do Cluster Acoplado (CC) são respostas alternativas [25]. Contudo, tais métodos levam a complexos cálculos quando o número de elétrons aumenta.

\subsection{Teoria do Funcional da Densidade - DFT}

Uma alternativa aos métodos anteriores é a Teoria do Funcional da Densidade $\left(\mathrm{DFT}^{5}\right)$. Anteriormente, a energia total era um funcional ${ }^{6}$ da função de onda total. Na DFT, o ponto de partida é um observável físico dependente de três variáveis espaciais, a densidade eletrônica, definida como:

$$
\rho(\vec{r})=N \int d \vec{r}_{2} \int d \vec{r}_{3} \int \ldots \int d \vec{r}_{N}\left|\psi\left(\vec{r}, \vec{r}_{2}, \ldots, \vec{r}_{N}\right)\right|^{2}
$$

Observe-se que aqui, $\vec{r}$ não mais representa um conjunto de $\mathrm{N}$ variáveis explicitamente. A DFT é fundamentada nos teoremas de Hohenberg-Kohn [26]:

Teorema 1 O potencial externo, a menos de uma constante, é univocamente determinado pela densidade eletrônica $\rho(\vec{r})$.

\footnotetext{
${ }^{5}$ Do inglês Density Functional Theory

${ }^{6}$ Funcional é um ente matemático que associa um número a uma função.
} 
Teorema 2 A energia $E_{0}$ assume seu valor mínimo para a densidade $\rho\left(\vec{r}_{0}\right)$ do estado fundamental sob a restrição $N[\rho]=\int \rho(\vec{r}) d \vec{r}=N$.

Ambos são provados por argumentos simples [27]. De (1.17) obtém-se a expressão da energia como funcional da densidade

$$
E[\rho]=T[\rho]+V_{N e}[\rho]+V_{e e}[\rho]
$$

onde os termos são tomados como $O=\langle\psi|\hat{O}| \psi\rangle$, com $\psi=\psi[\rho]$, pelo primeiro teorema. Os funcionais $T[\rho]$ e $V_{e e}[\rho]$ são ditos universais devido a não dependência do sistema específico e a energia potencial externa, cujo operador é $\hat{V}_{N e}=\frac{1}{2} \sum_{i, j=1}^{N} \frac{Z_{i} e}{\left|\vec{R}_{i}-\vec{r}_{j}\right|}=\sum_{j=1} v\left(\vec{r}_{j}\right)$ pode ser escrito como um funcional da densidade de uma forma geral, como segue:

$$
\begin{aligned}
\left\langle\psi\left|\hat{V}_{N e}\right| \psi\right\rangle & =V_{N e}=\int d \vec{r} \int d \vec{r}_{2} \int d \vec{r}_{3} \int \ldots \int d \vec{r}_{N} \sum_{j=1} v\left(\vec{r}_{j}\right)\left|\psi\left(\vec{r}, \vec{r}_{2}, \ldots, \vec{r}_{N}\right)\right|^{2}= \\
& =\sum_{j} \int d \vec{r} \int d \vec{r}_{2} \int d \vec{r}_{3} \int \ldots \int d \vec{r}_{N} v\left(\vec{r}_{j}\right)\left|\psi\left(\vec{r}, \vec{r}_{2}, \ldots, \vec{r}_{N}\right)\right|^{2}= \\
& =\int \ldots \int d \vec{r} d \vec{r}_{2} \ldots d \vec{r}_{N} v(\vec{r})\left|\psi\left(\vec{r}, \vec{r}_{2}, \ldots, \vec{r}_{N}\right)\right|^{2}+\ldots+ \\
& +\int \ldots \int d \vec{r} d \vec{r}_{2} \ldots d \vec{r}_{N} v\left(\vec{r}_{N}\right)\left|\psi\left(\vec{r}, \vec{r}_{2}, \ldots, \vec{r}_{N}\right)\right|^{2}= \\
& =N \int \ldots \int d \vec{r} d \vec{r}_{\ldots} . . d \vec{r}_{N} v(\vec{r})\left|\psi\left(\vec{r}, \vec{r}_{2}, \ldots, \vec{r}_{N}\right)\right|^{2}= \\
& =\int d \vec{r} v(\vec{r}) \rho(\vec{r}) .
\end{aligned}
$$

O último passo deve-se à definição (1.21). Então, pode-se dizer que a equação (1.22) é a formulação da energia em termos de uma função densidade $\rho(\vec{r})$, que, para representar corretamente uma função de onda de estado fundamental antissimétrica, deve poder ser escrita como a definição $(1.21)$ [28,29]. A densidade de carga do estado fundamental, portanto, é capaz de determinar a função de onda do estado fundamental, a partir da qual todas as propriedades do sistema nesse estado podem ser extraídas. O estudo dos estados excitados também pode ser realizado a partir do estado fundamental através do formalismo da DFT dependente do tempo - TDDFT [30]. 


\subsubsection{Equações de Kohn-Sham}

A minimização direta do funcional (1.22) não é de uso prático devido ao fato de que a energia cinética é conhecida somente como funcional explícito de orbitais e não da densidade. Assim, o cálculo da energia mínima é implementado novamente através da idéia de funções orbitais, os orbitais de KohnSham. Diferente dos tratamentos anteriores, esses orbitais não representam aproximações diretas dos orbitais interagentes (anteriormente isso era feito por valores médios), pois agora o foco está sobre a densidade do sistema interagente e não mais sobre os orbitais de cada elétron do sistema. Eles compreendem todos os orbitais ocupados e são definidos como

$$
\rho(\vec{r})=\sum_{i=1}^{\text {ocup. }}\left|\phi_{i}(\vec{r})\right|^{2} .
$$

O funcional $\mathrm{E}[\rho]$ pode ser escrito em termos de funcionais de um elétron ${ }^{7}$ como segue:

$$
E[\rho]=T[\rho]+V_{N e}[\rho]+V_{e e}[\rho]=T_{s}[\rho]+V_{N e}[\rho]+E_{H}[\rho]+E_{X C}[\rho]
$$

onde $T_{s}\left[\phi_{i}[\rho]\right]=-\frac{\hbar^{2}}{2 m} \sum_{i=1}^{N}\left\langle\phi_{i}^{*}(\vec{r}) \mid \nabla^{2} \phi_{i}(\vec{r})\right\rangle$ e todos os efeitos de interação elétron-elétron estão reunidos no já conhecido termo de Hartree e o chamado termo de troca-correlação $E_{X C}[\rho]$, composto por um termo de troca e um de correlação, para o qual não se conhece forma definida. Ele também compreende os efeitos de correlação da energia cinética:

$$
T_{c}[\rho]=T[\rho]-T_{s}[\rho]
$$

A idéia de Kohn-Sham é, então, minimizar o funcional de energia a partir da solução de uma equação de Schrödinger para os orbitais fictícios, portanto, uma equação de um sistema não-interagente no potencial $V_{s}$ equivalente, do tipo:

$$
\hat{H}_{s} \phi_{i}=\left(-\frac{\hbar^{2}}{2 m} \nabla^{2}+V_{s}(\vec{r})\right)=\epsilon_{i} \phi_{i}
$$

e os autovalores são:

${ }^{7} \mathrm{O}$ índice $s$ indica single-particle 


$$
\sum_{i} \epsilon_{i}=\sum_{i}\left\langle\phi_{i}\left|\hat{H}_{s}\right| \phi_{i}\right\rangle=T_{s}+V_{s}=T_{s}+\int d \vec{r} v_{s} \rho(\vec{r}) .
$$

De (1.22) e (1.28), o funcional pode então ser reescrito como

$$
E=\sum_{i} \epsilon_{i}-\int d \vec{r} v_{s} \rho(\vec{r})+V_{N e}+E_{H}+E_{X C}
$$

Da minimização do funcional, encontra-se uma condição para a "quantidade imposta", $V_{s}$ em relação ao sistema interagente. Variando-se a energia do sistema não-interagente (portanto $E_{H}=E_{X C}=0$ ) com respeito à densidade, tem-se de (1.29)

$$
\frac{\delta E_{s}}{\delta \rho}=0 \Rightarrow \frac{\delta T_{s}}{\delta \rho}+\frac{\delta V_{s}}{\delta \rho}=0
$$

cuja solução é uma densidade $\rho_{s}$.

Da condição de minimização do sistema interagente,

$$
\frac{\delta E}{\delta \rho}=0 \Rightarrow \frac{\delta T_{s}}{\delta \rho}+\frac{\delta V_{N e}}{\delta \rho}+\frac{\delta E_{H}}{\delta \rho}+\frac{\delta E_{X C}}{\delta \rho}=0
$$

tem-se que $V_{s}$ reproduzirá o estado fundamental do sistema interagente, se [31]

$$
v_{s}=\frac{\delta V_{N e}}{\delta \rho}+e^{2} \int \frac{\rho\left(\overrightarrow{r^{\prime}}\right) d \overrightarrow{r^{\prime}}}{\left|\vec{r}-\overrightarrow{r^{\prime}}\right|}+\frac{\delta E_{X C}}{\delta \rho}=v_{K S}+\text { constante } .
$$

Esse potencial, que minimiza o funcional, é chamado potencial de KohnSham $v_{K S}$. O conjunto de equações abaixo são chamadas equações de Kohn-Sham:

$$
\begin{array}{r}
\left(-\frac{\hbar^{2}}{2 m} \nabla_{i}^{2}+v_{K S}(\vec{r})\right) \phi_{i}(\vec{r})=\epsilon_{i} \phi_{i}(\vec{r}) \\
\rho_{0}(\vec{r})=\sum_{i=1}^{\text {ocup. }}\left|\phi_{i}(\vec{r})\right|^{2} .
\end{array}
$$

Observe-se que a densidade calculada dessa forma obedece a condição de minimização, portanto é a densidade do estado fundamental.

Como nas aproximações anteriores, essas $\mathrm{N}$ equações são resolvidas auto-consistentemente. Apesar de utilizar a idéia de orbitais de uma partícula, a função de onda de muitos elétrons não é o determinante de Slater dos orbitais de Kohn-Sham. 
Diferente de Hartree-Fock, onde os autovalores possuem uma interpretação relativa às energias de ionização [32], os autovalores de Kohn-Sham não possuem significado físico, exceto aquele do último elétron, $\epsilon_{N}$ (o negativo da energia de ionização) [27]. A energia cinética é calculada através do potencial $V_{K S}$ encontrado ao final dos ciclos autoconsistentes e atingida a convergência da densidade:

$$
\begin{aligned}
& \sum_{i} \epsilon_{i}=T_{s}\left[\rho_{0}\right]+\int d \vec{r} v_{K S} \rho_{0}(\vec{r}) \Rightarrow \\
& T_{s}\left[\rho_{0}(\vec{r})\right]=\sum_{i} \epsilon_{i}-\int d \vec{r} v_{K S} \rho_{0}(\vec{r}) .
\end{aligned}
$$

A partir da equação acima e do seguinte funcional

$$
E_{0}=T_{s}\left[\rho_{0}\right]+V_{N e}\left[\rho_{0}\right]+E_{H}+E_{X C}\left[\rho_{0}\right],
$$

a energia do sistema no estado fundamental torna-se [29]

$$
\begin{aligned}
E_{0} & =\sum_{i} \epsilon_{i}+V_{N e}\left[\rho_{0}(\vec{r})\right]+E_{X C}\left[\rho_{0}(\vec{r})\right]-\int d \vec{r} v_{K S} \rho_{0}(\vec{r})+E_{H} \\
& =\sum_{i} \epsilon_{i}-\frac{e^{2}}{2} \iint \frac{\rho_{0}\left(\overrightarrow{r^{\prime}}\right) \rho_{0}(\vec{r}) d \vec{r} d \overrightarrow{r^{\prime}}}{\left|\vec{r}-\overrightarrow{r^{\prime}}\right|}-\int \frac{\delta E_{X C}}{\delta \rho} \rho_{0}(\vec{r}) d \vec{r}+E_{X C}(1.37)
\end{aligned}
$$

Definindo-se $\varepsilon_{X C}$ como a energia de troca-correlaçõ por partícula, ou seja, $E_{X C}=\int \varepsilon_{X C} \rho(\vec{r}) d \vec{r}$, tem-se ${ }^{8}$

$$
E_{0}=\sum_{i} \epsilon_{i}-\frac{e^{2}}{2} \iint \frac{\rho_{0}\left(\overrightarrow{r^{\prime}}\right) \rho_{0}(\vec{r}) d \vec{r} d \overrightarrow{r^{\prime}}}{\left|\vec{r}-\overrightarrow{r^{\prime}}\right|}+\int\left(\varepsilon_{X C}-\frac{\delta E_{X C}}{\delta \rho}\right) \rho_{0}(\vec{r}) d \vec{r} .
$$

Essa forma seria exata se $E_{X C}\left[\rho_{0}\right]$ fosse exatamente conhecido em termos da densidade. A natureza dessa energia é mais facilmente compreendida através do fato de que um elétron estando na posição $\vec{r}$ com um dado spin diminui a probabilidade de um outro com igual spin (troca) ou mesmo com spin diferente (correlação) estar em $\vec{r}^{\prime}$, na vizinhança de $\vec{r}$. Essa baixa de probabilidade é o que caracteriza o "buraco de troca-correlação". Imaginando-se então,

\footnotetext{
${ }^{8}$ Apesar de $V_{N e}$ não aparecer explicitamente nessa relação, a própria densidade já traz a informação desse potencial do sistema.
} 
uma "distribuição de buracos-de-carga", dependente das posições dos elétrons $\vec{r}$ e também das posições "proibidas", $\rho_{X C}^{\prime}(\vec{r}, \vec{r})$, tem-se que essa energia pode ser pensada como uma interação entre essa densidade e a densidade de carga eletrônica

$$
E_{X C}[\rho]=\frac{1}{2} \iint \frac{\rho(\vec{r}) \rho^{\prime}\left(\vec{r}, \vec{r}^{\prime}\right)}{\left|\vec{r}-\vec{r}^{\prime}\right|} d \vec{r} d \vec{r}^{\prime}
$$

Devido ao não conhecimento da densidade do buraco de troca-correlação, não é direta a exclusão da auto-interação desse termo, novamente diferente de Hartree-Fock. Esse erro adicional produz certas incertezas na energia final e também adiciona maiores erros na estimativa do gap do sistema [33].

Na prática, recorre-se a aproximações para o tratamento desse termo $[27,29,32,34,35]$. A mais simples é a aproximação da densidade local (LDA) [34], que considera o sistema dividido em pequenas partes onde a energia de troca-correlação é tomada como a de um gás homogêneo com densidade $\rho(\vec{r})$. A energia de troca-correlação por partícula torna-se, então:

$$
\varepsilon_{X C}^{L D A}[\rho]=\frac{1}{2} \int \frac{\rho_{X C}^{\prime L D A}\left(\vec{r}, \vec{r}^{\prime}\right)}{\left|\vec{r}-\vec{r}^{\prime}\right|} d \vec{r}^{\prime}
$$

e o funcional de troca-correlação

$$
E_{X C}=\int \rho(\vec{r}) \varepsilon_{X C}^{L D A}[\rho] d \vec{r}
$$

Claramente para sistemas onde a densidade varia muito ou há regiões de muita inomogeneidade, essa aproximação pode vir a falhar. Melhoramentos surgem com a análise da expansão desse funcional com o gradiente da densidade. A aproximação generalizada do gradiente (GGA) toma a expansão até o gradiente da densidade [27], contudo a meta-GGA vai além, através do laplaciano da densidade [27]. O funcional GGA tem a forma:

$$
E_{X C}=\int \rho(\vec{r}) \varepsilon_{X C}^{G G A}[\rho, \nabla \rho] d \vec{r}
$$

\subsection{Dinâmica de Rede}

Como já discutido anteriormente, o Hamiltoniano do sistema é constituído de duas partes separadas, nuclear e eletrônica. O problema eletrônico 
já foi discutido. Para os íons, o Hamiltoniano a ser resolvido é o seguinte:

$$
\hat{H}=\hat{T}_{N}+\hat{V}_{N N}+E_{e l}
$$

O estudo da dinâmica de rede de um cristal compreende a análise das respostas do Hamiltoniano acima a uma perturbação do tipo:

$$
\vec{R}_{n, l}(t)=\vec{R}_{n, l}^{(0)}+\vec{u}_{n, l}(t)
$$

onde $\vec{R}_{n, l}(t)$ é a posição do l-ésimo átomo da $n$-ésima célula unitária da rede após a perturbação $\vec{u}_{n, l}(t)$, que também pode depender do tempo, aplicada a sua posição de equilíbrio $\vec{R}_{n, l}^{(0)}$. A Figura 1.1 ilustra esses vetores para uma célula unitária do nanotubo $(5,5)$ armchair.
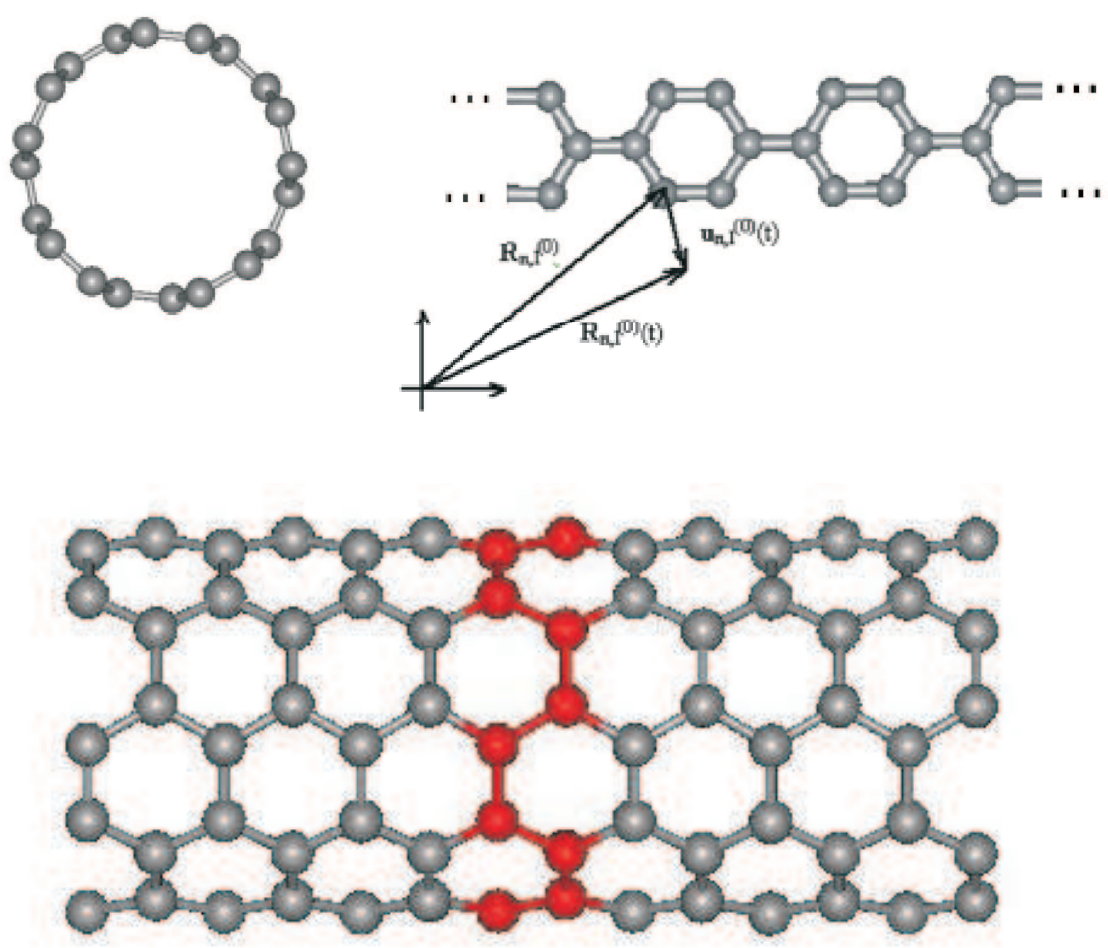

Figura 1.1: Parte da célula unitária do nanotubo $(5,5)$ "desenrolada", onde os vetores estão representados em negrito. Abaixo está um tubo e a representação em vermelho da célula unitária. 
A forma explícita da dependência do potencial $U=E_{e l}+V_{N N}\left(\vec{R}_{1}\right.$, $\left.\vec{R}_{2}, \ldots, \vec{R}_{N}\right)$ com a configuração iônica não é facilmente encontrada. O grau de dificuldade está relacionado novamente a efeitos de muitos corpos. Para cristais onde há fortes ligações covalentes, por exemplo, as interações devido aos demais corpos tornam-se importantes. ${ }^{9}$

\subsubsection{Aproximação Harmônica}

$\mathrm{Na}$ aproximação harmônica, o potencial é expandido numa série de Taylor com respeito às posições deslocadas dos íons, considerando-se a configuração de equilíbrio como referencial do potencial $\left(U_{0}=0\right)$ e tomandose como termo não-nulo somente a derivada segunda do potencial (o termo harmônico), desprezando-se, portanto, os termos anarmônicos.

$$
\begin{aligned}
U\left(\left\{\vec{R}_{n, l}\right\}\right) & =U\left(\left\{\vec{R}_{n, l}^{(0)}\right\}\right)+\sum_{\alpha=1}^{3}\left[\sum_{n=1}^{N} \sum_{l=1}^{b}\left(\frac{\partial U\left(\vec{R}_{n, l}^{(0)}\right)}{\partial R_{n, l}}\right)\left(\vec{u}_{n, l}\right)_{\alpha}\right]+ \\
& +\frac{1}{2} \sum_{\alpha, \beta=1}^{3}\left[\sum_{n, m=1}^{N} \sum_{l, l^{\prime}=1}^{b} \frac{\partial^{2} U\left(\vec{R}_{n, l}^{(0)} ; \vec{R}_{m, l^{\prime}}^{(0)}\right)}{\left(\partial R_{n, l}\right)_{\alpha}\left(\partial R_{m, l^{\prime}}\right)_{\beta}}\left(\vec{u}_{n, l}\right)_{\alpha}\left(\vec{u}_{m, l^{\prime}}\right)_{\beta}\right]+ \\
& +O\left\{\left(u_{n, l, \alpha}\right)^{3}\right\}
\end{aligned}
$$

Da expansão, somente o terceiro termo é considerado, já que por ser tomado nas posições de equilíbrio, a primeira derivada é nula. Acima, $N$ é o número de células unitárias e $b$, o número de átomos em cada uma e as componentes cartesianas são representadas pelas letras gregas $\alpha$ e $\beta$.

Definindo-se o tensor constante de força entre os átomos $\vec{R}_{n, l}^{(0)}$ e $\vec{R}_{m, l^{\prime}}^{(0)}$ como

$$
\Phi_{\alpha \beta}\left(\vec{R}_{n, l}^{(0)}-\vec{R}_{m, l^{\prime}}^{(0)}\right)=\frac{\partial^{2} U\left(\vec{R}_{n, l}^{(0)} ; \vec{R}_{m, l^{\prime}}^{(0)}\right)}{\left(\partial R_{n, l}\right)_{\alpha}\left(\partial R_{m, l^{\prime}}\right)_{\beta}},
$$

a equação do movimento torna-se

$$
m_{l} \frac{\partial^{2}\left(\vec{u}_{n, l}\right)_{\alpha}}{\partial t^{2}}=-\sum_{m} \sum_{l^{\prime}} \sum_{\beta} \Phi_{\alpha \beta}\left(\vec{R}_{n, l}^{(0)}-\vec{R}_{m, l^{\prime}}^{(0)}\right) \vec{u}_{m, l^{\prime}, \beta} .
$$

${ }^{9}$ Contudo, essas contribuições podem ser divididas em parcelas de interações de dois corpos [36], tornando a distância interatômica a variável importante para o potencial. 
Tomando-se a solução:

$$
\vec{u}_{n, l}=\vec{U}_{l}\left(\vec{R}_{n}\right) e^{i \vec{q} \cdot \overrightarrow{R_{n}}} e^{-i \omega t}
$$

A equação do movimento torna-se

$$
\left[\omega^{2} m_{l}\right] \vec{U}_{l}=\left[\sum_{m}^{N} \sum_{l^{\prime}}^{b} \sum_{\beta}^{3} \Phi_{\alpha \beta}\left(\vec{R}_{n, l}^{(0)}-\vec{R}_{m, l^{\prime}}^{(0)}\right) e^{-i \vec{q} \cdot\left(R_{n}^{(0)}-R_{m}^{(0)}\right)}\right] \vec{U}_{l^{\prime}}
$$

Definindo-se a matriz dinâmica como

$$
D_{\alpha, \beta}\left(\vec{q} ; l, l^{\prime}\right)=\frac{1}{m_{l}} \sum_{m}^{N} \Phi_{\alpha \beta}\left(\vec{R}_{n, l}^{(0)}-\vec{R}_{m, l^{\prime}}^{(0)}\right) e^{-i \vec{q} \cdot\left(R_{n}^{(0)}-R_{m}^{(0)}\right)}
$$

a equação acima torna-se simplesmente,

$$
\omega^{2} \vec{U}_{l}=\sum_{l^{\prime}}^{b} \sum_{\beta}^{3} D_{\alpha, \beta}\left(\vec{q} ; l, l^{\prime}\right) \vec{U}_{l^{\prime}}
$$

Essas equações possuem apenas $3 b$ elementos que, após diagonalização, fornecem também $3 b$ autovalores (freqüências) e $3 b$ autovetores $\vec{U}$. A matriz dinâmica é hermitiana e positiva, portanto, seus autovalores são reais e positivos, o que implica na existência única de freqüências reais. Freqüências imaginárias surgem quando a estrutura não está em seu mínimo de energia, pois estando numa região instável do potencial, ao se deslocar, o átomo não encontraria uma forma do potencial que o fizesse retornar e oscilar (como na situação de mínimo). A tendência deste seria então, continuar a decair na direção de uma energia mais baixa (ou seja, uma região mais estável). Esse movimento é matematicamente descrito por funções exponenciais de expoente real (ou seja, na Equção (1.49), $\omega$ deverá ser imaginário puro). Um ponto de sela na superfície do potencial é um exemplo.

\subsection{Cálculos $a b$ initio de fônons}

Da definição da matriz dinâmica, conclui-se que a informação necessária para o cálculo dos modos normais de vibração de um sólido, os fônons, é 
o tensor constante de força. Cálculos ab initio de fônons consistem da determinação desse tensor através de cálculos de energia total, com a parte eletrônica tratada pela DFT.

Há basicamente duas formas de calcular o espectro de fônons no tratamento ab initio, a saber, o Método da Resposta Linear e o Método Direto.

No primeiro, as distorções da rede advindas dos fônons são consideradas como perturbações estáticas para a densidade eletrônica. Essa variação da densidade, devido a essa perturbação externa (movimento dos núcleos) permite o cálculo da variação da energia total do sistema. As constantes de força são, então, obtidas via derivada segunda da energia total do cristal no equilíbrio, podendo-se separá-las em dois conjuntos conforme as duas contribuições, iônica e eletrônica. Aqui a contribuição eletrônica refere-se ao potencial elétron-íon de interação entre a nuvem eletrônica e os íons:

$$
\Phi_{\alpha \beta}\left(\vec{R}_{n, l}^{(0)}-\vec{R}_{m, l^{\prime}}^{(0)}\right)=\Phi_{n \alpha, m \beta}=\Phi_{n \alpha, m \beta}^{\text {ion }}+\Phi_{n \alpha, m \beta}^{\text {elet }} .
$$

O Teorema de Hellman-Feynman [31,37] é utilizado para o cálculo do segundo termo:

$$
\begin{aligned}
\Phi_{n \alpha, m \beta}^{\text {elet }} & =-\frac{d}{d u_{n, l, \alpha}}\left(F_{\alpha \beta}^{\text {elet }}\right)=\frac{d}{d u_{n, l, \alpha}}\left(\frac{d}{d u_{m, l^{\prime}, \beta}} \int d \vec{r} V_{i o n} \rho(\vec{r})\right)= \\
& =\int d \vec{r}\left(\frac{d V_{i o n}}{d u_{m, l^{\prime}, \beta}}\right)\left(\frac{d \rho(\vec{r})}{d u_{n, l, \alpha}}\right)+ \\
& +\int d \vec{r} \rho(\vec{r}) \frac{d^{2} V_{i o n}}{d u_{n, l, \alpha} d u_{m, l^{\prime}, \beta}}
\end{aligned}
$$

A resposta (derivada) da densidade é encontrada por uma linearização, ou seja, uma expansão até a primeira ordem dos resultados para o estado fundamental não perturbado (Eqs. 1.32, 1.33 e 1.34). As equações tornam-se [38]:

$$
\begin{array}{r}
\left(H^{(0)}-\epsilon_{i}\right) \phi_{i}(\vec{r})=-\left(\Delta v_{K S}-\Delta \epsilon_{i}\right) \phi_{i}(\vec{r}) \\
\Delta v_{K S}=\Delta v_{N e}+e^{2} \int \frac{\Delta \rho\left(\overrightarrow{r^{\prime}}\right) d \vec{r}^{\prime}}{\left|\vec{r}-\overrightarrow{r^{\prime}}\right|}+\Delta \rho(\vec{r})\left(\frac{\delta E_{X C}}{\delta \rho}\right)_{\rho=\rho(\vec{r})} \\
\Delta \rho(\vec{r})=\Re \sum_{i=1} \phi_{i}^{*}(\vec{r}) \Delta \phi_{i}(\vec{r}),
\end{array}
$$


onde $H^{(0)}$ é o Hamiltoniano definido no lado direito da Eq. 1.33.

O termo restante, $\Phi_{n \alpha, m \beta}^{i o n}$, compreende a derivada segunda do potencial íon-íon, que pode ser tratado, por exemplo, através da soma de Ewald [31].

No Método Direto, ou "frozen-phonon", a estrutura cristalina distorcida é tomada como uma nova estrutura para um novo cálculo de energia total. A partir disso são calculadas as derivadas segundas das energias diretamente para obtenção das constantes de força, ou de forma equivalente, usar o Teorema de Hellman-Feynman para o cálculo das forças e então, extrair as constantes de força. A implementação desse método exige a utilização de supercélulas, cujo tamanho deve ser comensurável com o momento do fônon (vetor de onda) relacionado [39]. Tomando-se uma supercélula, o decréscimo das constantes de força ocorre de maneira suave, o que facilita a implementação numérica no cálculo da matriz dinâmica. 


\section{Capítulo 2}

\section{Espectroscopia Raman}

\subsection{Espalhamento Raman}

A análise do espalhamento Raman é um dos principais métodos na caracterização de um material. Uma das muitas informações obtidas refere-se aos modos vibracionais, especialmente, quanto às simetrias.

Radiação, ao incidir num material, induz um momento de dipolo $\vec{M}$ dependente do tempo devido ao seu campo eletromagnético. O momento induzido pode ser expandido em termos do campo $\vec{E}$ da radiação:

$$
\vec{M}=\alpha \vec{E}+\frac{1}{2} \beta \vec{E}^{2}+\ldots
$$

Aqui, $\vec{M}_{0}=\vec{\mu}$ é o momento natural não induzido (portanto, o momento total seria $\vec{M}_{\text {total }}=\vec{\mu}+\vec{M}$ ), $\alpha$ é a polarizabilidade do sistema e $\beta$ é a hiperpolarizabilidade do sistema [40]. Ao vibrar, as partículas do sistema modificam a polarizabilidade, tal que uma expansão também pode ser feita em termos das coordenadas vibracionais q, ou seja, aquelas que descrevem o movimento de deslocamento vibracional:

$$
\alpha=\alpha_{0}+\left(\frac{\partial \alpha}{\partial q}\right)_{0} q+\frac{1}{2}\left(\frac{\partial^{2} \alpha}{\partial q^{2}}\right)_{0} q^{2}+\ldots
$$

O efeito Raman de primeira ordem é determinado pelo termo linear da expansão. Tomando-se um sistema vibrante de freqüência $\nu_{0}$, tem-se $q=$ $q_{0} \cos \nu_{0} t$ e a polarizabilidade torna-se: 


$$
\alpha=\alpha_{0}+\left(\frac{\partial \alpha}{\partial q}\right)_{0} q_{0} \cos \nu_{0} t .
$$

Supondo um campo oscilante de freqüência $\nu$, tal que $\vec{E}=\vec{E}_{0} \cos \nu t, \mathrm{o}$ momento total induzido será, considerando-se somente os efeitos lineares:

$$
\begin{aligned}
\vec{M} & =\left(\alpha_{0}+\left(\frac{\partial \alpha}{\partial q}\right)_{0} q_{0} \cos \nu_{0} t\right) \vec{E}_{0} \cos \nu t \\
& =\alpha_{0} \vec{E}_{0} \cos \nu t+\left(\frac{\partial \alpha}{\partial q}\right)_{0} q_{0} \vec{E}_{0} \cos \nu_{0} t \cos \nu t \\
& =\vec{A} \cos \nu_{0} t+\vec{B}\left[\cos \left(\nu-\nu_{0}\right) t+\cos \left(\nu+\nu_{0}\right) t\right]
\end{aligned}
$$

com $\vec{A}=\alpha_{0} \vec{E}_{0}$ e $\vec{B}=\frac{1}{2}\left(\frac{\partial \alpha}{\partial q}\right)_{0} q_{0} \vec{E}_{0}$. O último passo deve-se à relação trigonométrica $2 \cos \theta \cdot \cos \phi=\cos (\theta+\phi)+\cos (\theta-\phi)$.

Essa explicação clássica simples é suficiente para o entendimento da existência das três formas possíveis de espalhamento pela interação da luz com a polarizabilidade do sistema:

\section{Espalhamento Elástico, ou Espalhamento Ray-}

leigh - A luz é espalhada na mesma freqüência que a luz incidente $\nu$.

II. Espalhamento Inelástico Stokes - A luz é espalhada numa freqüência $\left(\nu-\nu_{0}\right)$ menor que a incidida.

III. Espalhamento Inelástico Anti-Stokes - A luz é espalhada numa freqüência $\left(\nu+\nu_{0}\right)$ maior que a incidida.

Os espalhamentos inelásticos correspondem aos espalhamentos Raman.

Quanticamente, os espalhamentos são vistos como colisões entre fótons da luz, elétrons excitados e os fônons do cristal. Naqueles inelásticos (Raman), há perda de um ou mais fônons (Stokes) ou ganho desses (anti-Stokes). No espalhamento Raman de primeira ordem somente um fônon está envolvido. $\mathrm{O}$ processo é ilustrado na Figura 2.1.

O processo pode ser entendido como composto de três etapas. O fóton incidente com momento $\vec{k}_{1}$ e freqüência $\omega_{1}$ é virtualmente absorvido. Contudo, 


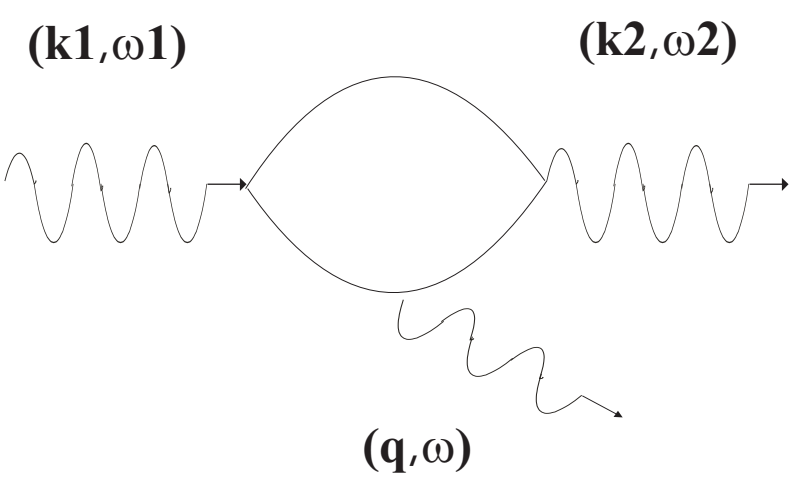

Figura 2.1: Diagrama para o espalhamento Raman de primeira ordem. $(k 1, \omega 1)$ representa o fóton incidente, $(k 2, \omega 2)$ é o espalhado e $(q, \omega)$, o fônon envolvido.

se esse fóton pertencer à radiação visível ou ultravioleta (o que ocorre no efeito Raman), sua freqüência é tal que somente os elétrons são leves suficiente para responder à rápida taxa de variação do campo, portanto, ele perturbará diretamente as funções eletrônicas do sistema, produzindo um par elétron-buraco ${ }^{1}$. Essa resposta eletrônica é representada pela deformação da nuvem nuclear, ou seja, uma perturbação à polarizabilidade (anteriormente discutida) do sistema.

A seguir, o elétron, num estado não estacionário (nível virtual) decai, com probabilidades de interagir com os fônons do sistema. Quando isso não ocorre, o elétron volta exatamente ao mesmo estado inicial, emitindo um fóton de mesma freqüência que o incidente e momento igual em módulo (mas não necessariamente a mesma direção), caracterizando o espalhamento Rayleigh. Ocorrendo tal interação, o elétron retornará à função eletrônica estacionária anterior, contudo, em outro nível vibracional. A diferença de energia é utilizada na criação (Stokes) ou aniquilação (anti-Stokes) de um quantum vibracional, ou seja, um fônon, de momento ${ }^{2} \vec{q}$ e freqüência $\omega$. Este último caso ocorre para a situação do fóton encontrar o sistema num estado vibracional excitado. Como os níveis mais populados são os de mais baixa energia (estado fundamental), a

\footnotetext{
${ }^{1} \mathrm{O}$ conceito de buraco em Estrutura Eletrônica é bastante usual e consiste de uma falta de elétrons. Como os elétrons, eles também têm liberdade de locomoção ao longo de todo o sistema. Isso é apenas uma outra interpretação para o fato de que a vizinhança eletrônica irá suprir a vaga produzida pelo buraco, o que causará o deslocamento da lacuna.

${ }^{2}$ Aqui $\vec{q}$ é o momento do fônon, e não coordenadas vibracionais, claramente explicado no texto.
} 
probabilidade do processo anti-Stokes é bem menor que o Stokes, produzindo uma diferença de intensidades no espectro.

Na etapa final, o elétron espalhado recombina-se com o buraco, produzindo o fóton espalhado com momento $\vec{k}_{2}$ e freqüência $\omega_{2}$. A escala temporal envolvida no efeito Raman é da ordem de $10^{-15} \mathrm{~s}$ e o estado virtual referido não necessariamente é um estado estacionário do sistema. [41]

A Figura 2.2 ilustra os espalhamentos em termos dos níveis de energia. Quando a freqüência do fóton é tal que o estado virtual excitado produzido é próximo de uma transição eletrônica, a intensidade do espalhamento é aumentada e o espectro obtido chama-se Raman ressonante, como na Figura 2.3.
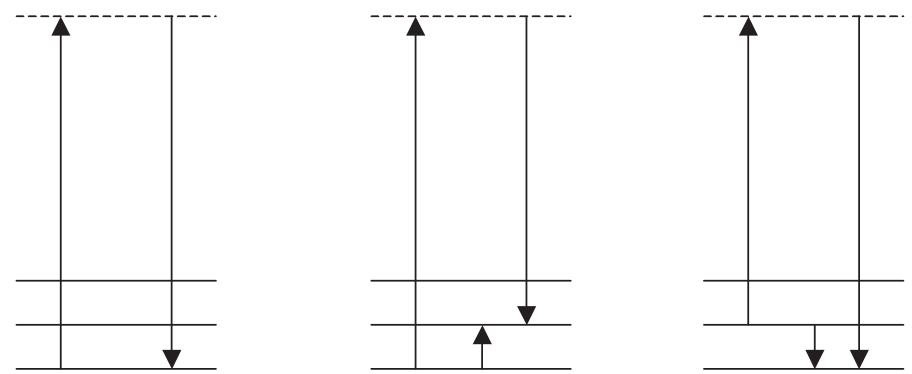

Figura 2.2: Diagrama de transições de energias para os espalhamentos possíveis. À esquerda: Rayleigh. Ao centro: Stokes. À direita: anti-Stokes. As setas ascendentes correspondem ao fóton incidente e as descendentes, ao fóton espalhado. As linhas cheias representam níveis vibracionais e a tracejada corresponde ao nível virtual excitado. A diferença entre dois níveis é um número inteiro de $\hbar \omega$.

As Leis de Conservação para o espalhamento Rayleigh são:

$$
k_{1}=k_{2} \quad \omega_{1}=\omega
$$

Enquanto para o espalhamento Raman, tornam-se:

$$
\vec{k}_{1}=\vec{k}_{2} \pm \vec{q} \quad \omega_{1}=\omega_{2} \pm \omega
$$

Uma vez que $\omega_{1} \gg \omega$, vem da Lei de Conservação para o espalhamento Raman que $\omega_{1} \cong \omega_{2}$. Além disso, os experimentos costumam ser realizados na região transparente do sistema, ou seja, praticamente não há dispersão do índice de refração $n$ em relação às direções incidente e espalhada $\left(n\left(\omega_{1}\right)=\right.$ $\left.n\left(\omega_{2}\right)\right)$ [40]. Da definição de $n$, 


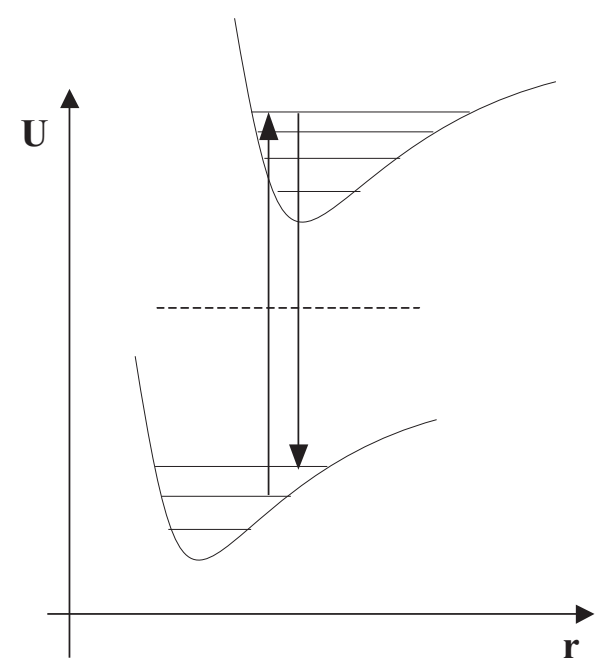

Figura 2.3: Diagrama de transições de energias para o caso ressonante. A linha tracejada representa o estado virtual para o caso não-ressonante. As duas curvas de potencial representam os estados fundamental e o primeiro excitado eletrônicos com os níveis vibracionais.

$$
\begin{aligned}
& n\left(\omega_{1}\right)=\frac{\lambda_{\text {vácuo }}}{\lambda_{1}} \\
& n\left(\omega_{2}\right)=\frac{\lambda_{\text {vácuo }}}{\lambda_{2}}
\end{aligned}
$$

e pela relação entre os momentos e os comprimentos de onda e $c=\frac{\omega \lambda_{\text {vácuo }}}{2 \pi}$, vem que, para os fótons:

$$
\begin{aligned}
& k_{1}=\frac{2 \pi}{\lambda_{1}} \Rightarrow k_{1}=\frac{n\left(\omega_{1}\right) \omega_{1}}{c} \\
& k_{2}=\frac{2 \pi}{\lambda_{2}} \Rightarrow k_{2}=\frac{n\left(\omega_{2}\right) \omega_{2}}{c}
\end{aligned}
$$

Finalmente, uma vez que $\omega_{1} \cong \omega_{2}$, vem que $k_{1} \cong k_{2}$. Geralmente, o comprimento de onda do laser $\left(\lambda_{1}\right)$ é bem maior que o espaçamento entre os átomos da rede (o parâmetro de rede $a$ ), implicando,

$$
\lambda_{1} \gg a \Rightarrow k_{1} \cong k_{2} \ll \frac{1}{a}
$$

Como os limites da zona de Brillouin [22] são $q_{\max }= \pm \frac{\pi}{a}$, vem que no 
espalhamento Raman de primeira ordem, somente os modos em $q \cong 0$ podem ser excitados, ou seja, somente os fônons do ponto $\Gamma$ são espalhados.

\subsection{Nanotubos de Carbono}

O sinal experimental do espectro Raman normalmente é baixo. Contudo, grande melhoramento pode ser obtido através do processo acima discutido, o Raman ressonante, dependendo da energia do laser e da densidade de estados do nanotubo. A energia do laser deve entrar em ressonância com as energias de transições permitidas para os elétrons, que ocorrem em maior probabilidade entre as singularidades de van Hove [22] na Desidade de Estados Eletrônicos (DOS) da banda de valência e aquelas da banda de condução, por serem estas, regiões de alta densidade de estados. O espectro Raman experimental do nanotubo possui basicamente 3 picos característicos ou pelo menos, os mais intensos para lasers na faixa 514.5nm-1320nm [58]. Um na região de baixas freqüências, conhecido como $R B M$, largo e mais intenso, a banda $D$, e a banda $G$, como mostrado na Figura 2.4. A dependência da energia de transição entre singularidades de van Hove opticamente permitidas com o diâmetro é apresentada na Figura 2.5. Através dela, pode-se concluir qual energia do laser a ser utilizada para obtenção de um melhor sinal num nanotubo de determinado diâmetro.

\subsubsection{Modo de Respiração Radial}

O modo de Respiração Radial, ou RBM (Radial Breathing Mode) é um modo bastante específico da estrutura cilíndrica do nanotubo. Ele corresponde à configuração em que todos os átomos vibram em fase de forma radial ao tubo, como representado na Figura 2.6, e representa um dos mais importantes na caracterização de nanotubos.

Para tubos com uma distribuiçõ de diâmetros entre $1 \mathrm{~nm}$ e $4 \mathrm{~nm}$, a freqüência do RBM costuma ser bem representada pela relação:

$$
\omega_{R B M}=\frac{227}{d_{t}}\left(1+C d_{t}\right)^{\frac{1}{2}},
$$




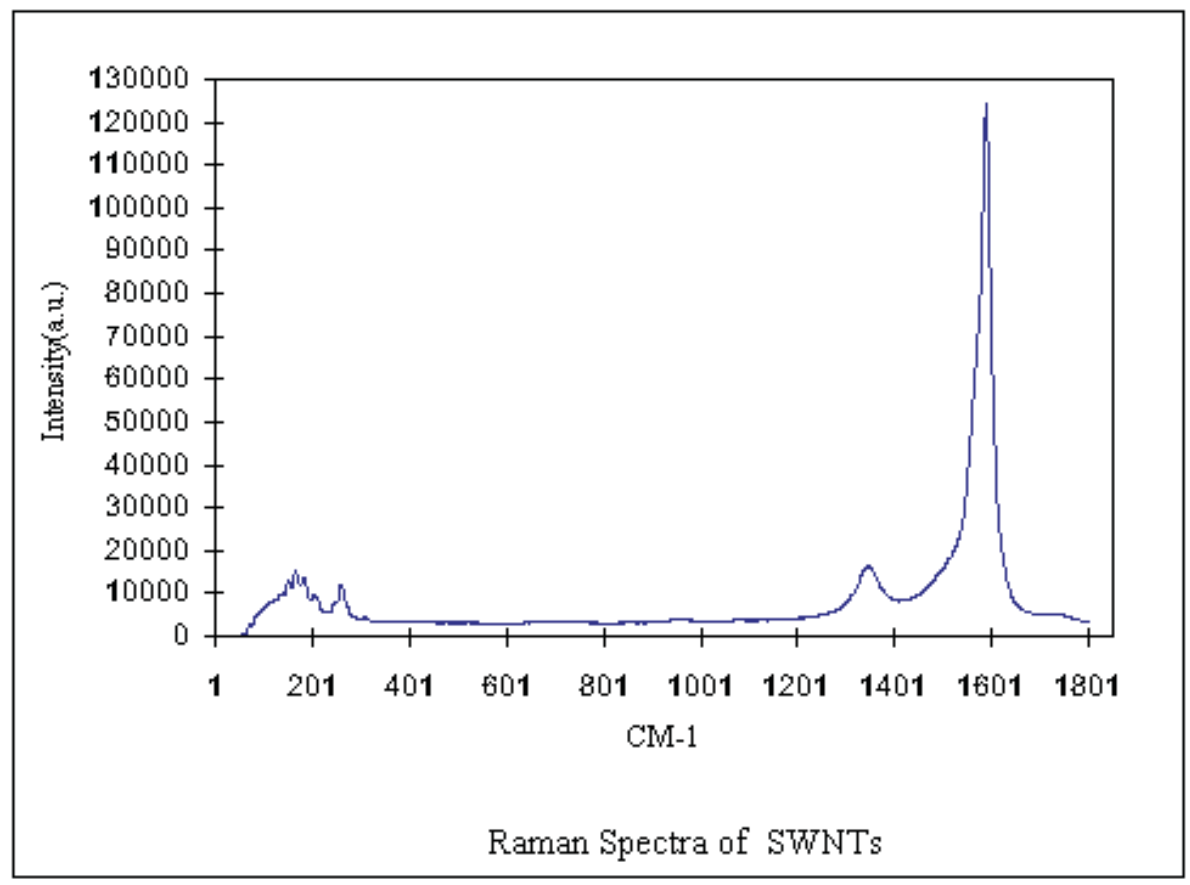

Figura 2.4: Espectro Raman de Nanotubos de Carbono. O pico em torno de $200 \mathrm{~cm}^{-1}$ é característico dessas estruturas. [43]

Figura 2.5: DOS para os nanotubos (a) armchair (10,10), (b) quiral $(11,9)$ e (c) zig-zag $(22,0)$ e (d) Energias de transição para todos os nanotubos $(n, m)$ com diâmetros entre $0,4 n m$ e $3,0 \mathrm{~nm}$ [19].

onde C é um parâmtero ajustável. e $d_{t}$, o diâmetro do tubo [19,69]. Os valores dessa freqüência costumam estar numa faixa entre $120 \mathrm{~cm}^{-1} \mathrm{e} 400 \mathrm{~cm}^{-1}$.

A região em torno de $200 \mathrm{~cm}^{-1}$ na Figura 2.4 representa um sinal de vários RBM, de vários tubos de diferentes diâmetros presentes na amostra.

Figura 2.6: Modo RBM para o nanotubo zig-zag $(8,0)$.

\subsubsection{Banda D}

A Banda D, ou Banda Induzida por Desordem, é um sinal presente no espectro devido aos defeitos da amostra que surgem na produção dos na- 
notubos. Também se associa a esta banda processos de espalhamento Raman envolvendo dois fônons, bem como a quebra da conservação do momento [70]. A intensidade do seu sinal depende da quiralidade do tubo, mas geralmente é bem mais fraco quando comparado àquele da banda $\mathrm{G}$ (torno de 100 vezes menor) ${ }^{3}$, como mostra a Figura 2.7 .

\subsubsection{Banda G}

A banda $\mathrm{G}$ corresponde às vibrações tangenciais também observadas no grafite e surge na região de freqüências em torno de $1580 \mathrm{~cm}^{-1}$. É composta por dois picos mais pronunciados: o pico $G^{-}$, menos energético e $G^{+}$, mais energético como na Figura 2.7. Uma das muitas peculiaridades desses modos é que possuem distinta dependência com o diâmetro. A freqüência do modo $G^{+}$não depende do diâmetro, bem como do ângulo quiral e da energia do laser [45]. Contudo, a freqüência do modo $G^{-}$possui forte dependência tanto do diâmetro como do caráter eletrônico do tubo. A Figura 2.8 mostra a dependência desses modos com o inverso do diâmetro. Os dados se ajustam numa relação experimental simples $\omega^{-}=1591-C / d^{2}$, com $C$ assumindo os valores $47.7 \mathrm{~cm}^{-1} \mathrm{~nm}^{2}$ e $79.5 \mathrm{~cm}^{-1} \mathrm{~nm}^{2}$ para tubos semicondutores e metálicos, respectivamente [45].

Figura 2.7: Comparação entre as bandas D e G para três nanotubos semicondutores e metálicos isolados, com os diâmetros discriminados. A banda D é muito fraca, quase nula, quando há ótima ressonância com o laser incidente. No tubo de diâmetro 1,47nm a alta intensidade deve-se a uma má ressonância [45].

Figura 2.8: Frequiências dos picos $G^{-}$e $G^{+}$em função do inverso do diâmetro dos tubos. Os círculos cheios representam tubos semicondutores e os vazios os metálicos [45].

$\mathrm{O}$ assinalamento desses modos está associado às simetrias $A_{1}$ e $E_{1}$ [45]. Outra propriedade bastante útil dessa banda deve-se a sua forma. O pico $G^{+}$permanece com o mesmo perfil independente do sistema, contudo, o pico

\footnotetext{
${ }^{3} \mathrm{Na}$ realidade, isso depende da qualidade da amostra (presença de muitos defeitos ou não)
} 
$G^{-}$muda de forma novamente dependendo do caráter eletrônico. Para tubos semicondutores ele apresenta uma forma mais estreita com uma grande diferença entre os picos $G^{+}$e $G^{-}$, tendendo à formação de um único pico. Já o metálico tende a apresentar os dois picos mais pronunciados, sendo mais largo. Nesse caso, o pico $G^{+}$tem uma forma Lorentziana e o $G^{-}$uma curva assimétrica da forma Breit-Wigner-Fano (BWF) [45], como na Figura 2.9

Figura 2.9: Formas da banda G para nanotubos. No meio o espectro para nanotubos semicondutores e abaixo para metálicos. Ao topo também é mostrado o pico $E_{2 g}$ do espectro Raman do grafite, correspondente à banda G desse material. [46]. 


\section{Capítulo 3}

\section{Metodologia}

Os cálculos realizados cumpriram, basicamente, duas etapas bem definidas:

I. Cálculo de energia total mínima, onde se extrai informação sobre as posições de equilíbrio, necessárias para um cálculo de fônons, como visto no primeiro capítulo.

II. Cálculo das propriedades vibracionais (fônons), via Método Direto.

Como o intuito do projeto é identificar os efeitos relativos dos diferentes defeitos no espectro de fônons, e também pelo interesse recair sobre o defeito isolado (ou seja, não há interesse na contribuição da periodicidade do defeito no sistema) os cálculos das frequências foram restritos ao ponto $\Gamma$ da relação de dispersão vibracional. Além disso, os experimentos Raman estão associados a esse ponto. A identificação consiste em encontrar possíveis modos localizados introduzidos pelos defeitos.

\subsection{Programa Utilizado}

O programa utilizado para todos os cálculos foi o pacote SIESTA [67]. Spanish Initiative for Electronic Simulation with Thousands of Atoms é um programa baseado em DFT com condições periódicas de contorno, funcionais LDA ou GGA, tratando os elétrons do caroço e os íons por pseudopotenciais [22,47] 
de norma-conservada na forma de Kleinman-Bylander [47]. As propriedades estáticas de sistemas multieleletrônicos a uma certa distância dependem somente das condições de uma região localizada, ou seja, a uma distância de alguns vizinhos, as propriedades são independentes de outras perturbações (potenciais). Assim, por exemplo, as propriedades de bulk, na maioria dos casos podem ser definidas sem qualquer referência à superfície do material. Dessa forma, é de grande eficiência descrever as funções de onda eletrônicas através do uso de funções de base localizadas, ou seja, um conjunto de funções definidas até um dado raio de corte, a partir do qual ela é exatamente zero, controlando assim o overlap entre as funções. O SIESTA utiliza uma combinação linear de pseudo-orbitais atômicos numéricos como base (LCAO), construídos a partir dos pseudo-átomos (resolução numérica do Hamiltoniano de KohnSham para esses sistemas), definidos na elaboração dos pseudopotenciais. Isso garante a coerência entre a região do caroço no pseudopotencial e dos pseudoátomos da base. A grandeza que controla esse ganho de energia, portanto o raio de corte, dos orbitais é o Energy shift [49].

Orbitais atômicos possuem a forma:

$$
\phi_{i}(\vec{r})=\Phi_{i l}\left(\left|\vec{r}_{i}\right|\right) Y_{l m}\left(\theta_{i}, \varphi_{i}\right)
$$

com $\vec{r}_{i}=\vec{r}-\vec{R}_{i}$ a posição do elétron referente ao íon em $\vec{R}_{i}$.

A parte radial desses orbitais é representada por funções radiais $\zeta$. O conjunto mínimo de base (single $\zeta$ - SZ) utiliza somente uma $\zeta$ por momento angular. O SIESTA, porém é implementado também para o conjunto duplo $\zeta$ 's (double $\zeta$ - DZ) que utiliza uma combinação de duas funções $\zeta^{\prime}$ s. Para redução do custo computacional, tratar somente os orbitais de valência (mais importantes) pelo conjunto duplo e os demais pela base mínima é possível (conjunto de base split valence). O fato de que, quando átomos se aproximam para formar ligações, a distribuição de cargas é deformada por um efeito de polarização, uma vez que atrai o íon positivo e repele a outra nuvem eletrônica, é levado em conta considerando-se a possibilidade da forma de um orbital misturar aquelas de outras simetrias (exemplo, os orbitais $s$ e $p$ podem ter formas misturadas com as dos orbitais $d$ ). Um conjunto de base que reúne essa característica é dito polarizado. Nesse trabalho, usou-se o conjunto de base duplo- $\zeta$ 's polarizadas 
(DZP).

\subsubsection{Cálculo da Energia Total}

As equações de Kohn-Sham do sistema molecular são resolvidas autoconsistentemente, onde os autovalores do Hamiltoniano são obtidos por diagonalização [50]. Os termos de troca-correlação foram tratados na aproximação GGA com parametrização de Perdew-Burke-Ernzerhof - PBE [51]. Extraídos os autovalores e autofunções, um novo Hamiltoniano é construído e um novo ciclo é realizado até que a diferença entre a nova e a antiga densidades de carga atinja um critério de convergência previamente estabelecido (normalmente da ordem de $10^{-3}-10^{-4}$ em unidades de densidade de carga).

Parte das integrais envolvidas no cálculo dos autovalores do Hamiltoniano e, posteriormente, da energia são calculadas no espaço real e outras no recíproco. Aquelas do espaço real são calculadas num grid $^{1}$, cuja densidade de pontos é determinada pelo grau de suavidade das funções do integrando. Daí a grande importância da formulação dos pseudopotenciais, caso contrário o grid deveria ser muito fino para descrever as rápidas variações inerentes às funções na região do caroço. Os pseudopotenciais usados seguiram a parametrização de Troullier-Martins com correções relativísticas [52]. O quão fino deve ser esse grid (ou seja, o espaçamento entre os pontos do grid) é definido no SIESTA pela energia do menor comprimento de onda da onda-plana que pode ser descrita nele ${ }^{2}[50]$.

As integrais restantes são resolvidas num grid recíproco definido somente em alguns pontos especiais da zona de Brillouin, segundo alguns esquemas especiais. Para este trabalho foi-se utilizado o grid no esquema de Monkhorst-Pack [47].

Resolvido o Hamiltoniano, tem-se então os autovalores (estrutura de bandas) do sistema. O cálculo da energia total envolve, contudo, além das integrais vistas na Eq. (1.38), o termo de interação íon-íon:

\footnotetext{
${ }^{1}$ Em português a melhor tradução para esse termo é malha ou grade. Optou-se, contudo, pela manutenção desse termo pela grande popularidade assumida no meio.

${ }^{2} E=\frac{\hbar k^{2}}{2 m}$ é a energia da onda plana com vetor de onda $\vec{k}$. Como $k=\frac{2 \pi}{\lambda}$, quanto maior a energia, menor é o $\lambda$, portanto, menor é o espaçamento entre os pontos.
} 


$$
\hat{V}_{N N}=\frac{1}{2} \sum_{i, j=1}^{M} \frac{Z_{i} Z_{j} e^{2}}{\left|\vec{R}_{i}-\vec{R}_{j}\right|}
$$

Potenciais Coulombianos não são simples de lidar, devido ao seu alcance. Potenciais de longo alcance são aqueles que decaem muito mais lentamente que $r^{-d}$, onde $d$ é a dimensão do sistema ( $d=3$ para a maioria dos sistemas). A expansão de tais potenciais geram termos divergentes ou lentamente convergentes. O potencial entre os núcleos e mesmo as energias de interação entre os elétrons e os núcleos e o termo de Hartree possuem esse caráter. Contudo, felizmente é possível somar-se esses três termos de forma a resultar em algo não divergente [54]. Para o termo referente ao potencial interatômico, o SIESTA usa argumentos de densidade de carga do pseudopotencial local, eliminando ainda mais os efeitos de longo-alcance pertinentes a ele. Para um tratamento detalhado do assunto reportar-se à Ref. 55 .

\subsubsection{Cálculo das Forças}

As forças sobre os átomos são calculadas mediante derivada direta da energia total com respeito à variação das posições de equilíbrio dos núcleos devido ao deslocamento de um dado átomo:

$$
F_{i} \equiv \frac{\partial E_{\text {total }}}{\partial u_{i}}
$$

\subsubsection{Cálculo da Estrutura de Equilíbrio}

Para o cálculo das posições de equilíbrio, procede-se com a otimização dos dados necessários para um cálculo refinado (grid de pontos $\mathrm{k}$ do espaço recíproco e do espaço real, energy shift, entre outros). A partir disso, os átomos são deslocados em direções determinadas pelo método de minimização. No presente trabalho foi-se utilizada a técnica do Gradiente Conjugado. A convergência da minimização é controlada pelo critério de força máxima tolerada na estrutura. Com isso, obtém-se a constante de rede da estrutura.

Neste trabalho, os seguintes critérios foram utilizados, visando equilibrar a relação entre o custo computacional e a qualidade dos resultados: 
Tabela 3.1:

Critérios de convergência para as estruturas calculadas. $N$ : número de átomos; $F_{\max }$ : Força Máxima Tolerada; Mesh: Densidade de pontos no grid real, dada como energia, conforme relação $E=\frac{\hbar k^{2}}{2 m} ; E_{s}$ : Energy shift; DM.Tol: Critério de convergência da Matriz Densidade.

\begin{tabular}{l|c|c|c|c|r}
\hline Sistemas & $\mathrm{N}$ & $F_{\max }(\mathrm{eV} / \AA)$ & $M e s h(\mathrm{Ry})$ & $E_{s}(\mathrm{eV})$ & DM.Tol \\
\hline \hline Supercélula (5,5) & 140 & 0.03 & 250 & 0.03 & 0.002 \\
Supercélula (8,0) & 160 & 0.03 & 250 & 0.03 & 0.002 \\
Célula unitária (5,5) & 20 & 0.005 & 400 & 0.03 & 0.0001 \\
Célula unitária (8,0) & 32 & 0.005 & 400 & 0.03 & 0.0001 \\
\hline \hline
\end{tabular}

\subsubsection{Cálculo de Fônons}

Como mencionado no Capítulo 1, a ferramenta necessária para o cálculo das freqüências vibracionais é a matriz constante de força. O SIESTA calcula os fônons através do Método Direto [56]. A geometria inicial de equilíbrio é distorcida, ou seja, cada átomo é deslocado nas várias direções, e utilizada para o cálculo de nova energia total. O programa calcula as contantes de força para cada direção $(x, y, z)$ em ambos os sentidos para diminuir possíveis efeitos de anarmonicidade. $\mathrm{O}$ deslocamento utilizado nesse trabalho foi $\Delta=0.04 \mathrm{Bohr}=$ $0.02 \AA$.

Dessa forma, estarão associadas a cada deslocamento, duas constantes de força:

$$
\begin{aligned}
k_{i}^{+} & =\frac{\left|\vec{f}_{i}^{0}-\vec{f}_{i}\left(\vec{x}_{j}+\vec{\delta}\right)\right|}{|\vec{\delta}|} \\
k_{i}^{-} & =\frac{\left|\vec{f}_{i}\left(\vec{x}_{j}-\vec{\delta}\right)-\vec{f}_{i}^{0}\right|}{|\vec{\delta}|},
\end{aligned}
$$

onde $f_{i}^{0}$ é a força residual no átomo $i$, na configuração não-distorcida, e $f_{i}\left(\vec{x}_{j} \pm\right.$ $\delta$ ) são as forças nesse átomo devido ao deslocamento do átomo $j$ nas três direções, nos sentidos positivo $(+)$ e negativo $(-)$, respectivamente. A constante de força final é, então, a média desses valores: 


$$
k_{i}=\left(\frac{k_{i}^{+}+k_{i}^{-}}{2}\right)
$$

Esses são os valores dos elementos da matriz constante de força, de onde, após diagonalização, extrai-se diretamente os autovalores (que são os quadrados das freqüências) e os autovetores.

Nos cálculos de bulk, ou seja, os cálculos realizados numa única célula unitária com considerações periódicas de contorno tomando-se vários pontos k para a integração da zona de Brillouin (não somente o ponto $\Gamma$ ), construiu-se uma célula unitária otimizada nos parâmetros acima mencionados e posteriormente uma supercélula (o uso de supercélula nesse caso deve-se ao fato de se estar usando o método direto, como visto anteriormente). Permitiu-se, contudo, o deslocamento somente dos átomos da célula unitária. Para o nanotubo $(5,5)$ foram 20 átomos e para o sistema $(8,0), 32$.

Nos cálculos com o defeito, onde a periodicidade da célula unitária convencional fica comprometida, novamente foi-se construída uma supercélula com 140 e 160 átomos para os nanotubos $(5,5)$ e $(8,0)$, respectivamente. Nesse caso, os átomos deslocados foram todos, pois não há mais sentido em se tomar somente os 20 ou 32 átomos, como anteriormente, uma vez que essa estrutura não se repetirá nesse período. O número de repetições em cada supercélula foi definido visando-se eliminar as interações entre os defeitos, já que o interesse está na construção de defeitos isolados.

Devido às forças residuais no processo de relaxação das posições atômicas e, principalmente, um grid finito para a integração dos elementos da matriz Hamiltoniana, erros numéricos surgem [56], refletindo-se na simetria do sistema e produzindo, inclusive, o surgimento de frequências negativas, uma vez que elementos que deveriam ser nulos não necessariamente serão. Dependendo do quão apurado for a conta, esses erros podem ser muito pequenos, contudo, persistindo. 


\section{Capítulo 4}

\section{Resultados e Discussões}

\subsection{Sistemas Estudados}

Como mencionado na Introdução, apesar da proposta dos experimentais [14] ter sido a geometria de uma vacância rodeada por anéis tipo piridina (Figura 4.2 acima e à direita), estudos anteriormente realizados no nosso grupo [12], mostraram que, na faixa de potenciais químicos do nitrogênio utilizada nos experimentos, o defeito formado de uma divacância rodeada por quatro anéis tipo piridina é o mais estável e entra em acordo com os resultados experimentais. Ainda baseado nesses estudos, as geometrias mais estáveis para os nanotubos $(5,5)$ e $(8,0)$, quando dopados com defeitos de nitrogênio, são aquelas mostradas nas Figuras 4.2 e 4.3. Dessa forma, os modos vibracionais desses sistemas foram aqueles investigadas.

\subsection{Posições de Equilíbrio}

O cálculo das posições de equilíbrio iniciou-se com a otimização dos parâmetros de cálculo e a obtenção do parâmetro de rede. Esses dados foram extraídos da Ref. 12.

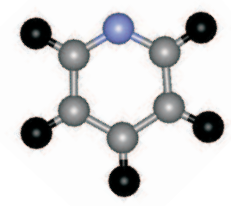

Figura 4.1: Molécula planar da piridina. C: cinzas, $\mathrm{N}$ : azul e $\mathrm{H}$ : pretos. 

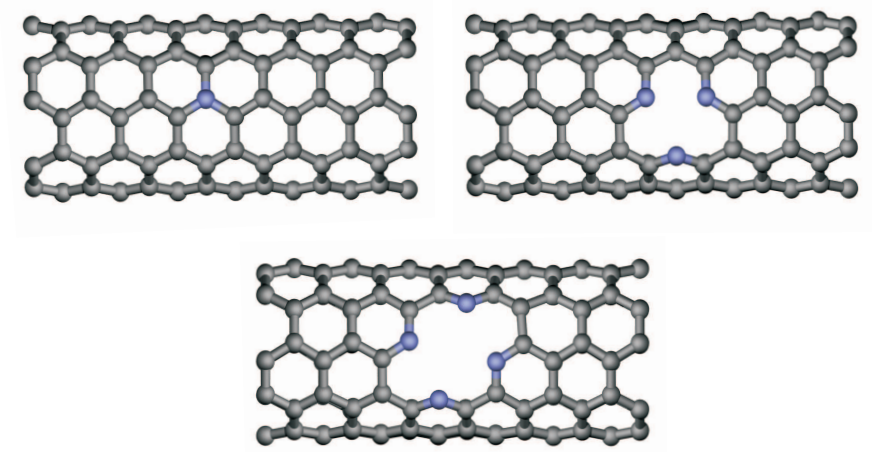

Figura 4.2: Estruturas mais estáveis para o nanotubo $(5,5)$ dopado com os seguintes defeitos: Acima e à esquerda - Nitrogênio Substitucional, Acima e à direita - Monovacância rodeada por 3 Nitrogênios e Abaixo - Divacância rodeada por 4 Nitrogênios.

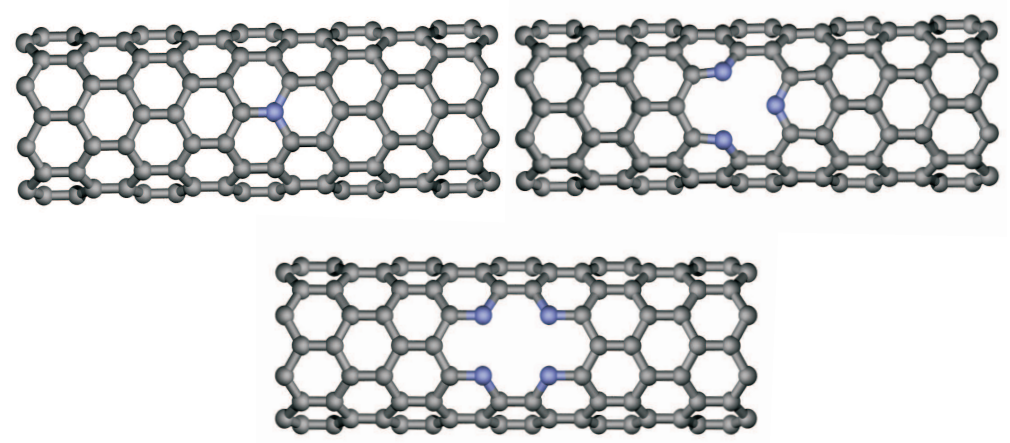

Figura 4.3: Estruturas mais estáveis para o nanotubo $(8,0)$ dopado com os seguintes defeitos: Acima e à esquerda - Nitrogênio Substitucional, Acima e à direita - Monovacância rodeada por 3 Nitrogênios e Abaixo - Divacância rodeada por 4 Nitrogênios.

Os valores da Tabela 4.1 foram utilizados para todos os sistemas, isto é, também para os defeitos construídos a partir da Supercélula.

\subsection{Sistemas Puros}

Inicialmente efetuou-se o cálculo das freqüências dos sistemas puros. A partir de então seguiu-se a identificação dos modos Raman ativos. O primeiro sistema foi a célula unitária dos nanotubos. Fez-se um cálculo no ponto $\Gamma$ e a seguir um cálculo da relação de dispersão, para o qual uma Supercélula 
com os parâmetros da Tabela 4.1 foi construída.

\begin{tabular}{l|c|r}
\hline Sistemas Puros & Constante de Rede da Supercélula & Grid Recíproco \\
\hline \hline Supercélula $(5,5)$ & $17,458(=7 \times 2,494) \AA$ & $1 \times 1 \times 3$ \\
Supercélula $(8,0)$ & $21,630(=5 \times 4,326) \AA$ & $1 \times 1 \times 3$ \\
Célula unitária $(5,5)$ & $2,494 \AA$ & $1 \times 1 \times 21$ \\
Célula unitária $(8,0)$ & $4,326 \AA$ & $1 \times 1 \times 30$ \\
\hline \hline
\end{tabular}

Tabela 4.1: Parâmetros otimizados para os sistemas puros: Supercélula do nanotubo $(5,5)$ contendo sete repetições da célula unitária e do nanotubo $(8,0)$, apenas cinco e suas respectivas células unitárias.

Tomou-se esse número de repetições baseado no fato de que as intensidades das forças surgidas pelo movimento de um átomo no momento da distorção do sistema cristalino necessário para o cálculo de fônons devem decair até um certo número de vizinhos. Para os sistemas utilizados observouse que essa condição era suficientemente satisfeita à distância relativa a essas repetições.

\subsubsection{Nanotubo $(5,5)$}

A célula unitária de um nanotubo de carbono $(5,5)$ contém 20 átomos, portanto sua matriz dinâmica será $60 \times 60$, ou seja, a dispersão dos fônons constará de 60 ramos. A primeira dispersão (Figura 4.4, à direita) foi obtida com as posições relaxadas a partir dos parâmetros da Ref. 12 (Cálculo I). Ao se comparar com resultados da literatura, observou-se que os ramos de baixa energia não foram bem descritos e um novo cálculo (Cálculo II) foi realizado com parâmetros mais refinados, primeiro para a obtenção das novas posições e a partir dessas, com os mesmos novos parâmetros um novo cálculo de freqüências. Os parâmetros utilizados em ambos os cálculos constam na Tabela 4.2.

O Critério de Força determina o fim da relaxação das posições e o Critério de Convergência da Matriz Densidade (DM.Tol, como explicado no Capítulo anterior) determina a tolerância sobre as diferenças em cada ciclo 


\begin{tabular}{l|c|r}
\hline & Cálculo I & Cálculo II \\
\hline \hline Critério de Força & $0,03 \mathrm{eV} / \AA$ & $0,005 \mathrm{eV} / \AA$ \\
MeshCutoff & $250 \mathrm{Ry}$ & $400 \mathrm{Ry}$ \\
Critério da DM & 0,002 & 0,0001 \\
\hline
\end{tabular}

Tabela 4.2: Parâmetros utilizados nos cálculos.

auto-consistente para cada elemento da matriz densidade. O MeshCutoff mede o quão fino é o grid (número de pontos no grid) para o cálculo das integrais no espaço real, como explicado na Metodologia.
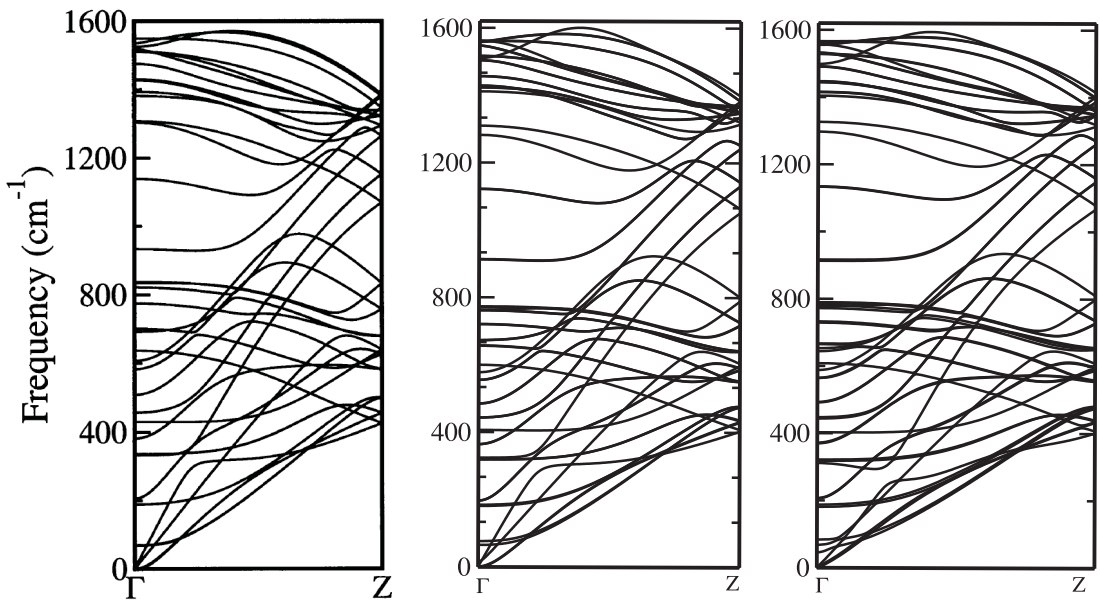

Figura 4.4: Dispersão dos fônons para a célula unitária do nanotubo armchair $(5,5)$. À esquerda, os resultados da Ref. 57. Ao meio, o cálculo mais refinado e à direita o cálculo inicial.

Comparando-se esses resultados com aqueles da Ref. 57, que utilizou um conjunto de ondas planas e pseudopotencial ultrasoft, bem como GGAPBE para o termo de troca-correlação, nota-se que o Cálculo II reproduz melhor os ramos de baixa energia. Os modos de alta energia são igualmente bem descritos por ambos os cálculos.

Ainda devido a uma não perfeita presença das simetrias no sistema, 
observa-se que as degenerescências não são tão bem reproduzidas no método utilizado, como no ramo logo acima de $1200 \mathrm{~cm}^{-1}$. Assim, a aplicação de alguma operação de simetria em um átomo da estrutura construída não reproduz exatamente a posição de outro átomo nessa rede (já que as posições da rede foram obtidas através de cálculo numérico). Isso ocorre devido a pequenos erros inerente a cálculos numéricos. Apesar disso, a diferença máxima entre as posições para ambos os cálculos foi de $0.08 \AA$. A Figura 4.6 mostra a densidade de estados vibracionais - VDOS ${ }^{1}$ para o Cálculo II e para a Supercélula com sete repetições no ponto $\Gamma$.

Independente de como foram calculados, todos os modos normais devem aparecer, com maiores ou menores erros quanto à orientação dos autovetores e diferenças de valores numéricos das freqüências. Assim, os modos $\Gamma$ foram reconhecidos em ambos os cálculos, com ênfase para aqueles Raman ativos.

Haja vista a grande diferença no tempo computacional entre os cálculos nesse sistema com apenas 20 átomos, optou-se pela utilização do padrão de Cálculo I para a supercélula e os defeitos.

A seguir foi realizado o cálculo de fônons para a Supercélula com sete repetições (Figura 4.5), com os parâmetros da Tabela 4.1 [12]. Nas Figuras $4.7 \mathrm{e}$ 4.8 estão representados os sete modos mais intensos [58] no espectro Raman de um total de oito modos ativos ${ }^{2}$. Os perfis dessas vibrações estão esquematizados na Figura 4.7, da Ref. 59. A VDOS foi calculada no ponto $\Gamma$ para posterior comparação com aquelas dos sistemas dopados. Utilizou-se o mesmo alargamento ( broadening) gaussiano para ambas as densidades de estados.

\footnotetext{
${ }^{1}$ do inglês Vibrational Density Of States.

${ }^{2} \mathrm{O}$ número de modos ativos é dado pela aplicação das regras de seleção da Teoria de Grupos [59].
} 


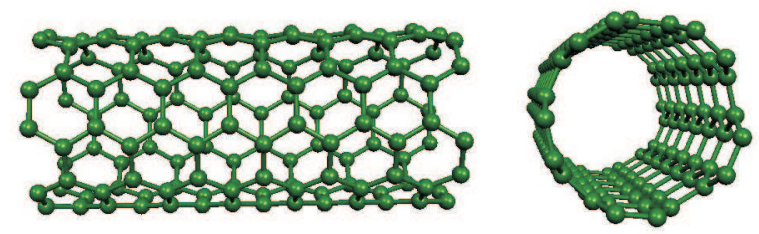

Figura 4.5: Tubo puro com sete repetições da célula unitária convencional do nanotubo $(5,5)$.
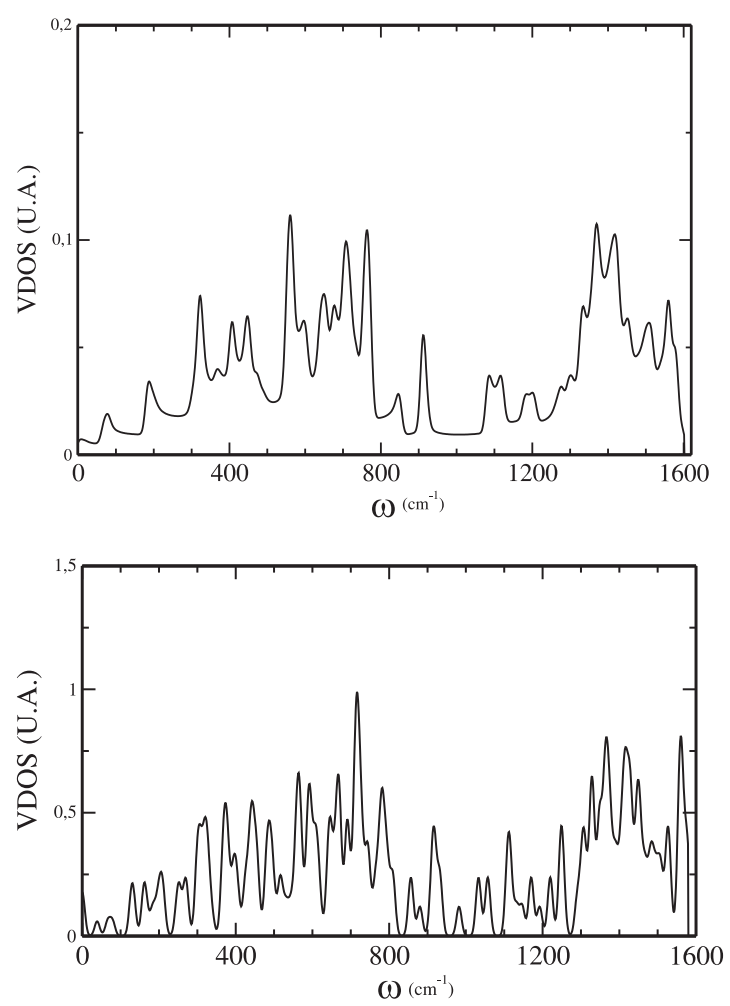

Figura 4.6: Acima: VDOS para a célula unitária do nanotubo armchair $(5,5)$ para toda a dispersão. Abaixo: VDOS para a Supercélula com sete repetições no ponto $\Gamma$. 


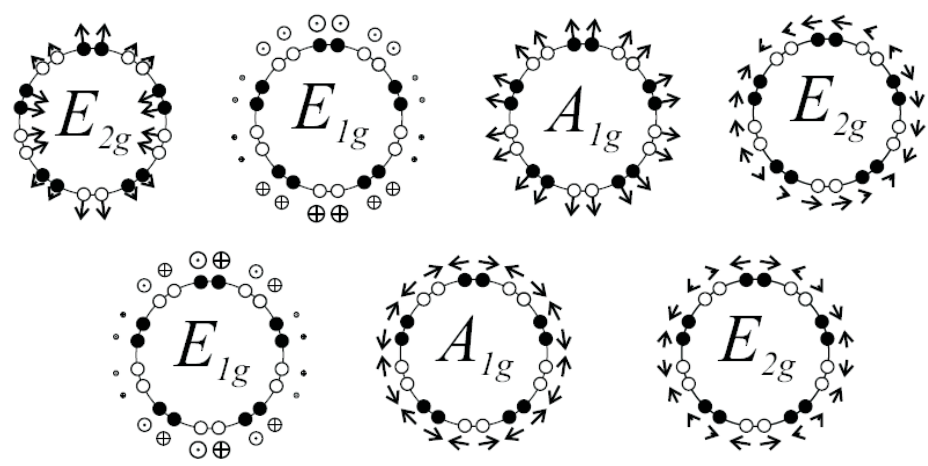

Figura 4.7: Representação esquemática dos perfis das vibrações dos sete modos Raman ativos mais fortes para o nanotubo $(5,5)[59]$.

\begin{tabular}{c|c|c}
\hline Simetria & $\omega\left(\mathrm{cm}^{-1}\right)$ & $\Delta\left(\mathrm{cm}^{-1}\right)$ \\
\hline \hline E2g & $(66,79)$ & 13 \\
E1g & $(197,197)$ & 0 \\
A1g & 311 & - \\
E2g & $(638,649)$ & 11 \\
E1g & $(1531,1532)$ & 1 \\
A1g & 1557 & - \\
E2g & $(1564,1565)$ & 1 \\
\hline \hline
\end{tabular}

Tabela 4.3: Freqüências $(\omega)$ e erros numéricos de degenerescência $(\Delta)$ para os sete modos Raman ativos mais fortes para a Supercélula do nanotubo $(5,5)$ com o Cálculo I.

Como já discutido anteriormente, as degenerescências não foram bem descritas e os sete modos Raman ativos mais fortes na Supercélula ${ }^{3}$ pura, bem como os erros de degenerescência $\Delta$ dos modos que deveriam possuir mesma energia ( e, portanto, mesma freqüência) constam na Tabela 4.3. Dessas freqüências, como mostrado no espectro Raman (Capítulo 2) somente o modo $A_{1 g}$ da região de baixas freqüências $(\mathrm{RBM})$ e os três últimos (banda $\mathrm{G}$ ) são os mais importantes. Observe-se que para a banda G a degenerescência foi bem

\footnotetext{
${ }^{3} \mathrm{O}$ sistema mais interessante é a Supercélula, pois os defeitos foram inseridos nesse sistema e não na célula unitária.
} 
descrita.

\subsubsection{Nanotubo $(8,0)$}

Para o caso do nanotubo $(8,0)$, que possui 32 átomos em sua célula unitária, haverá 96 modos e portanto, igual número de ramos. Também para esse sistema foram feitos dois tipos de cálculos, com os mesmos parâmetros da Tabela 4.2. As dispersões resultantes são mostradas na Figura 4.9.

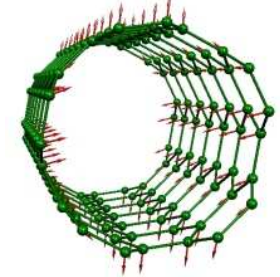

$66 \mathrm{~cm}^{-1}$

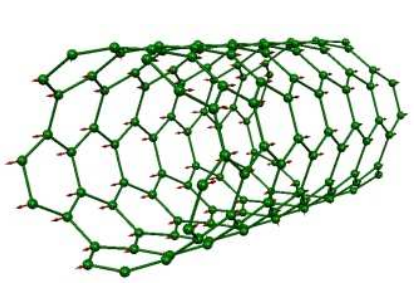

$197 \mathrm{~cm}^{-1}$

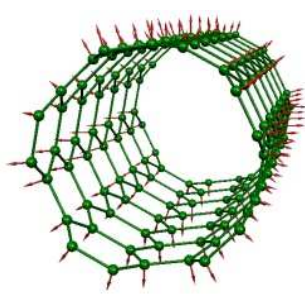

$311 \mathrm{~cm}^{-1}$

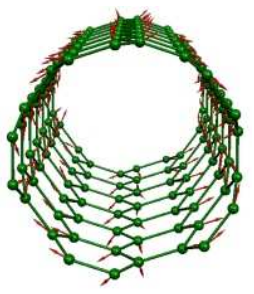

$638 \mathrm{~cm}^{-1}$

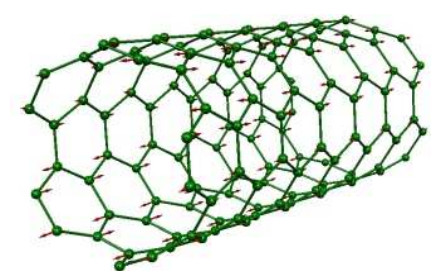

$1531 \mathrm{~cm}^{-1}$

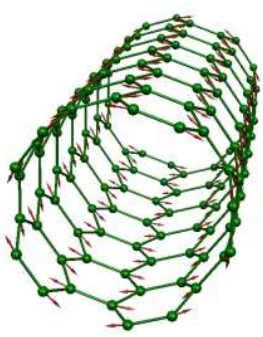

$1557 \mathrm{~cm}^{-1}$

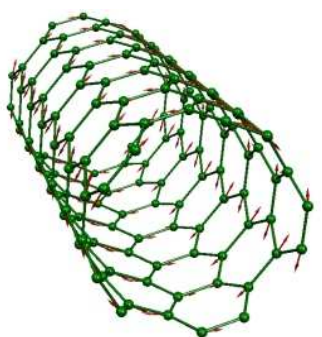

$1564 \mathrm{~cm}^{-1}$

Figura 4.8: Representação dos sete modos Raman ativos mais fortes para a supercélula com sete repetições do nanotubo $(5,5)$ no ponto $\Gamma$.

Novamente a diferença é significativa somente na região de baixas energias. No Cálculo II há o surgimento de um ramo que atinge algumas freqüências negativas. Isso se deve ao fato de que a freqüência em $\Gamma$ utilizada para a interpolação ${ }^{4}$ correspondente ao modo de rotação rígida do tubo foi negativa $\left(-13 \mathrm{~cm}^{-1}\right)$ em vez de nula. Essa freqüência surge novamente devido a pequenos erros numéricos advindos da não perfeita simetria das posições atômicas, o que implica no cálculo das constantes de força não perfeitamente simetrizadas.

\footnotetext{
${ }^{4}$ a dispersão é calculada através de uma interpolação de pontos cujos valores são obtidos a partir daquele em $\Gamma$
} 
Conclui-se que o Cálculo II novamente representa melhor os ramos e as degenerescências, tomando-se como refência novamente os resultados da Ref. 57. Contudo, a máxima diferença entre as posições para ambos os cálculos foi de $0.003 \AA$. Novamente o cálculo a ser escolhido foi aquele menos refinado (Cálculo I), devido ao tempo computacional exigido. Os modos $\Gamma$ foram reconhecidos, como anteriormente, enfatizando aqueles Raman ativos. A Figura
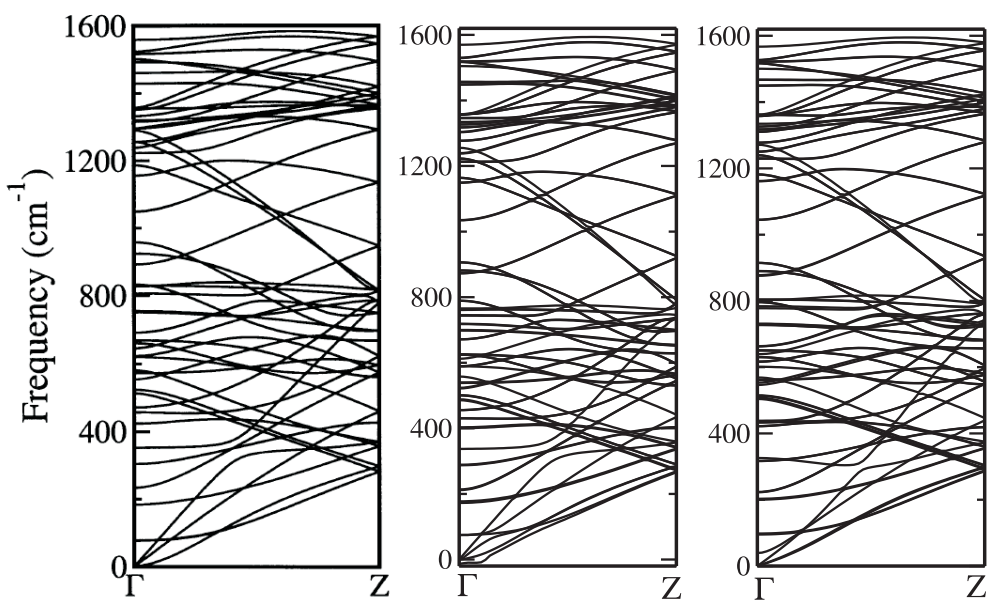

Figura 4.9: Dispersão dos fônons para a célula unitária do nanotubo zigzag $(8,0)$. À esquerda, os resultados da Ref. 57. Ao meio, o cálculo mais refinado e à esquerda o cálculo inicial.

4.10 mostra a VDOS para o sistema resultante do Cálculo II para toda a dispersão.

Uma Supercélula com cinco repetições (Figura 4.11) foi construída para o nanotubo $(8,0)$, conforme a Tabela 4.1 [12]. A VDOS calculada no ponto $\Gamma$ da Supercélula está mostrada na Figura 4.10. O alargamento foi o mesmo que aquele anteriormente utilizado para as Densidades anteriores. Os sete modos Raman mais intensos também são representados na Figura 4.12.

Para o tubo semicondutor os erros de degenerescências foram bem menores, como mostra a Tabela 4.4 . 

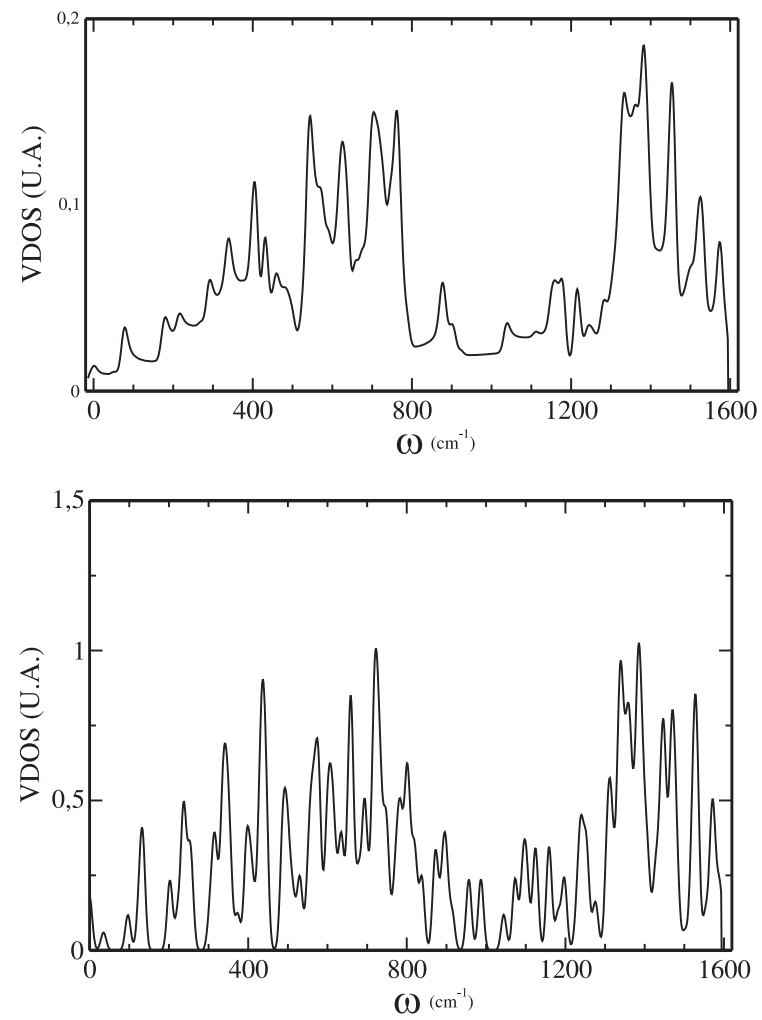

Figura 4.10: Acima: VDOS para a célula unitária do nanotubo zigzag $(8,0)$ para toda a dispersão. Abaixo: VDOS para a Supercélula com cinco repetições no ponto $\Gamma$.

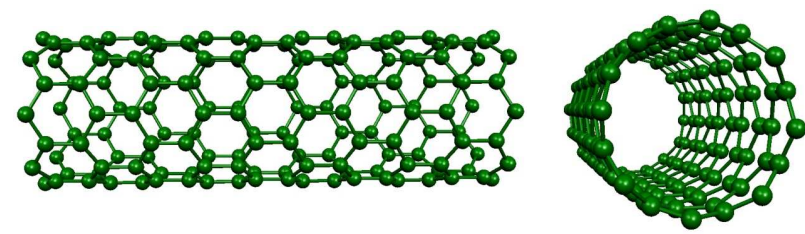

Figura 4.11: Tubo puro com cinco repetições da célula unitária convencional do nanotubo $(8,0)$. 


\begin{tabular}{c|c|c}
\hline Simetria & $\omega\left(\mathrm{cm}^{-1}\right)$ & $\Delta\left(\mathrm{cm}^{-1}\right)$ \\
\hline \hline E2g & $(96,97)$ & 1 \\
E1g & $(222,223)$ & 1 \\
A1g & 326 & - \\
E2g & $(662,663)$ & 1 \\
E2g & $(1450,1450)$ & 0 \\
E1g & $(1527,1527)$ & 0 \\
A1g & 1567 & - \\
\hline \hline
\end{tabular}

Tabela 4.4: Frequiências $(\omega)$ e erros numéricos de degenerescência $(\Delta)$ para os sete modos Raman ativos mais fortes para a Supercélula do nanotubo $(8,0)$.

Novamente desses modos, somente o RBM e banda G são importantes no espectro Raman.

\subsection{Sistemas com Defeitos}

A partir da geometria da Supercélula pura foram introduzidos os defeitos das Figuras 4.2 e 4.3. Isso ocasionou a quebra da simetria anterior do sistema. Como a periodicidade do sistema com defeito não é o interesse da pesquisa $^{5}$, não há sentido em se efetuar um cálculo de relação de dispersão para a supercélula nem para os defeitos. Novamente, a utilização de supercélulas é uma ferramenta de cálculo. Os modos que realmente interessam quando se fazem medidas são os modos $\Gamma$ da célula unitária convencional, que foi repetida. Visando uma comparação com resultados experimentais, focalizou-se somente aqueles sete modos Raman ativos mais fortes, anteriormente mostrados, para ambos os sistemas, isto é, aqueles com caráter $\Gamma$ da célula unitária convencional.

Ao se efetuar o cálculo na supercélula, alguns modos que anteriormente não pertenciam ao ponto $\Gamma$ na célula unitária passam a pertencer ao ponto $\Gamma$ da Supercélula. A relação é construída a partir do folding da dispersão

\footnotetext{
${ }^{5}$ De fato não há ordenamento no surgimento dos defeitos quando os sistemas são produzidos experimentalmente, portanto, não há interesse em estudar defeitos periódicos.
} 
da célula unitária exatamente $n$ vezes quanto a célula primitiva (célula unitária convencional) foi repetida na construção da Supercélula. Por exemplo, para o tubo $(5,5)$, na região de baixas freqüências (Figura 4.13), cuja Supercélula é composta por $n=7$ repetições,

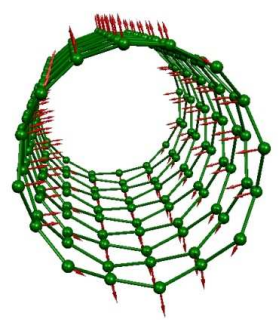

$96 \mathrm{~cm}^{-1}$

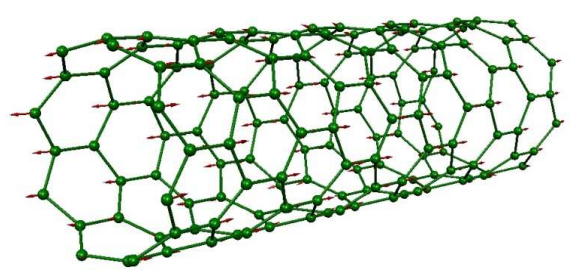

$222 \mathrm{~cm}^{-1}$

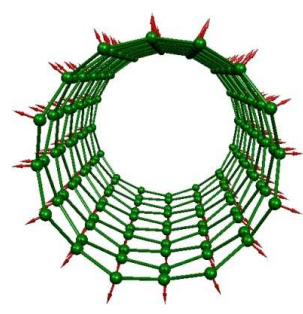

$326 \mathrm{~cm}^{-1}$

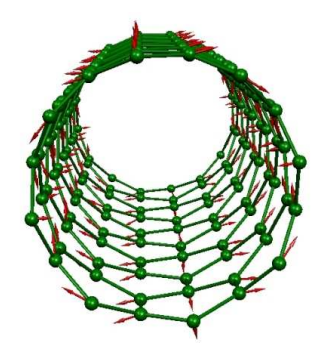

$662 \mathrm{~cm}^{-1}$

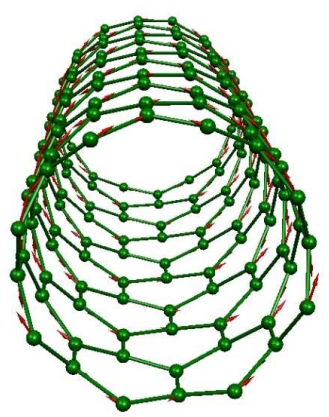

$1527 \mathrm{~cm}^{-1}$

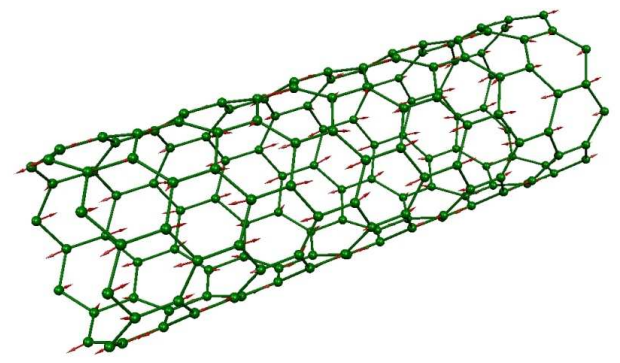

$1450 \mathrm{~cm}^{-1}$

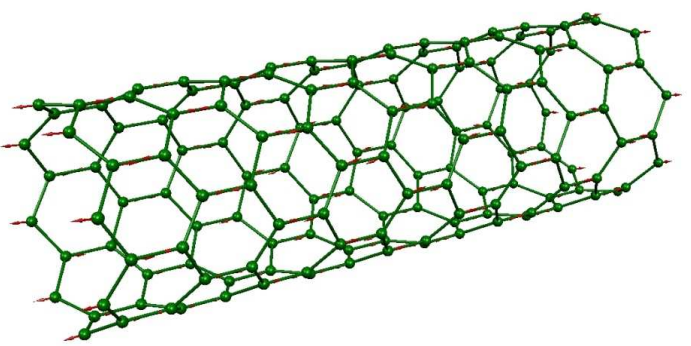

$1567 \mathrm{~cm}^{-1}$

Figura 4.12: Representação dos sete modos Raman ativos mais fortes para a supercélula com cinco repetições do nanotubo $(8,0)$ no ponto $\Gamma$.

a relação de dispersão deverá sofrer um 7-folding, ou seja, o gráfico deverá ser "dobrado"sete vezes, como mostram as retas verticais da Figura 4.13 para 
a região de baixas energias. Portanto, além daqueles oriundos do cálculo de célula unitária, constarão também como modos de ponto $\Gamma$ para a Supercélula aqueles marcados por quadrados vermelhos ${ }^{6}$. A Figura 4.14 mostra um modo $\Gamma$ da Supercélula $\left(\omega=127 \mathrm{~cm}^{-1}\right)$, que na célula unitária possui vetor de onda de comprimento $q=4 \times\left(\frac{\pi}{7 a}\right)$ (conforme a Figura 4.13), com $a$ o parâmetro de rede do nanotubo $(5,5)$. Observe-se que, os padrões se invertem a cada 3 células e meia (Figura 3.14), isto é, na Equação $1.52, R_{n}-R_{m}=3,5 a^{7}$. Assim,

$$
\frac{U_{n}}{U_{m}}=-1 \Rightarrow \frac{U_{n}}{U_{n} e^{-i q 3,5 a}}=e^{-i \pi} \Rightarrow i q 3,5 a=i \pi \Rightarrow q=\frac{2 \pi}{7 a} .
$$

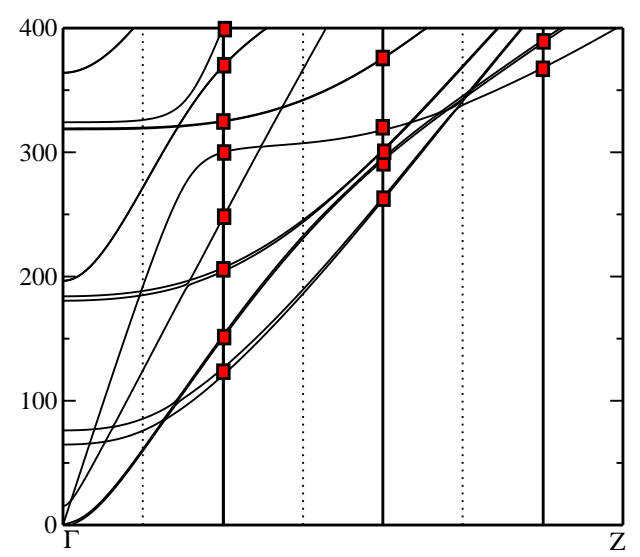

Figura 4.13: Relação de dispersão para a região de baixas freqüências do nanotubo $(5,5)$. Os eixos coincidentes com o eixo $\Gamma$ após o folding são mostrados por linhas cheias, enquanto aqueles que não se sobrepõem estão pontilhados. Os pontos de intersecção dos ramos com o eixo $\Gamma$, isto é, os novos modos $\Gamma$, são representados por quadrados vermelhos.

Esse vetor de onda do fônon corresponde à segunda divisão da Figura 4.13, exatamente onde está o primeiro quadrado vermelho ${ }^{8}$. Como todos esses modos pertencem ao mesmo vetor de onda $\vec{q}$ (no caso, Gamma),

${ }^{6} \mathrm{Na}$ relação de dispersão mostra-se somente metade da zona de Brillouin (os valores positivos de $\vec{q}$ ), portanto, a cada quadrado vermelho tem-se a intersecção dos ramos mostrados e daqueles "dobrados"provenientes dos pontos negativos zona. Assim, cada quadrado vermelho representa a adição de 2 modos. No caso de ramos degenerados, são quatro.

${ }^{7}$ Os nanotubos são unidimensionais, portanto, as setas vetoriais são desnecessárias

${ }^{8}$ Observe-se que, pela paridade da função cosseno, o ponto $q=\frac{-2 \pi}{7 a}$ também é solução, bastando para isso usar $e^{i \pi}$ na Equação 4.1. 
a combinação deles continua sendo uma função base (modo normal) para o sistema (da mesma forma que as funções de Bloch e seus vetores $\vec{k}$ no caso eletrônico). Portanto, no momento da diagonalização, esses modos podem se misturar, resultando em modos acoplados. Esse efeito se apresenta como desvios no perfil do modo correspondente no sistema puro, ou seja, desvios nas orientações dos autovetores daquelas do puro. Assim, por exemplo, um modo que deveria manter seu perfil ao longo do tubo não o fará perfeitamente.
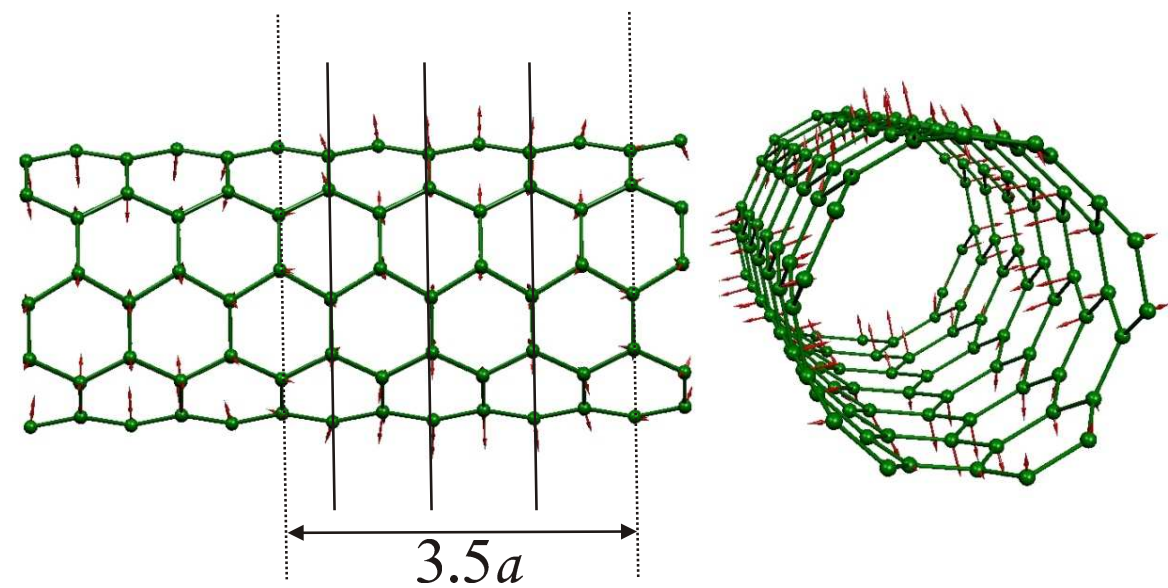

Figura 4.14: Modo $\Gamma$ da Supercélula correspondente ao primeiro quadrado vermelho de mais baixa energia. Observe-se que ele correponde exatamente ao modo que o gerou em $\Gamma$ na célula unitária primitiva, de freqüência $66 \mathrm{~cm}^{-1}$, porém com uma ondulação devido ao vetor de onda $q \neq 0$ da célula unitária primitiva. As retas pontilhadas representam a repetição de padrão dos autovetores(no caso os nodos) e as linhas cheias as divisões entre as células primitivas.

Esse efeito não é fortemente observado nas Supercélulas puras ${ }^{9}$ porque nesse caso, não há uma quebra de simetria como no caso do defeito. Mover um átomo da $n$-ésima célula primitiva, então, produz uma constante de força igual àquele devido ao movimento do átomo a ele correspondente nas outras células primitivas que compõem a Supercélula ${ }^{10}$. Já no defeito, as constantes de força calculadas pelo movimento dos átomos da região do defeito serão diferentes das demais células primitivas que compõem a Supercélula, um vez que não há

\footnotetext{
${ }^{9}$ Por isso os perfis da célula unitária foram bem descritos também na Supercélula

${ }^{10}$ no caso de cálculos numéricos, onde não se obtém exatamente as posições simétricas, essa condição não é precisamente satisfeita.
} 
simetria entre as células primitivas.

\subsubsection{Nanotubo $(5,5)$}

\subsubsection{Nitrogênio Substitucional - 1N}

O primeiro defeito estudado foi o Nitrogênio Subtitucional. Esse defeito foi construído pela simples substituição de um sítio de Carbono por um de Nitrogênio, tornando o sistema puro $(140 C)$ em $139 C+1 N$. Como mostra a Figura 11 da Introdução, esse defeito é o de menor energia de formação para a faixa de potencial químico do $N_{2}$, ou seja, numa atmosfera de $N_{2}$ esse seria o defeito mais estável. O sistema $139 C+1 N$ relaxado [12] é mostrado na Figura 4.15 .
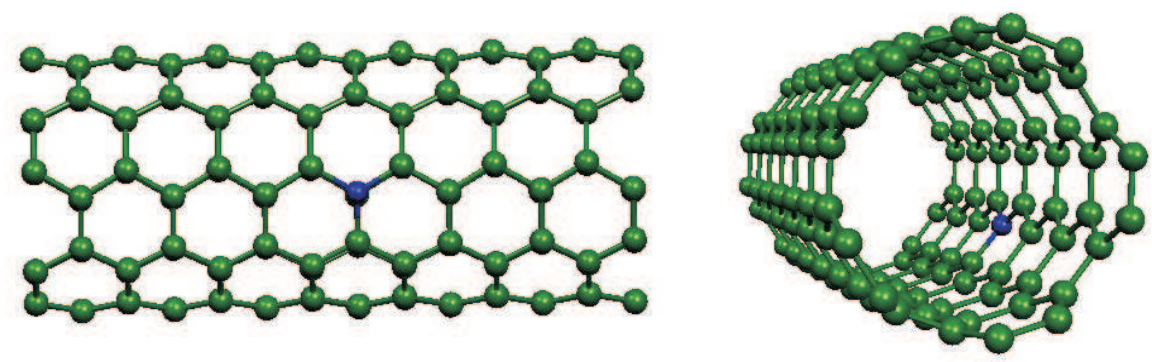

Figura 4.15: Estrutura do nanotubo $(5,5)$ dopado com nitrogênio substitucional.

Uma comparação entre as VDOS ${ }^{11}$ dos tubo puro e com defeito é mostrada na Figura 4.16. Observe-se que o defeito não introduz diferenças significativas nos estados. Apesar de reduzir as intensidades (curva preta da Figura 4.16), o perfil da VDOS do tubo puro (curva vermelha) é mantido. Na região $1250 \mathrm{~cm}^{-1}<\omega<1300 \mathrm{~cm}^{-1}$ há o surgimento de novos modos. Contudo, nenhum deles são Raman ativos nem possuem caráter $\Gamma$ da célula unitária convencional, ou seja, aqueles modos que pertencem ao ponto $\Gamma$ da célula unitária convencional. Além disso, a PVDOS ${ }^{12}$ do Nitrogênio indica que eles também não estão localizados nesse átomo, ou seja, não constitui a maior contribuição

\footnotetext{
11 as unidades das VDOS em todo esse trabalho são arbitrárias

${ }^{12}$ Densidade Vibracional de Estados Projetada. Ela foi representada pelo módulo quadrado das componentes dos autovetores do átomo considerado, para todos os modos.
} 
do defeito (Figura 4.17). Para a construção da Figura 4.16, utilizou-se o mesmo alargamento para ambas as densidades de estados com funções gaussianas.

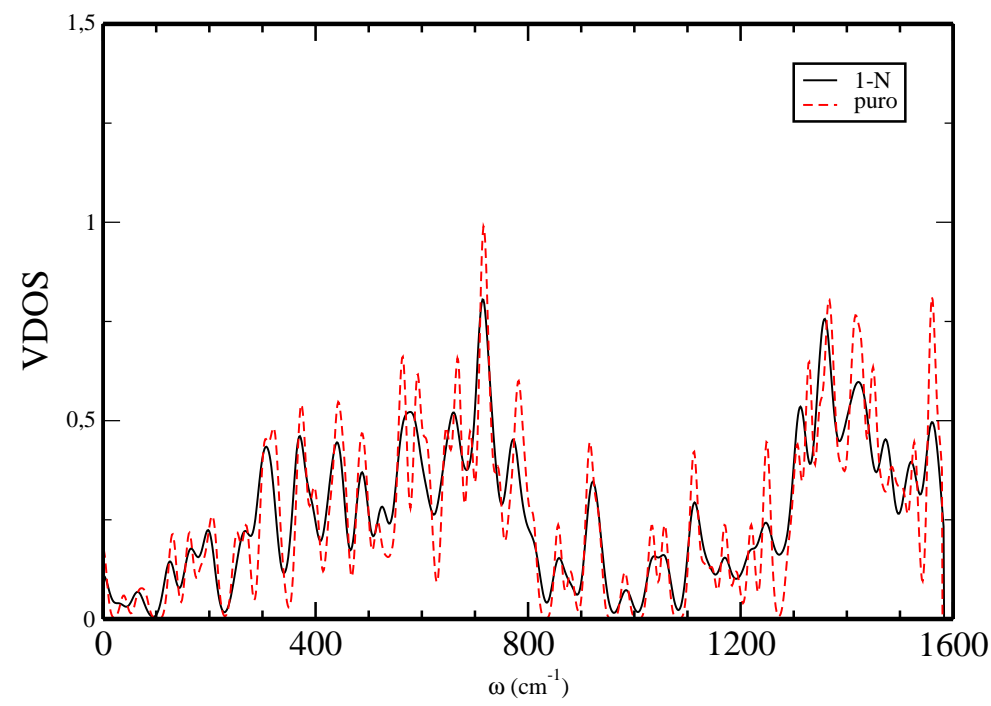

Figura 4.16: VDOS do sistema $139 C+1 N$ (linha cheia preta) comparada com aquela do puro (linha pontilhada e vermelha) para a Supercélula do nanotubo $(5,5)$ no ponto $\Gamma$.

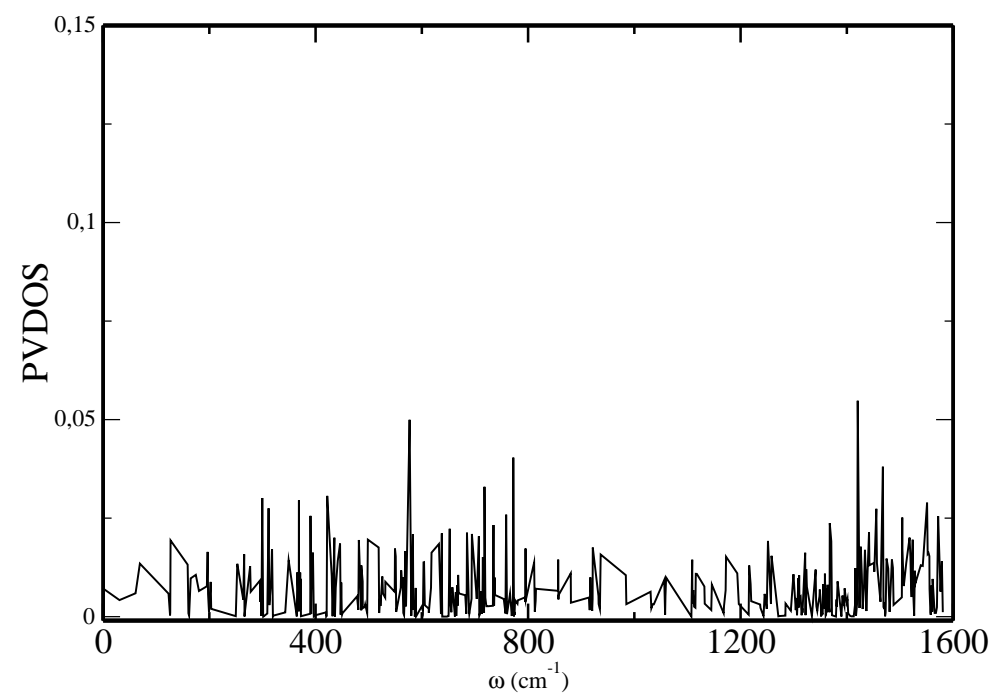

Figura 4.17: PVDOS para o átomo de nitrogênio na Supercélula do nanotubo $(5,5)$ no ponto $\Gamma$.

Devido aos possíveis acoplamentos entre os modos advindos do "dobramento"dos ramos da célula unitária, que projeta modos anteriormente fora 
do ponto $\Gamma$ nesse ponto da Supercélula, como discutido acima, assinalar os modos do defeito correspondentes àqueles no puro, exige uma análise detalhada.

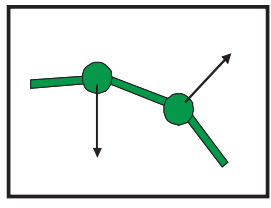

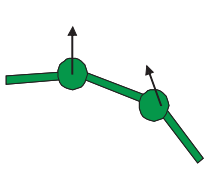

II

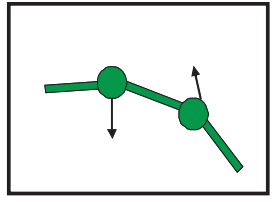

$0,8 \mathrm{I}+0,2 \mathrm{II}$

Figura 4.18: Acoplamento entre modos, ilustrando desvios de orientação. O modo final (à direita) possui um caráter misturado dos dois modos à esquerda.

Contudo, para se ter uma idéia do quanto que esses modos misturam (os coeficientes na Figura 4.18), fez-se a projeção dos modos com caráter esperado $^{13}$ no cálculo com defeito nos seus correspondentes no cálculo do sistema puro. Na Figura 4.18, portanto, o modo à direita seria um modo no defeito que possui um grande caráter do modo (I) (à extrema esquerda) do tubo puro. A Tabela 4.5 resume os dados para os sete modos Raman ativos.

Também estão mostrados os shifts ${ }^{14}$ sofridos pelos modos do defeito relativos aos valores deles no puro. Esses shifts foram calculados como a diferença entre os valores das freqüências do modo nos sistemas com e sem defeito. Os valores no sistema puro são tomados pela média, quando as freqüências, por erros numéricos, não são iguais. Então, um sinal negativo implica que o modo tornou-se menos energético no defeito.

Na região de baixas energias, as freqüências possuem desvios negativos e na região de freqüência intermediária há um desvio positivo. Na banda G o modo de simetria $A_{1 g}$ torna-se o menos energético (pode ser resultado de efeitos de transferência de carga $[60,61])$ e os desvios nessa região também negativos.

Quanto às projeções, aqueles que não possuem valor na Tabela 4.5, apresentam um caráter idêntico àquele no puro, portanto, pouco ou nenhum

\footnotetext{
${ }^{13}$ A projeção consiste em fazer o produto escalar entre os vetores de mesma orientação, ou de orientações mais próximas possíveis, ou seja, os 2 n nodos de simetria $E_{n}$ do defeito devem ser projetados naqueles do puro. Analogamente, os axiais do defeito naqueles do puro e assim por diante.

${ }^{14}$ Desvios. Apesar de possuir tradução simples para o português, a palavra em inglês é de uso corriqueiro entre os físicos
} 


\begin{tabular}{c|c|c|l}
\hline Simetria & $\begin{array}{c}\omega \\
\left(\mathrm{cm}^{-1}\right)\end{array}$ & $\begin{array}{c}|\Sigma| \\
\left(\AA^{2}\right)\end{array}$ & $\begin{array}{l}\xi \\
\left(\mathrm{cm}^{-1}\right)\end{array}$ \\
\hline \hline$E_{2 g}$ & 61 & - & $\xi=61-72=-11$ \\
69 & - & $\xi=69-72=-3$ \\
\hline$E_{1 g}$ & 195 & - & $\xi=195-197=-2$ \\
\hline$A_{1 g}$ & 309 & - & $\xi=309-311=-2$ \\
\hline$E_{2 g}$ & 650 & - & $\xi=650-644=+6$ \\
\hline$A_{1 g}$ & 1564 & - & $\xi=664-644=+20$ \\
\hline$E_{1 g}$ & 1518 & 0.3 & $\xi=1512-1557=-45$ \\
\hline$E_{2 g}$ & 1524 & 0.9 & $\xi=1524-1532=-8$ \\
\hline \hline
\end{tabular}

Tabela 4.5: Freqüuencias $(\omega)$, Módulo das projeções $(|\Sigma|)$ e os "shifts"( $(\xi)$ para os sete modos Raman ativos mais fortes para o nanotubo $(5,5)$ com o defeito $1 \mathrm{~N}$.

acoplamento com outros modos. Para se ter uma referência para os padrões de projeção, fez-se a projeção de modos com perfis completamente diferentes. Tomou-se o modo de simetria $E_{2 g}$ da região de baixas freqüências do defeito e projetou-se no RBM do puro. O valor dessa projeção foi de $0.0005 \AA^{215}$, o que mostra que, de fato, todos os modos possuem significativo caráter daqueles no puro e pouco acoplamento com os outros. A Figura 4.19 mostra os modos do defeito (alguns dos modos da Tabela 4.5). Para esse defeito não se observou muitos desvios de orientação dos autovetores em relação aos autovetores do puro. Isso se deve ao fato de que o átomo de nitrogênio não possui massa tão distinta do carbono e também introduz somente uma pequena deformação na rede.

\footnotetext{
${ }^{15}$ Lembrando-se que um modo do puro projetado nele mesmo resulta na unidade
} 

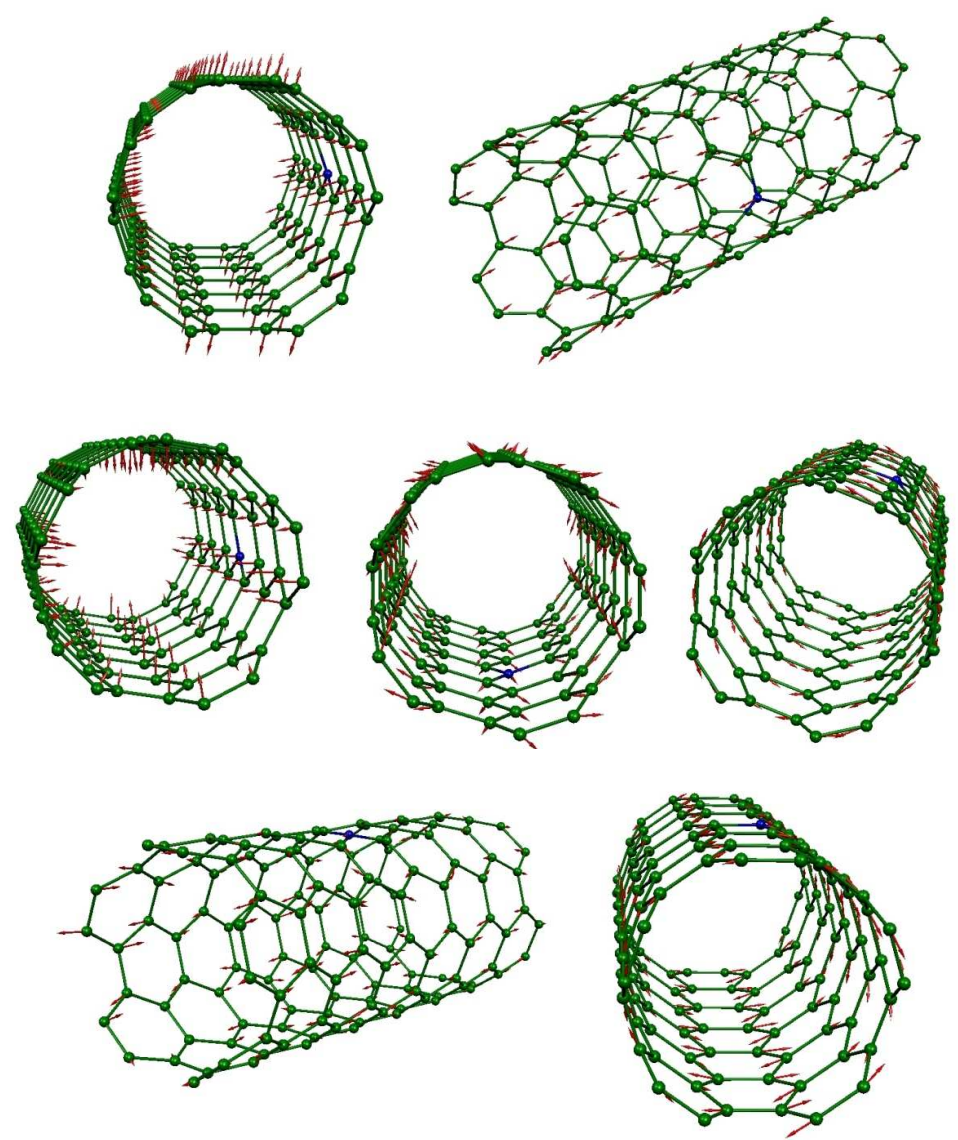

Figura 4.19: Modos vibracionais do nanotubo $(5,5)$ dopado com Nitrogênio Substitucional, com perfis semelhantes aos sete modos Raman ativos mais fortes do nanotubo puro.

Em geral, as frequiências da banda $G$ apresentam maior acoplamento em todos os defeitos. Isso porque na região de altas energias a densidade de estados do puro é maior, havendo maior possibilidade de acoplamento ao se introduzir o defeito, já que haverá mais modos para misturar. Assim, os perfis dos modos de alta energia tenderão a ter o caráter menos semelhantes àqueles do puro, apresentando assim, em geral, menores valores da projeção.

Uma análise mais detalhada é feita para os quatro modos mais importantes no espectro Raman de nanotubos (Capítulo 2), isto é, o RBM e a banda G. A Tabela 4.6 mostra também os splittings sofridos pelos modos anteriormente degenerados. 


\begin{tabular}{c|c|c|c|l}
\hline Simetria & $\begin{array}{c}\omega \\
\left(\mathrm{cm}^{-1}\right)\end{array}$ & $\begin{array}{c}|\Sigma| \\
\left(\AA^{2}\right)\end{array}$ & $\begin{array}{c}\Delta \\
\left(\mathrm{cm}^{-1}\right)\end{array}$ & $\begin{array}{l}\xi \\
\left(\mathrm{cm}^{-1}\right)\end{array}$ \\
\hline \hline$A_{1 g}(\mathrm{RBM})$ & 309 & - & - & $\xi=309-311=-2$ \\
\hline$A_{1 g}$ & 1512 & 0.3 & - & $\xi=1512-1557=-45$ \\
\hline$E_{1 g}(1)$ & 1518 & 0.7 & 6 & $\xi=1518-1532=-14$ \\
$E_{1 g}(2)$ & 1524 & 0.9 & & $\xi=1524-1532=-8$ \\
\hline$E_{2 g}(1)$ & 1554 & - & 2 & $\xi=1554-1564=-10$ \\
$E_{2 g}(2)$ & 1556 & - & & $\xi=1556-1564=-8$ \\
\hline \hline
\end{tabular}

Tabela 4.6: Freqüências $(\omega)$, Módulo das projeções $(|\Sigma|)$, "splittings" $(\Delta)$ e os "shifts" $(\xi)$ para o modo RBM e a banda G para o nanotubo $(5,5)$ com o defeito $1 \mathrm{~N}$. Os números em parênteses mostram a correspondência com o par degenerado do sistema puro

Observe-se que para o RBM $\left(A_{1 g}\right)$, o shift é de apenas $-2 \mathrm{~cm}^{-1}$. Para a banda $G$, surpreendentemente o modo que ainda conservou o perfil daquele $A_{1 g}$ do puro mostrou um grande desvio. Os desvios dos picos de simetria $E_{1 g}$ e $E_{2 g}$ são da mesma ordem, aproximadamente $10 \mathrm{~cm}^{-1}$. O par que conservou uma relação de simetria próxima àquela no puro $^{16}$ sofrem devido à introdução do defeito uma quebra de degenerescência, ou seja, um splitting, caracterizado por um afastamento dos picos. O pico referente àquele de simetria $E_{1 g}$ portanto, sofrerá uma divisão de pico $\Delta \sim 6 \mathrm{~cm}^{-1}$, enquanto que para aquele de simetria $E_{2 g}$ o splitting é de apenas $2 \mathrm{~cm}^{-1}$.

A Figura 4.20 mostra um esquema ilustrativo do que ocorre com os modos RBM e a banda G devido à introdução do defeito. Os shifts e splittings estão representados somente numa forma qualitativa, isto é, não necessariamente os valores numéricos dessas variáveis estão rigidamente mostrados.

\footnotetext{
${ }^{16}$ nos sistemas puros os modos degenerados diferenciaram-se por uma rotação de um ângulo $\theta$, portanto, os modos selecionados no defeito que mantiveram entre si essa relação de rotação com um ângulo próximo foram assinalados como o par degenrado.
} 
PICOS NO PURO

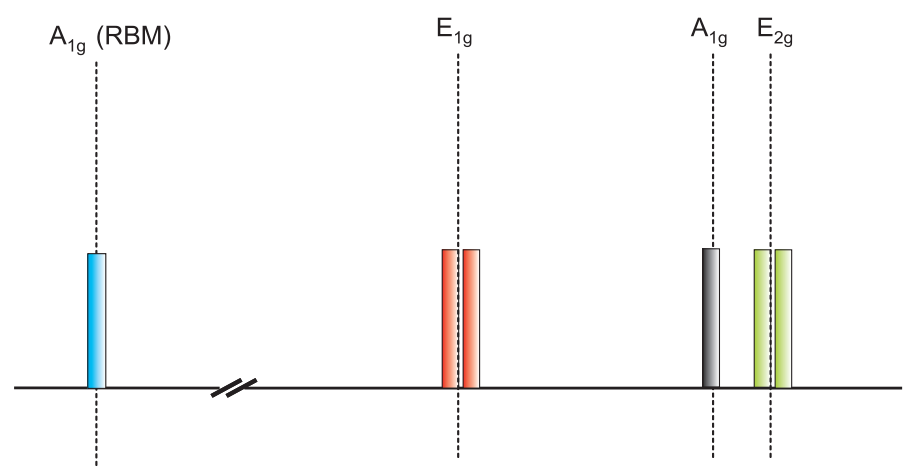

PICOS COM O DEFEITO

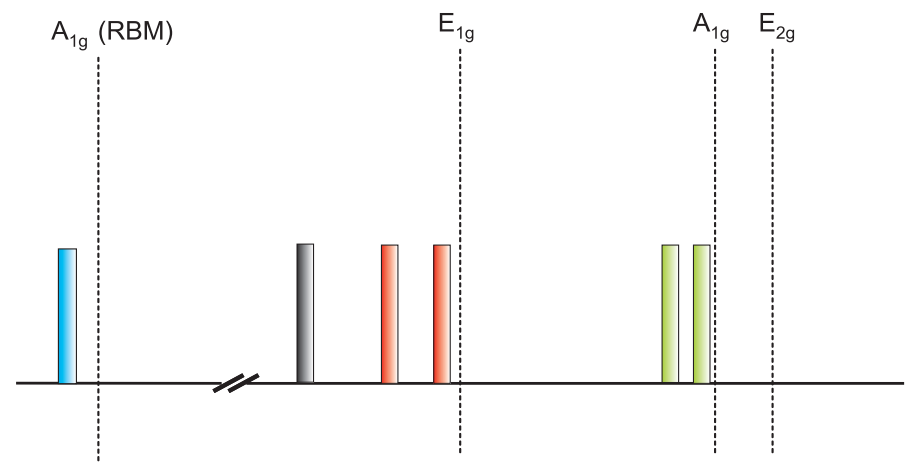

Figura 4.20: Representação qualitativa do que ocorre com as posições dos quatro mais importantes picos do puro quando se é introduzido o defeito Nitrogênio Substitucional - 1N. Acima: posição dos picos no sistema puro. Abaixo: posições dos picos no sistema com o defeito.

\subsubsection{Monovacância Rodeada por 3 Nitrogênios - 3NV}

O defeito seguinte possui uma vacância além de átomos de nitrogênio, como na Figura 4.21, formando o sistema $136 C+3 N$. Essa é a geometria proposta pelos experimentais para o defeito de nitrogênio tipo piridina [14]. Novamente a Figura 11 da Introdução mostra que numa atmosfera de $N_{2}$ ele, de fato é um dos mais estáveis depois do defeito $1 \mathrm{~N}$. Contudo, para valores de potencial químico mais próximos das condições experimentais, ele não é o mais estável, com considerável diferença de energia para o defeito com a divacância (4ND). 

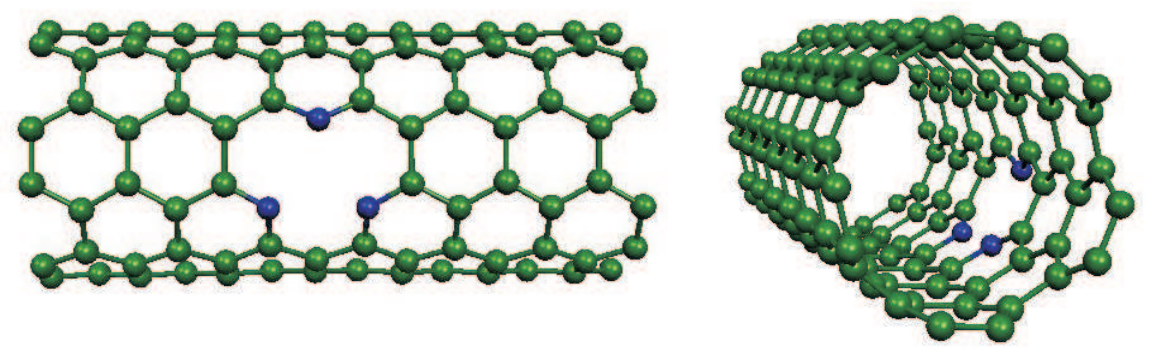

Figura 4.21: Estrutura da monovacância rodeada por três anéis tipo piridina no nanotubo $(5,5)$.

Diferente do sistema $139 C+1 N$, a estrutura da Monovacância rodeada por 3 Nitrogênios possui uma deformação na região do defeito. A Figura 4.22 mostra a VDOS para esse defeito (linha preta) superposta àquela do puro (linha vermelha). O alargamento utilizado foi o mesmo que para o $1 \mathrm{~N}$. O efeito desse defeito sobre essa Densidade ded Estados Vibracionais é, como no 1N, somente a redução nas intensidades dos picos do puro, mas os perfis das curvas na Figura 4.22 são idênticos. Mínimas alterações são observadas na região de altas freqüências para s VDOS em ambos os defeitos.

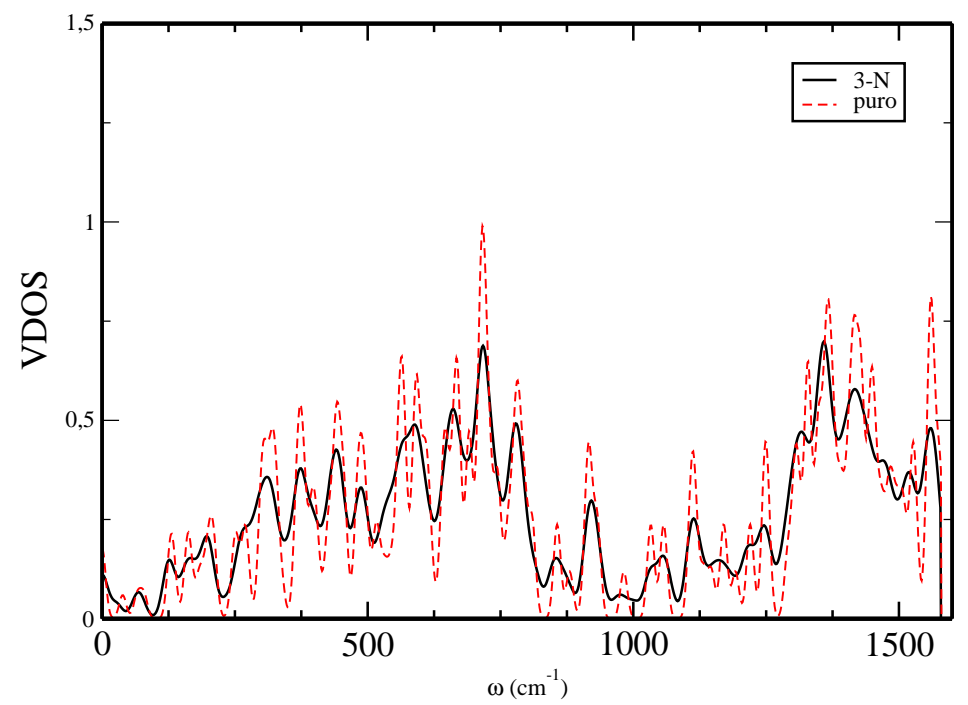

Figura 4.22: VDOS do sistema $136 C+3 N$ (linha cheia preta) comparada com aquela do puro (linha pontilhada e vermelha) para a Supercélula do nanotubo $(5,5)$ no ponto $\Gamma$.

As contribuições das componentes do nitrogênio para os autovetores 
mostram maior peso na região de baixas energias. Isso pode estar relacionado ao fato de que os átomos de nitrogênio tendem a não respeitar a curvatura do tubo, tendendo a formar anéis planares tipo piridina, deixando uma extremidade livre no nitrogênio (Figura 4.23). Assim, esse átomo vibrará mais livremente para movimentos com caráter perpendicular à circunferência do tubo, como são os modos de baixa energia. As PVDOS evidenciam esse fato (Figura $4.24)$.
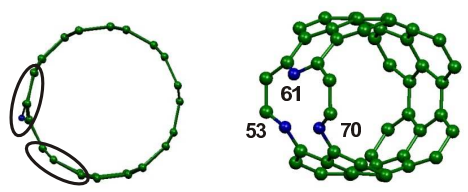

Figura 4.23: À esquerda: Vista frontal da estrutura do tubo $136 \mathrm{C}+3 \mathrm{~N}$ em projeção ortogonal. Os átomos de nitrogênio formam anéis piridina planares. A região desses anéis está destacada. À direita: Região do defeito com os átomos de nitrogênio identificados.

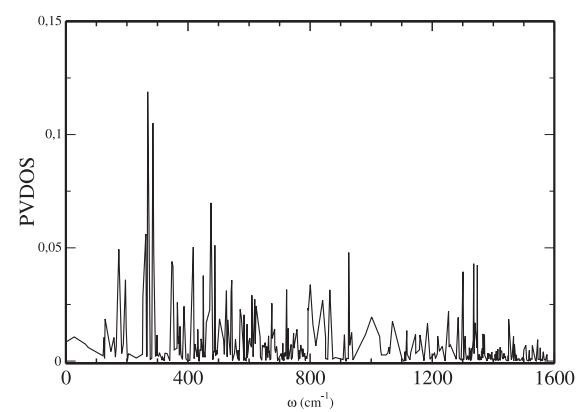

(a)

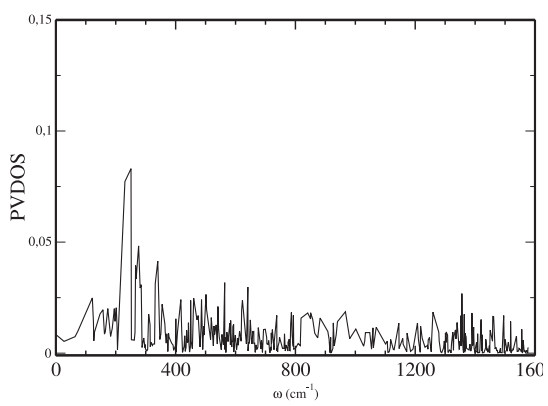

(b)

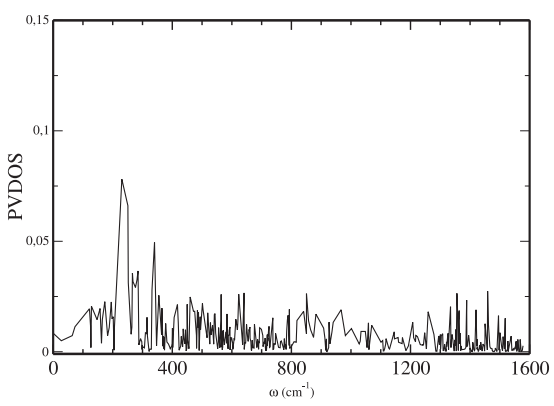

(c)

Figura 4.24: PVDOS para os 3 átomos de nitrogênio na Supercélula do nanotubo $(5,5)$ no ponto $\Gamma$. (a) átomo 61, (b) átomo 53 e (c) átomo 70, conforme Figura 4.23. 
Observe-se o caráter simétrico dos movimentos do nitrogênio: aqueles dispostos simetricamente em relação à vacância possuem módulos de autovetores bastante semelhantes (Figura 4.24 (b) e (c)).

O mesmo procedimento foi utilizado para esse defeito para o assinalamento dos correspondentes sete modos Raman ativos do tubo puro. A Tabela 4.6 mostra os resultados.

\begin{tabular}{c|c|c|l}
\hline Simetria & $\begin{array}{c}\omega \\
\left(\mathrm{cm}^{-1}\right)\end{array}$ & $\begin{array}{c}|\Sigma| \\
\left(\AA^{2}\right)\end{array}$ & $\begin{array}{l}\xi \\
\left(\mathrm{cm}^{-1}\right)\end{array}$ \\
\hline \hline$E_{2 g}$ & 64 & - & $\xi=64-72=-8$ \\
& 73 & - & $\xi=73-72=+1$ \\
\hline$E_{1 g}$ & 188 & - & $\xi=188-197=-9$ \\
& 198 & - & $\xi=198-197=+1$ \\
\hline$A_{1 g}$ & 315 & 0.2 & $\xi=315-311=+4$ \\
& 315 & 0.01 & $\xi=315-311=+4$ \\
\hline & 658 & 0.6 & $\xi=658-644=+14$ \\
$E_{2 g}$ & 665 & 0.1 & $\xi=665-644=+21$ \\
& 666 & 0.4 & $\xi=666-644=+22$ \\
\hline & 1511 & - & $\xi=1511-1532=-21$ \\
$E_{1 g}$ & 1524 & 0.6 & $\xi=1524-1532=-8$ \\
& 1526 & 0.8 & $\xi=1526-1532=-6$ \\
\hline$A_{1 g}$ & 1538 & 0.03 & $\xi=1538-1557=-19$ \\
\hline \multirow{2}{*}{$E_{2 g}$} & 1547 & 0.03 & $\xi=1547-1564=-17$ \\
& 1556 & 0.1 & $\xi=1556-1564=-8$ \\
\hline \hline
\end{tabular}

Tabela 4.7: Freqüências ( $\omega)$, Módulo das projeções $(|\Sigma|)$ e os "shifts" $(\xi)$ para os sete modos Raman ativos mais fortes para o nanotubo $(5,5)$ com o defeito $3 \mathrm{NV}$.

Os valores mostram que os modos de baixas freqüências apresentam desvios para a região de menor energia, exceto o RBM. Os modos de freqüências intermediárias novamente apresentam shifts postivos e, finalmente, os de mais alta freqüências, desviam-se negativamente. Portanto, exceto o RBM, os modos comportam-se de maneira semelhante àqueles no defeito $1 \mathrm{~N}$.

Pelas projeções, percebe-se que, em geral, os modos acoplaram bem 
mais nesse defeito. A projeção de referência desse defeito, ou seja, o modo de mais baixa energia do defeito projetado no RBM do puro resultou em $0,06 \AA^{2}$. Apesar de algumas projeções terem dado abaixo desse valor $\left(A_{1 g}\right.$ e $E_{2 g}$ da banda $G$ ), as freqüências mostraram um perfil com caráter periódico ao longo da Supercélula (ponto $\Gamma$ da célula primitiva). Contudo, o acoplamento com outros modos mudou, principalmente, a intensidade dos autovetores, tornando o produto escalar (a projeção) menor. Isso reforça a probabilidade que os modos mis energéticos de simetria $A_{1 g}$ e $E_{2 g}$ causarão algum tipo de alargamento relativamente ao pico no tubo puro, uma vez que apresentaram mais alterações de orientação dos autovetores ${ }^{17}$.

Novamente restringe-se os quatro modos RBM e a banda G para uma análise mais detalhada. A Tabela 4.8 mostra os resultados da tabela anterior incluindo os splittings para os modos da banda G.

\begin{tabular}{c|c|c|c|l}
\hline Simetria & $\begin{array}{c}\omega \\
\left(\mathrm{cm}^{-1}\right)\end{array}$ & $\begin{array}{c}|\Sigma| \\
\left(\AA^{2}\right)\end{array}$ & $\begin{array}{c}\Delta \\
\left(\mathrm{cm}^{-1}\right)\end{array}$ & $\begin{array}{l}\xi \\
\left(\mathrm{cm}^{-1}\right)\end{array}$ \\
\hline \hline $\mathrm{A}_{1 g}(\mathrm{RBM})$ & 315 & 0.2 & - & $\xi=315-311=+4$ \\
& 315 & 0.01 & - & $\xi=315-311=+4$ \\
\hline$E_{1 g}(1)$ & 1511 & - & 13 & $\xi=1511-1532=-21$ \\
$E_{1 g}(2)$ & 1524 & 0.6 & & $\xi=1524-1532=-8$ \\
$E_{1 g}(2)$ & 1526 & 0.8 & & $\xi=1526-1532=-6$ \\
\hline$A_{1 g}$ & 1538 & 0.03 & - & $\xi=1538-1557=-19$ \\
\hline$E_{2 g}(1)$ & 1547 & 0.03 & 9 & $\xi=1547-1564=-17$ \\
$E_{2 g}(2)$ & 1556 & 0.1 & & $\xi=1556-1564=-8$ \\
\hline \hline
\end{tabular}

Tabela 4.8: Freqüências $(\omega)$, Módulo das projeções $(|\Sigma|)$, "splittings" $(\Delta)$ e os "shifts" $(\xi)$ para o modo RBM e a banda G para o nanotubo $(5,5)$ com o defeito $3 \mathrm{NV}$. Os números em parênteses mostram a correspondência com o par degenerado do sistema puro

\footnotetext{
${ }^{17}$ Observe-se que de fato, a dificuldade no reconhecimento dos modos está relacionada com a concentração do defeito tomada nas simulações (por exemplo, no caso $3 \mathrm{NV}$ nesse tubo $(5,5)$ o defeito surge a cada 7 células unitárias), pois caso se tomasse mais repetições, esperar-se-ia que as células mais distantes do defeito mantivessem o comportamento do tubo puro.
} 
O modo RBM $\left(A_{1 g}\right)$ para esse defeito teve uma maior alteração no perfil em relação ao puro, apresentando acoplamentos com outros modos, tal que dois, dentre os acoplados, e de mesma energia mostraram o perfil mais próximo daquele no tubo puro. A distribuição das contribuições para o perfil do modo nesses dois de caráter mais próximo do respiratório mostrou-se bastante desigual, pois a projeção de um é dez vezes maior que a do outro. Grande diferença do $1 \mathrm{~N}$ é vista aqui quanto ao desvio sofrido pelo pico. No sistema $139 C+1 N$ o shift era negativo, sendo positivo para o $3 \mathrm{NV}$.

PICOS NO PURO

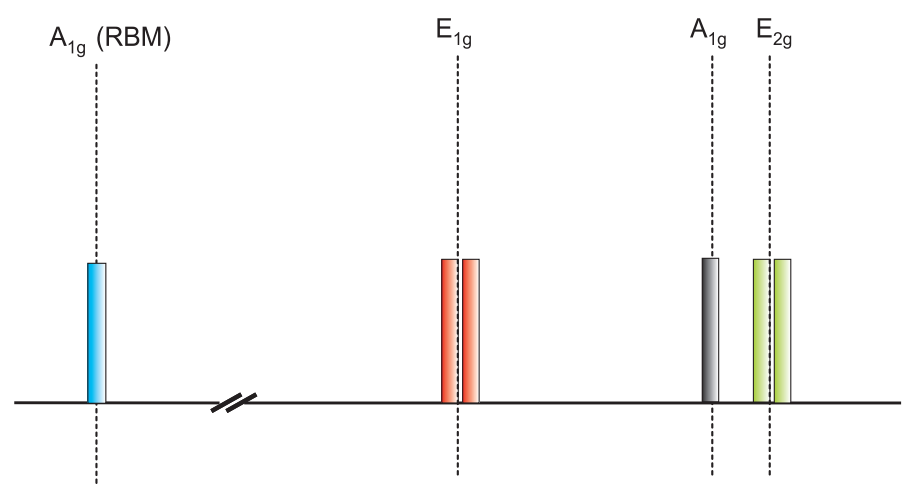

PICOS COM O DEFEITO

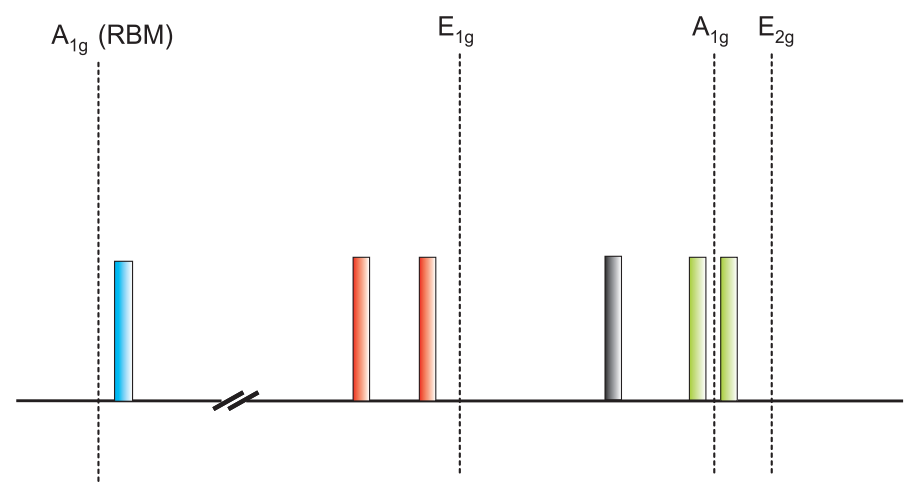

Figura 4.25: Representação qualitativa do que ocorre com as posições dos quatro mais importantes picos do puro quando se é introduzido o defeito $3 \mathrm{NV}$.

Como no defeito anterior, a Figura 4.25 ilustra o efeito sobre os quatro mais importantes picos, isto é, o RBM e a banda G com a introdução da Monovacância rodeada por 3 anéis piridina. O modo RBM sofre um shift positivo. Na 
região da banda $G$, a ordem energética permaneceu como no sistema puro. Os modos de simetria $A_{1 g}$ e $E_{1 g}$ sofrem desvios negativos, como anteriormente, mas agora com shifts menores. Os modos $E_{2 g}$ não mostram diferenças significativas quanto aos desvios. Os splittings na banda $G$ são maiores que no $1 \mathrm{~N}$ ficando em torno de $10 \mathrm{~cm}^{-1}$.
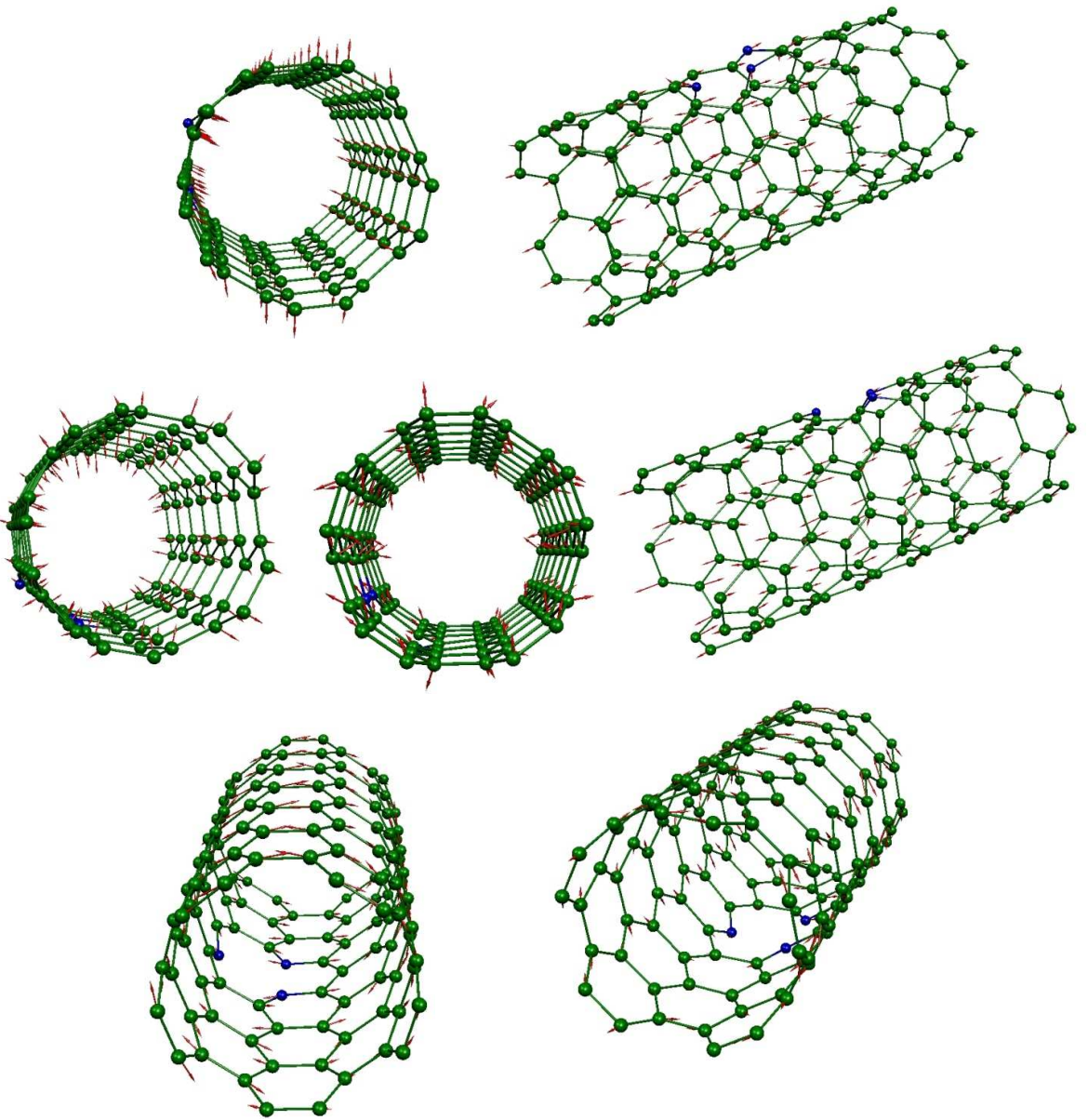

Figura 4.26: Modos vibracionais do nanotubo $(5,5)$ dopado com o defeito 3NV com perfis semelhantes aos sete Raman ativos do nanotubo puro.

A Figura 4.26 mostra os modos com perfis mais semelhantes aos modos do tubo puro para esse sistema. Uma característica geral desse defeito é que devido à simetria das posições dos Nitrogênios 53 e 70, as vibrações desses átomos tendem a manter uma relação de simetria com caráter de reflexão. 


\subsubsection{Divacância Rodeada por 4 Nitrogênios - 4ND}

O último defeito para esse sistema é formado por duas vacâncias rodeadas por 4 nitrogênios, isto é, aquele que nas prováveis condições experimentais [14] apresenta menor energia de formação, e portanto, a proposta do nosso grupo para a geometria mais estável [12]. Sua estrutura está representada na Figura 4.27.
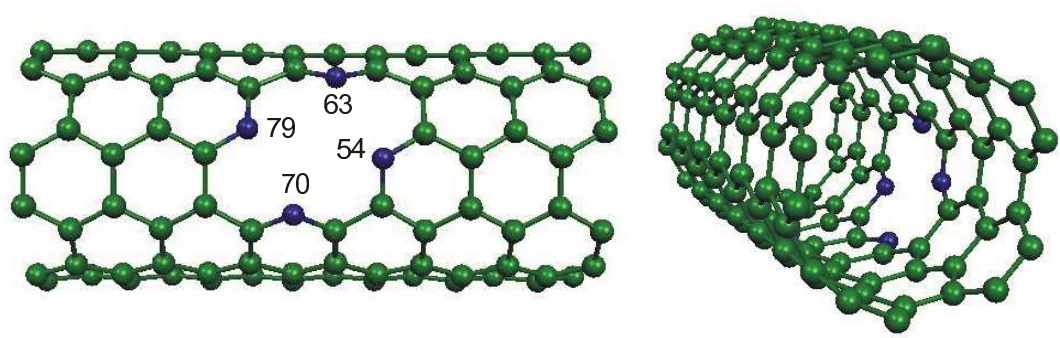

Figura 4.27: Estrutura da divacância rodeada por quatro nitrogênios no nanotubo $(5,5)$.

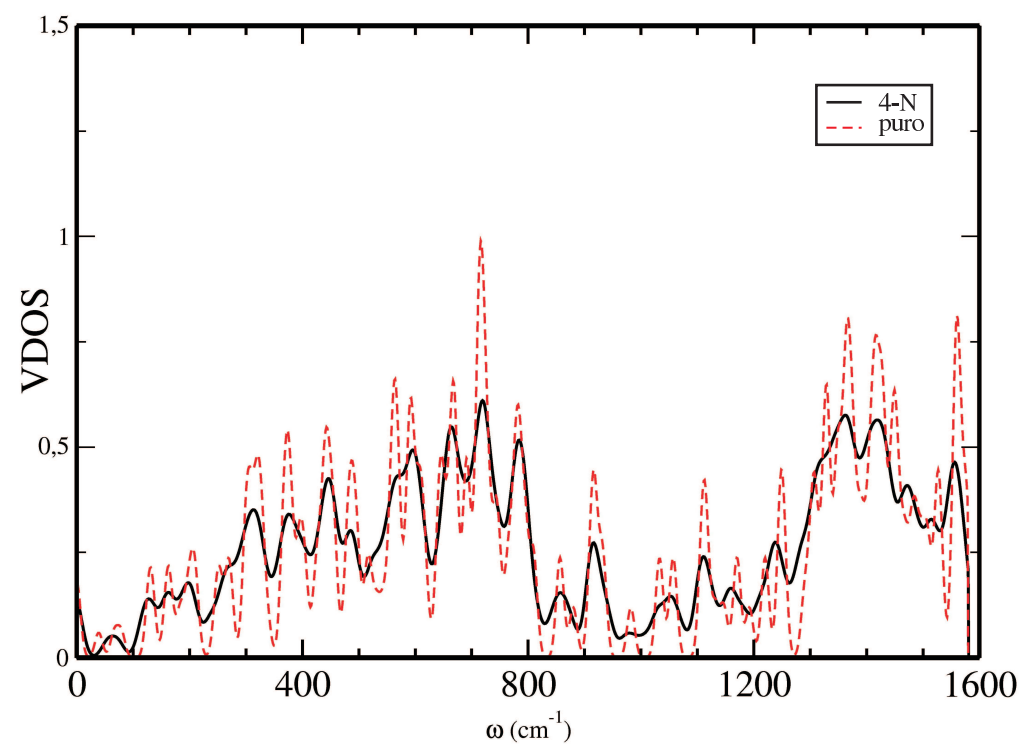

Figura 4.28: VDOS do sistema $134 C+4 N$ (linha cheia preta) comparada com aquela do puro (linha pontilhada e vermelha) para a Supercélula do nanotubo $(5,5)$ no ponto $\Gamma$. 
A densidade de estados (VDOS) desse defeito também foi calculada (Figura 4.28). Superpondo àquela do puro observa-se que, em geral, o efeito desse defeito é deixar mais uniforme a distribuição de estados (mais que no defeito $3 \mathrm{NV}$ ). Daí surgirem modos em regiões onde não haviam modos no puro. O alargamento gaussiano para esse gráfico também foi igual aos anteriores. Desses novos modos, merecem destaque aqueles na região em torno de $220 \mathrm{~cm}^{-1}$, onde a contribuição dos nitrogênios é máxima, conforme gráfico da PVDOS (Figura 4.29). Contudo, nessa região não há o surgimento claramente diferenciado de novos modos.

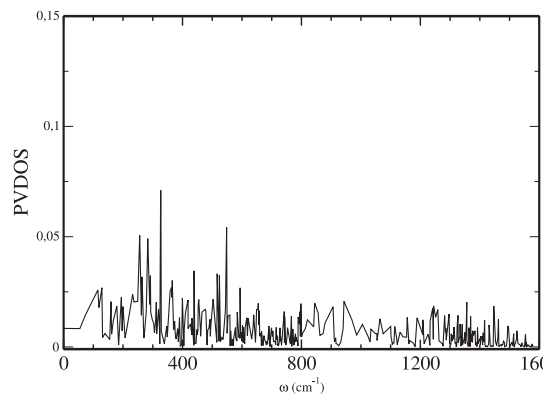

(a)

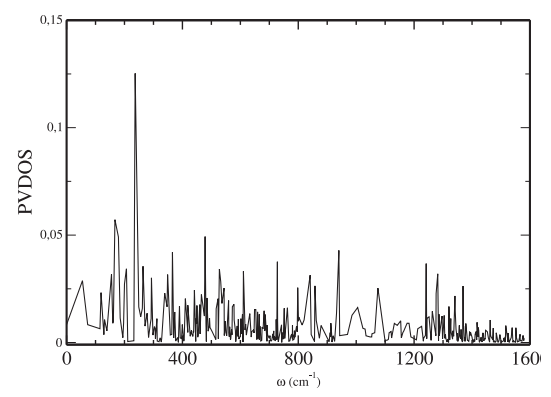

(c)

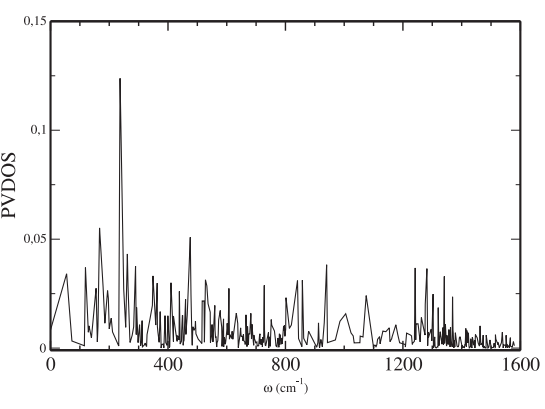

(b)

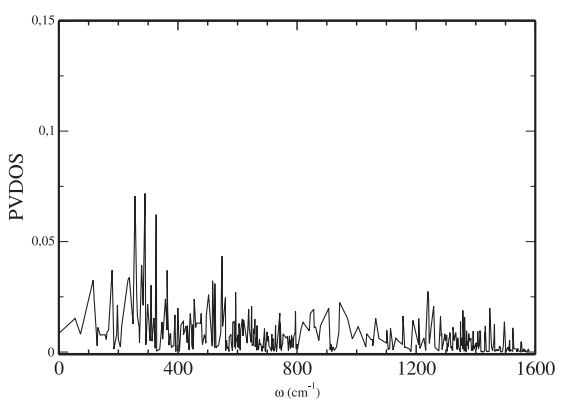

(d)

Figura 4.29: PVDOS para os 4 átomos de nitrogênio na Supercélula do nanotubo $(5,5)$ no ponto $\Gamma$. (a) átomo 54 , (b) átomo 63 , (c) átomo 70 e (d) átomo 79 , conforme Figura 4.27.

Os modos tendem a preservar a simetria relativa à vacância, vibrando de forma que os autovetores dos nitrogênios e da região próxima mantenham 
alguma relação de simetria, na maioria das vezes uma simetria de reflexão ${ }^{18}$

Como no defeito $3 \mathrm{NV}$, os modos também apresentaram muitos acoplamentos. Na Tabela 4.9 estão os resultados para os modos com maior caráter dos modos Raman ativos do puro, como feito anteriormente. Esses acoplamentos entre os modos resulta em significativas alterações do perfil dos autovetores em relação ao tubo puro, pois as projeções são baixas. A projeção de referência feita entre o modo de mais baixa energia do defeito e o RBM do puro resultou em $0,01 \AA^{2}$.

\begin{tabular}{|c|c|c|c|}
\hline Simetria & $\begin{array}{c}\omega \\
\left(\mathrm{cm}^{-1}\right)\end{array}$ & $\begin{array}{c}|\Sigma| \\
\left(\AA^{2}\right)\end{array}$ & $\begin{array}{l}\xi \\
\left(c m^{-1}\right)\end{array}$ \\
\hline \multirow{2}{*}{$E_{2 g}$} & 55 & - & $\xi=55-72=-17$ \\
\hline & 73 & - & $\xi=73-72=+1$ \\
\hline \multirow{2}{*}{$E_{1 g}$} & 185 & 0.7 & $\xi=185-197=-12$ \\
\hline & 197 & 0.4 & $\xi=197-197=0$ \\
\hline \multirow{2}{*}{$A_{1 g}$} & 307 & 0.1 & $\xi=307-311=-4$ \\
\hline & 313 & 0.07 & $\xi=313-311=+2$ \\
\hline \multirow{3}{*}{$E_{2 g}$} & 655 & 0.1 & $\xi=655-644=+11$ \\
\hline & 658 & 0.1 & $\xi=658-644=+14$ \\
\hline & 660 & 0.4 & $\xi=660-644=+16$ \\
\hline \multirow{2}{*}{$E_{1 g}$} & 1524 & 0.7 & $\xi=1524-1532=-8$ \\
\hline & 1528 & 0.8 & $\xi=1528-1532=-4$ \\
\hline \multirow[t]{2}{*}{$A_{1 g}$} & 1541 & 0.1 & $\xi=1541-1557=-16$ \\
\hline & 1556 & 0.04 & $\xi=1556-1564=-8$ \\
\hline$E_{2 g}$ & 1557 & 0.3 & $\xi=1557-1564=-7$ \\
\hline
\end{tabular}

Tabela 4.9: Frequiências ( $\omega)$, Módulo das projeções $(|\Sigma|)$ e os "shifts"( $(\xi)$ para os sete modos com caráter mais semelhantes aos sete modos Raman ativos mais fortes para o nanotubo $(5,5)$ dopado com o defeito $4 \mathrm{ND}$.

O comportamento geral dos shifts dos modos nesse defeito é semelhante àquele no $1 \mathrm{~N}$, ou seja, são negativos na região de baixas energias, posi-

\footnotetext{
${ }^{18}$ Esse espelho de reflexão dos autovetores não é nenhum dos elementos de simetria do nanotubo.
} 
tivos para a freqüência intermediária e negativos na região de altas energias.

Informações mais detalhadas para o RBM e a banda G estão resumidas na Tabela 4.10.

\begin{tabular}{c|c|c|c|l}
\hline Simetria & $\begin{array}{c}\omega \\
\left(\mathrm{cm}^{-1}\right)\end{array}$ & $\begin{array}{c}|\Sigma| \\
\left(\AA^{2}\right)\end{array}$ & $\begin{array}{c}\Delta \\
\left(\mathrm{cm}^{-1}\right)\end{array}$ & $\begin{array}{l}\xi \\
\left(\mathrm{cm}^{-1}\right)\end{array}$ \\
\hline \hline$A_{1 g}(\mathrm{RBM})$ & 307 & 0.1 & - & $\xi=307-311=-4$ \\
& 313 & 0.07 & & $\xi=313-311=+2$ \\
\hline$E_{1 g}(1)$ & 1524 & 0.7 & 4 & $\xi=1524-1532=-8$ \\
$E_{1 g}(2)$ & 1528 & 0.8 & & $\xi=1528-1532=-4$ \\
\hline$A_{1 g}$ & 1541 & 0.1 & - & $\xi=1541-1557=-16$ \\
\hline$E_{2 g}(1)$ & 1556 & 0.04 & 1 & $\xi=1556-1564=-8$ \\
$E_{2 g}(2)$ & 1557 & 0.3 & & $\xi=1557-1564=-7$ \\
\hline \hline
\end{tabular}

Tabela 4.10: Freqüências $(\omega)$, Módulo das projeções $(|\Sigma|)$, "splittings" $(\Delta)$ e os "shifts" ( $\xi$ ) para o modo RBM e a banda G para o nanotubo $(5,5)$ com o defeito 4ND. Os números em parênteses mostram a correspondência com o par degenerado do sistema puro

O RBM do defeito 4ND apresentou grande acoplamento de forma a alterar bastante o perfil em relação àquele no tubo puro. Os shifts dos modos mais semelhantes são diferentes para o caso $3 \mathrm{NV}$, que possui um valor positivo $+4 \mathrm{~cm}^{-1}$. No $4 \mathrm{ND}$ ele tende a assumir valor negativo.

Na região da banda $\mathrm{G}$ a ordem energética para esse defeito $4 \mathrm{ND}$ é mantida como aquela do puro, como ocorrido no defeito 3NV. Os shifts para essa banda nesse defeito tendem a assumir valores menores que no defeito 3NV.

A Figura 4.30 apresenta os modos mais semelhantes aos perfis dos sete Raman ativos mais fortes do tubo metálico puro. 

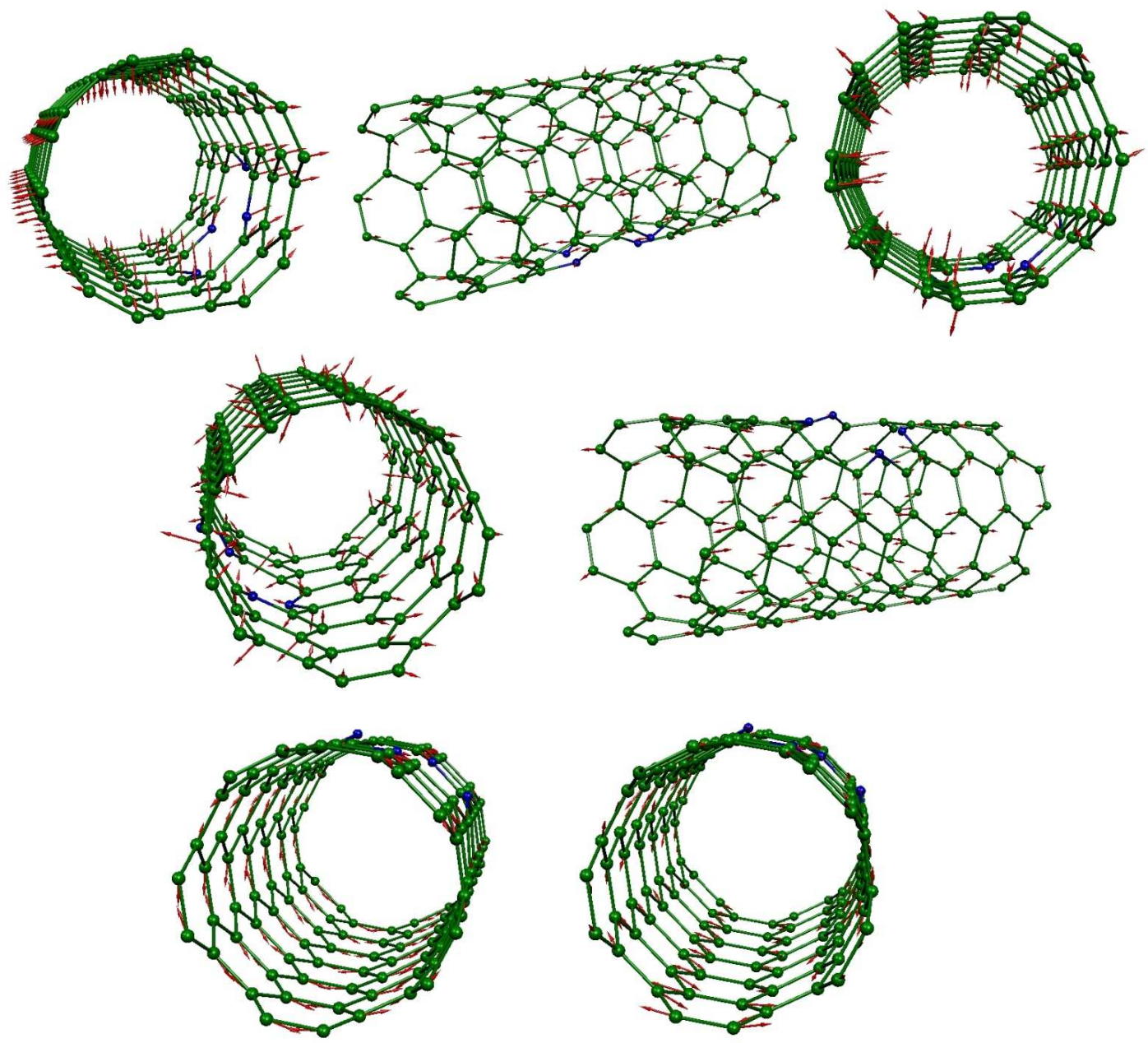

Figura 4.30: Modos vibracionais do nanotubo $(5,5)$ dopado com o defeito 4ND com perfis semelhantes aos sete Raman ativos do nanotubo puro.

Finalmente para o nanotubo $(5,5)$, a Figura 4.31 representa os shifts e splitings de forma qualitativa para os quatro modos principais do espectro Raman (RBM e banda G) devido à introdução da Divacância. 
PICOS NO PURO

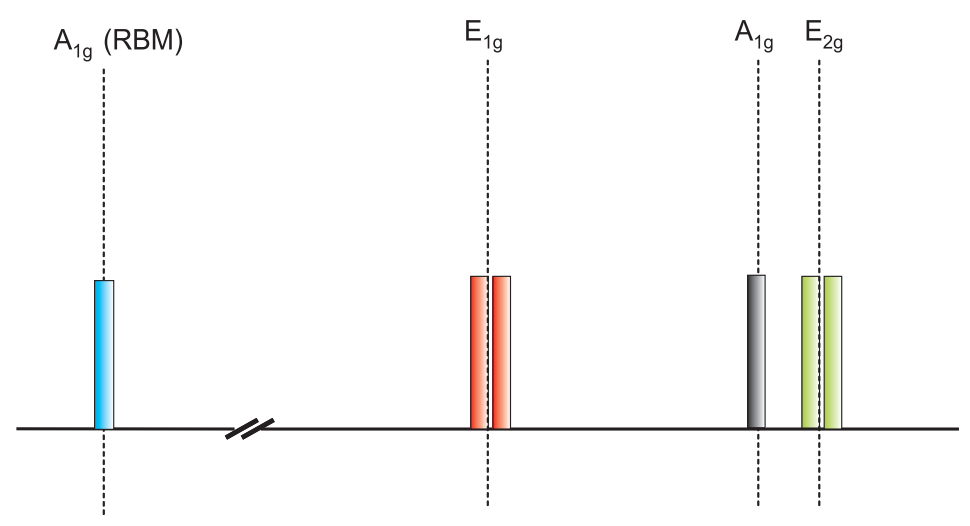

PICOS COM O DEFEITO

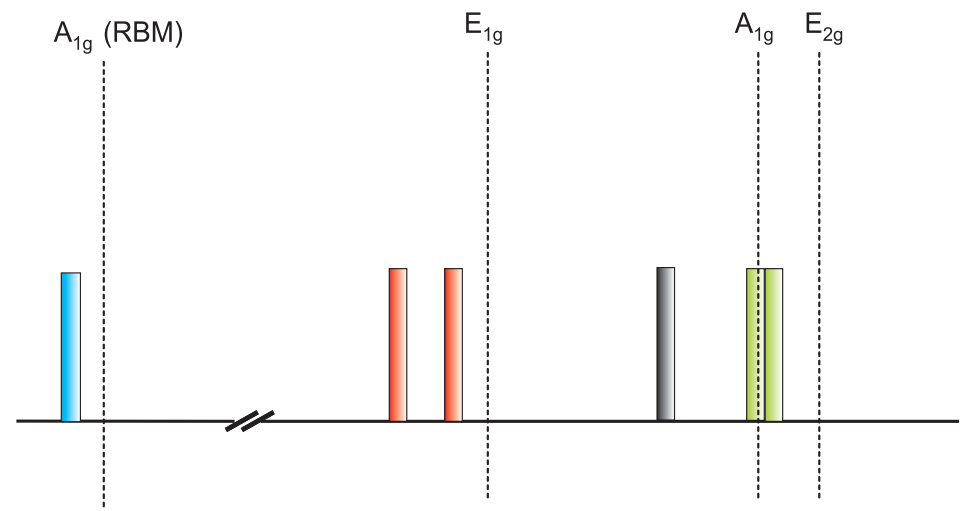

Figura 4.31: Representação qualitativa do que ocorre com as posições dos quatro mais importantes picos do puro quando se é introduzido o defeito 4ND.

\subsubsection{Nanotubo $(8,0)$}

\subsubsection{Nitrogênio Substitucional}

Também para o nanotubo semicondutor o primeiro defeito estudado foi aquele formado pela simples substituição do sítio de carbono por um átomo de nitrogênio (sistema $159 C+1 N$ ) com a geometria mostrada na Figura 4.32.

A comparação entre as VDOS para o tubo com defeito e para a Supercélula pura para o nanotubo $(8,0)$ (Figura 4.33) mostra que a distribuição de estados não sofre alteração considerável. A PVDOS do átomo de nitrogênio apresenta uma maior intensidade na região em torno de $1200 \mathrm{~cm}^{-1}$ (Figura 
4.34), contudo, como mostra a VDOS, não representa o surgimento de nenhum pico novo. O alargamento utilizado aqui também foi o mesmo que anteriormente para o tubo $(5,5)$.
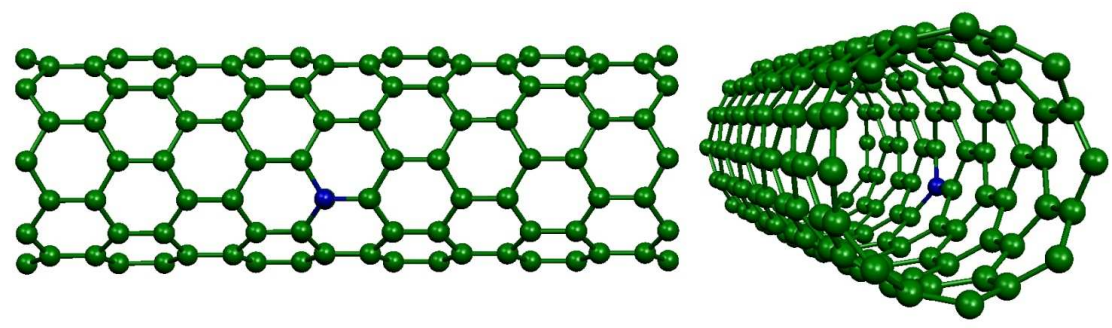

Figura 4.32: Estrutura do nanotubo $(8,0)$ dopado com nitrogênio substitucional.

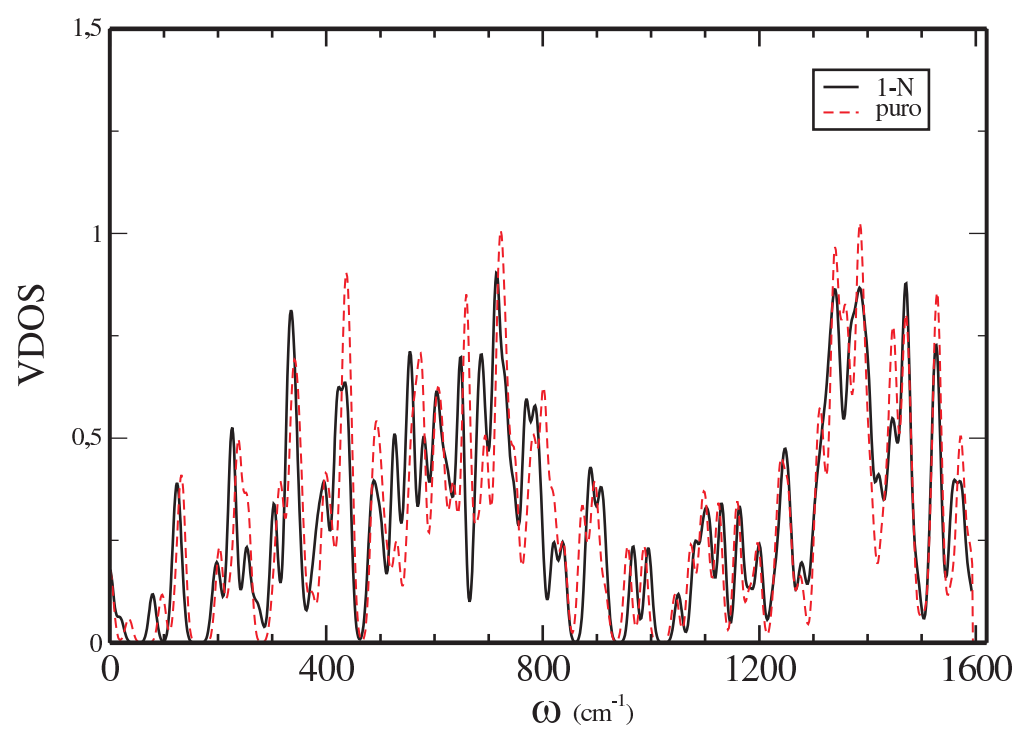

Figura 4.33: VDOS do sistema $159 C+1 N$ (linha cheia preta) comparada com aquela do puro (linha pontilhada e vermelha) para a Supercélula do nanotubo $(8,0)$ no ponto $\Gamma$. 


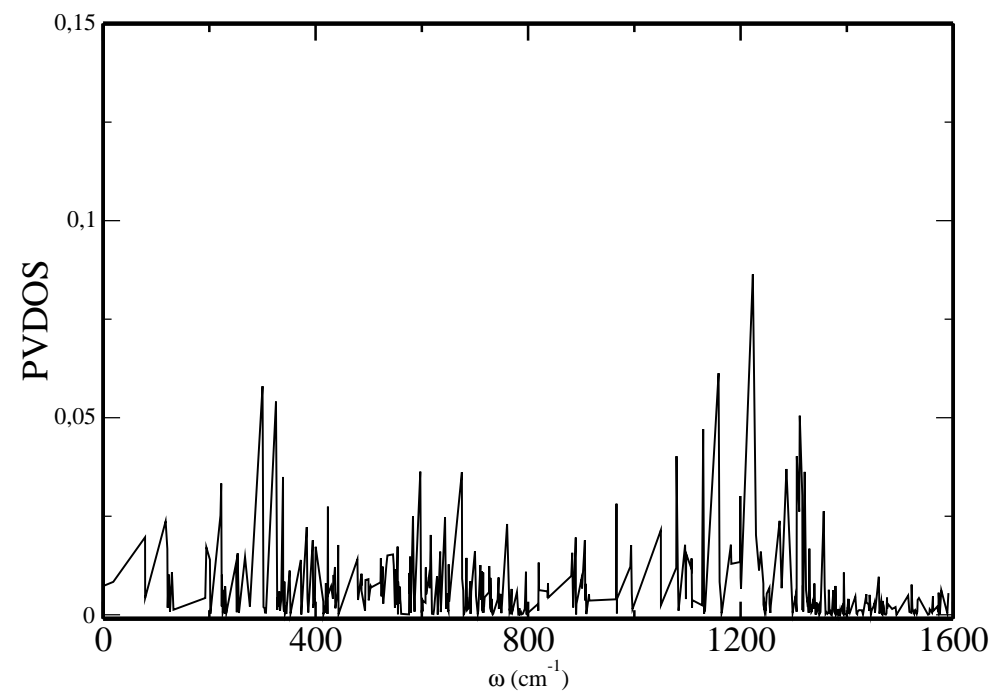

Figura 4.34: PVDOS para o átomo de nitrogênio na Supercélula do nanotubo $(8,0)$ no ponto $\Gamma$.

Os modos assinalados com aqueles do puro estão representados na Figura 4.35 e os valores das projeções, bem como das freqüências, constam na Tabela 4.11. Novamente, os modos do tubo puro com defeito que têm clara correspondência com os modos do tubo puro não foram projetados. Como no tubo $(5,5)$ os shifts foram calculados em relação aos valores médios das freqüências do sistema puro para os modos degenerados desse sistema que não apresentaram valores iguais. 

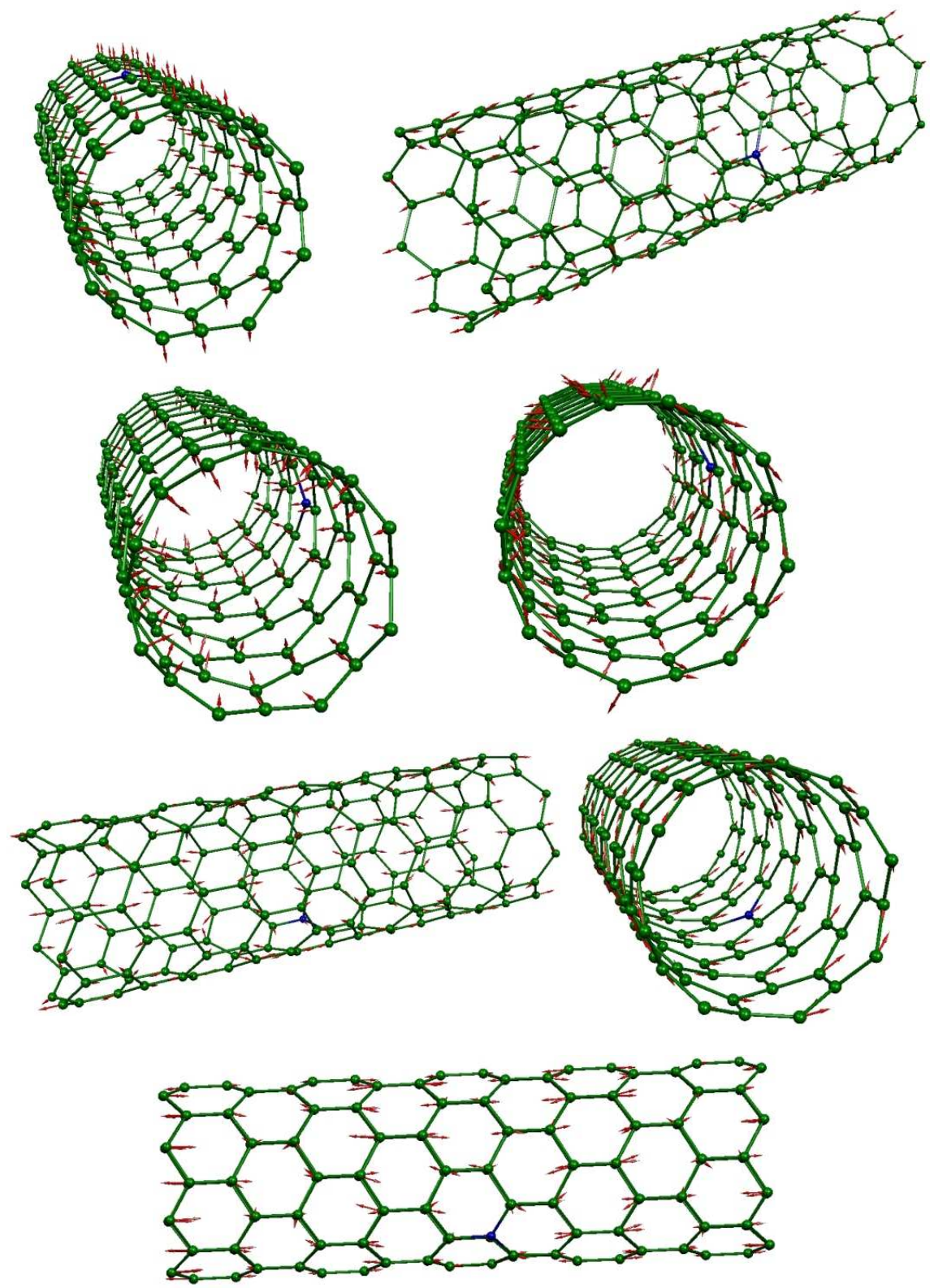

Figura 4.35: Modos vibracionais do nanotubo $(8,0)$ dopado com o defeito $1 \mathrm{~N}$ com perfis semelhantes aos sete Raman ativos do nanotubo puro. 


\begin{tabular}{c|c|c|l}
\hline Simetria & $\begin{array}{c}\omega \\
\left(\mathrm{cm}^{-1}\right)\end{array}$ & $\begin{array}{c}|\Sigma| \\
\left(\AA^{2}\right)\end{array}$ & $\begin{array}{l}\xi \\
\left(\mathrm{cm}^{-1}\right)\end{array}$ \\
\hline \hline$E_{2 g}$ & 79 & - & $\xi=79-96=-17$ \\
& 79 & - & $\xi=79-96=-17$ \\
\hline \multirow{2}{*}{$E_{1 g}$} & 223 & - & $\xi=223-222=+1$ \\
\hline$A_{1 g}$ & 330 & - & $\xi=330-326=+4$ \\
\hline \multirow{2}{*}{$E_{2 g}$} & 676 & 0.6 & $\xi=676-662=+14$ \\
& 682 & - & $\xi=682-662=+20$ \\
\hline \multirow{2}{*}{$E_{2 g}$} & 1420 & 0.8 & $\xi=1420-1450=-30$ \\
& 1423 & 0.7 & $\xi=1423-1450=-27$ \\
\hline & 1515 & 0.4 & $\xi=1515-1527=-12$ \\
& 1518 & 0.2 & $\xi=1518-1527=-9$ \\
\hline$A_{1 g}$ & 1556 & 0.7 & $\xi=1556-1567=-11$ \\
\hline \hline
\end{tabular}

Tabela 4.11: Freqüências ( $\omega)$, Módulo das projeções ( $|\Sigma|)$ e os "shifts" $(\xi)$ para os sete modos Raman ativos mais fortes para o nanotubo $(8,0)$ com o defeito $1 \mathrm{~N}$.

Nesse nanotubo semicondutor, o edfeito $1 \mathrm{~N}$ produz mais acoplamentos. Os picos serão deslocados de maneira diferente daquela no tubo metálico. Para o modo de mais baixa energia o shift é negativo. Os seguintes são positivos até que na banda $G$ eles voltam a ser negativos. A Tabela 4.12 mostra também os splittings para os modos RBM e banda G. 


\begin{tabular}{c|c|c|c|l}
\hline Simetria & $\begin{array}{c}\omega \\
\left(\mathrm{cm}^{-1}\right)\end{array}$ & $\begin{array}{c}|\Sigma| \\
\left(\AA^{2}\right)\end{array}$ & $\begin{array}{c}\Delta \\
\left(\mathrm{cm}^{-1}\right)\end{array}$ & $\begin{array}{l}\xi \\
\left(\mathrm{cm}^{-1}\right)\end{array}$ \\
\hline \hline$A_{1 g}(\mathrm{RBM})$ & 330 & - & - & $\xi=330-326=+4$ \\
\hline$E_{2 g}(1)$ & 1420 & 0.8 & 3 & $\xi=1420-1450=-30$ \\
$E_{2 g}(2)$ & 1423 & 0.7 & & $\xi=1423-1450=-27$ \\
\hline$E_{1 g}(1)$ & 1515 & 0.4 & 8 & $\xi=1515-1527=-12$ \\
& 1518 & 0.2 & & $\xi=1518-1527=-9$ \\
& 1521 & 0.3 & & $\xi=1521-1527=-6$ \\
$E_{1 g}(1)$ & 1523 & 0.1 & & $\xi=1523-1527=-4$ \\
\hline$A_{1 g}$ & 1556 & 0.7 & - & $\xi=1556-1567=-11$ \\
\hline \hline
\end{tabular}

Tabela 4.12: Freqüuências $(\omega)$, Módulo das projeções $(|\Sigma|)$, "splittings" $(\Delta)$ e os "shifts" $(\xi)$ para o modo RBM e a banda G para o nanotubo $(8,0)$ com o defeito $1 \mathrm{~N}$. Os números em parênteses mostram a correspondência com o par degenerado do sistema puro

O modo RBM sofre um shift positivo e, como no defeito $1 \mathrm{~N}$ no tubo metálico, há um bixo acoplamento o que implica que o modo com o defeito possui um perfil bastante semelhante àquele do nanotubo $(8,0)$ puro. Dos três mais energéticos (banda $\mathrm{G}$ ), somente o correspondente àquele de simetria $E_{1 g}$ apresentou grande acoplamento. Os autovetores dos modos mais semelhantes sofreram grandes desvios de orientação e nenhum dentre os esperados conseguiu concentrar grande característica do perfil do puro. Apesar de pequenas, as projeções ainda ficaram distantes daquela de referência, feita entre dois modos não correspondentes. Projetando-se, por exemplo, o modo de freqüência mais baixa do defeito no RBM do puro obtém-se $0,004 \AA^{2}$. Provavelmente haverá também aqui um alargamento do pico relativo ao puro, pois observe-se que os modos que preservaram a mesma realação de rotação que no par degenerado do puro foram os de freqüência $1515 \mathrm{~cm}^{-1}$ e $1523 \mathrm{~cm}^{-1}$. Assim, os demais modos que ainda mantiveram o caráter próximo desse modo no puro certamente contribuirá pra o alargmento de um dos picos. O splitting será, portanto, de $8 \mathrm{~cm}^{-1}$. O modo $E_{2 g}$ apresenta pequeno aplitting. Aquele assinalado como o $A_{1 g}$ ainda manteve um bom perfil do seu correspondente no tubo puro, 
gerando provavelmente um pico bem mais estreito. Quanto aos shifts dos picos dessa banda, em geral, apresentaram valores consideráveis e todos tornam-se menos energéticos, isto é, assumem valores negativos.

A Figura 4.36 mostra qualitativamente o que ocorre com o sistema semicondutor $(8,0)$ devido à introdução desse defeito.

$$
\text { PICOS NO PURO }
$$

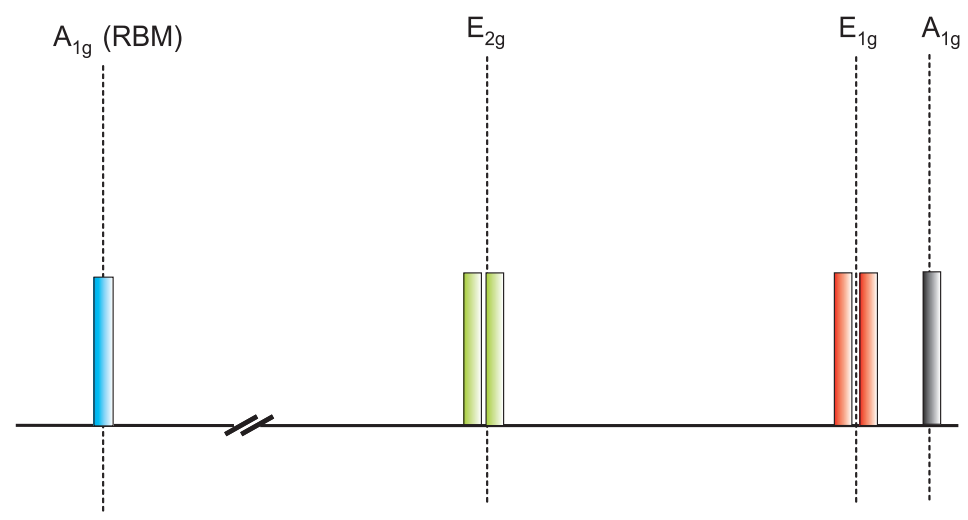

PICOS COM O DEFEITO

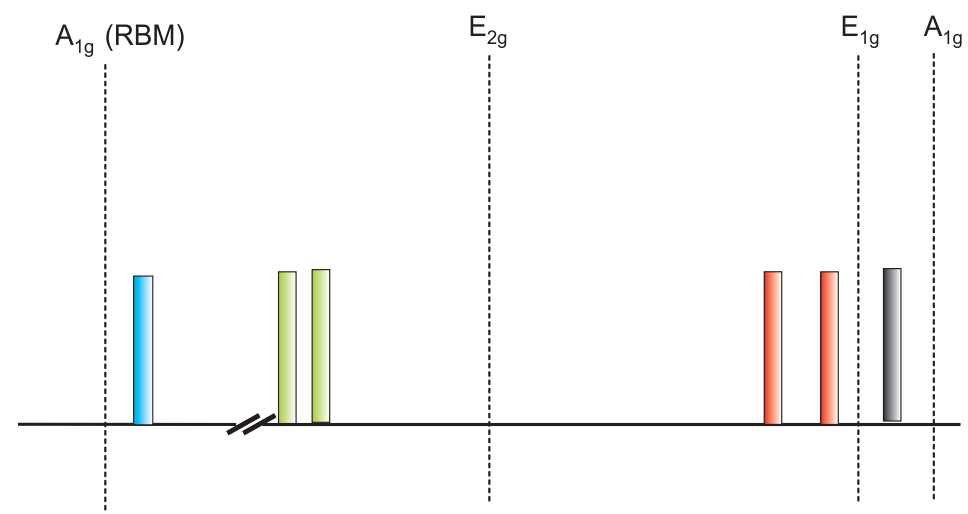

Figura 4.36: Representação qualitativa do que ocorre com as posições dos quatro mais importantes picos do puro quando se é introduzido o defeito $1 \mathrm{~N}$.

\subsubsection{Monovacância Rodeada por 3 Nitrogênios - 3NV}

Da mesma forma que para o nanotubo armchair, seguiu-se com o defeito formado por uma vacância rodeada por 3 nitrogênios, cuja estrutura é ilustrada na Figura 4.37. 

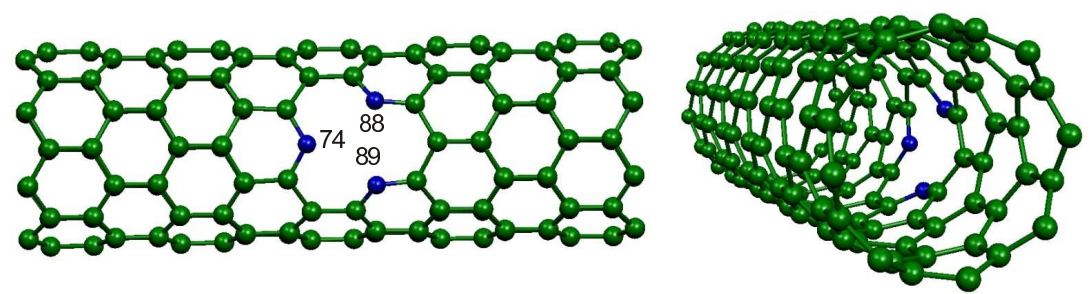

Figura 4.37: Estrutura da monovacância rodeada por três anéis tipo piridina no nanotubo $(8,0)$.

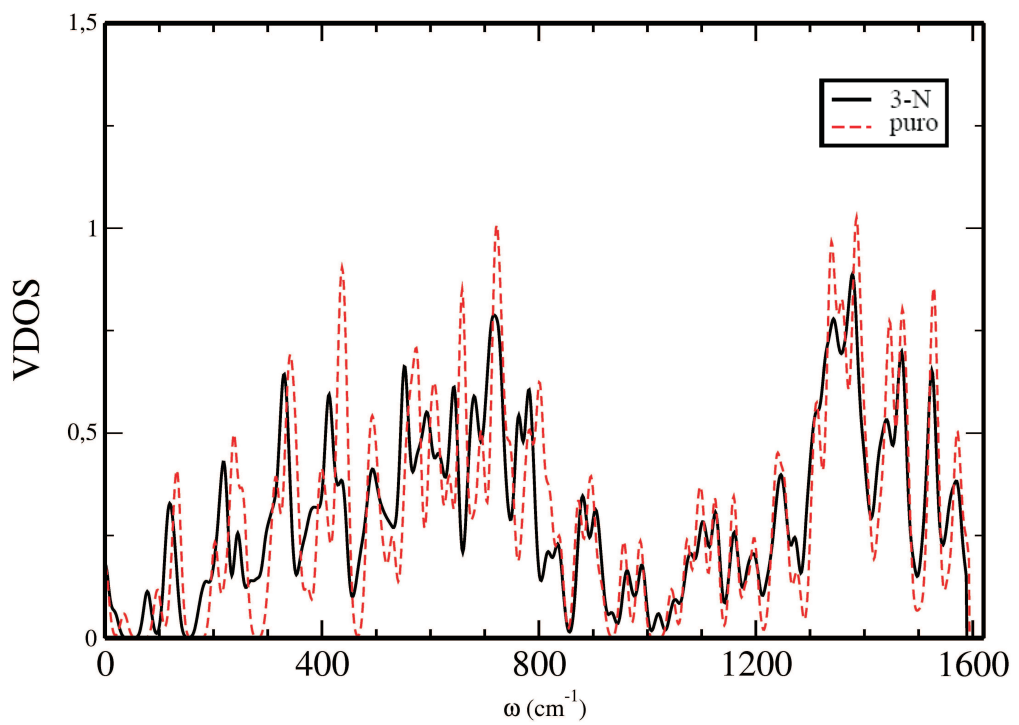

Figura 4.38: VDOS do sistema $156 C+3 N$ (linha cheia preta) comparada com aquela do puro (linha pontilhada e vermelha) para a Supercélula do nanotubo $(8,0)$ no ponto $\Gamma$.

A comparação das densidades de estados vibracionais (Figura 4.38) revela dessa vez, o surgimento de alguns modos na região das baixas freqüências. O intervalo $250 \mathrm{~cm}^{-1}<\omega<300 \mathrm{~cm}^{-1}$, corresponde a modos não- $\Gamma$ da célula unitária primitiva (portanto, não ativos no processo Raman analisado o longo do trabalho) com grande contribuição dos átomos de nitrogênio (Figura 4.39). Essa contribuição não é significativa para os modos de freqüências mais altas ${ }^{19}$. O alargamento usado nos gráficos foi o mesmo que anteriormente.

\footnotetext{
${ }^{19}$ de interesse para esse projeto.
} 


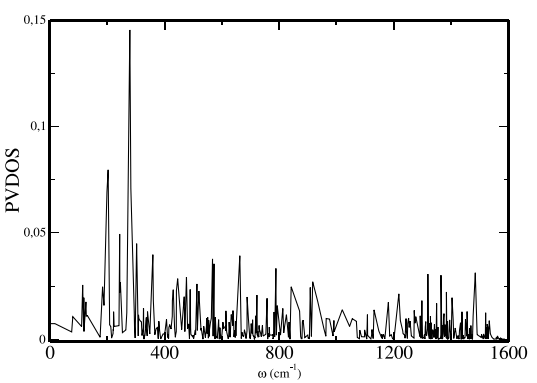

(a)

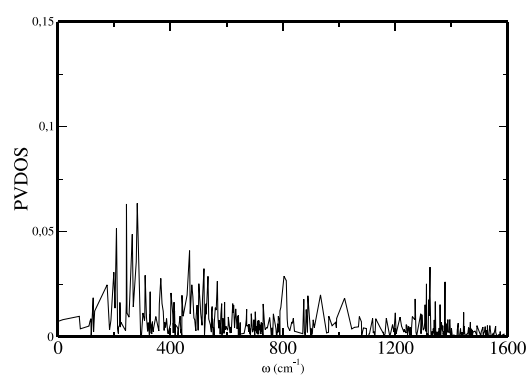

(b)

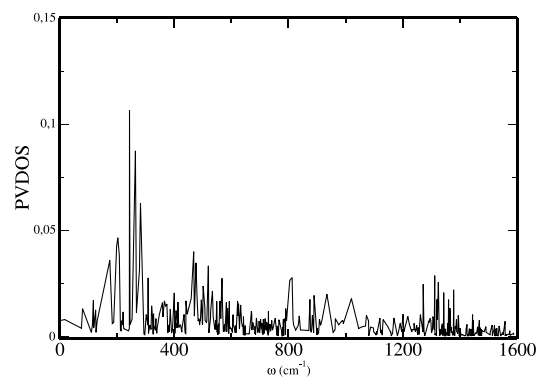

(c)

Figura 4.39: PVDOS dos três nitrogênios do sistema $156 C+3 N$. (a) átomo 74 (b) átomo 88 e (c) átomo 89.

A etapa seguinte, ou seja, o assinalamento dos modos semelhantes aos Raman ativos no tubo puro para esse defeito, mostrou-se difícil, pois muitos modos acoplaram, produzindo alterações consideráveis dos perfis do tubo puro. Os dados da Tabela 4.13 destacam que, de fato, somente o modo de freqüência mais baixa manteve um caráter bastante semelhante àquele do tubo puro.

Para esse sistema os shifts tendem a ser negativos para a região de baixas energias, exceto o RBM que não apresent desvio, tornando-se positivos para os modos intermediários e finalmente negativos para a banda G. 


\begin{tabular}{c|c|c|l}
\hline \multirow{2}{*}{ Simetria } & $\begin{array}{c}\omega \\
\left(\mathrm{cm}^{-1}\right)\end{array}$ & $\begin{array}{c}|\Sigma| \\
\left(\AA^{2}\right)\end{array}$ & $\begin{array}{l}\xi \\
\left(\mathrm{cm}^{-1}\right)\end{array}$ \\
\hline \hline$E_{2 g}$ & 76 & - & $\xi=76-96=-20$ \\
& 80 & - & $\xi=80-96=-16$ \\
\hline \multirow{2}{*}{$E_{1 g}$} & 212 & 0.7 & $\xi=212-222=-10$ \\
& 222 & 0.3 & $\xi=222-222=0$ \\
\hline \multirow{2}{*}{$A_{1 g}$} & 326 & 0.3 & $\xi=326-326=0$ \\
\hline \multirow{2}{*}{$E_{2 g}$} & 326 & 0.6 & $\xi=326-326=0$ \\
\hline$A_{1 g}$ & 670 & 0.2 & $\xi=670-662=+8$ \\
\hline \multirow{2}{*}{$E_{2 g}$} & 1551 & 0.2 & $\xi=672-662=+10$ \\
& 1442 & 0.3 & $\xi=672-662=+10$ \\
\hline & 1513 & 0.4 & $\xi=1513-1527=-14$ \\
\hline \multirow{2}{*}{$E_{1 g}$} & 1521 & 0.3 & $\xi=1521-1527=-6$ \\
\hline
\end{tabular}

Tabela 4.13: Freqüiências ( $\omega)$, Módulo das projeções $(|\Sigma|)$ e os "shifts" $(\xi)$ para os sete modos Raman ativos mais fortes para o nanotubo $(8,0)$ com o defeito $3 \mathrm{NV}$.

Uma análise dos quatro modos mais importantes também é feita para esse defeito, como mostrado na Tabela 4.14. 


\begin{tabular}{c|c|c|c|l}
\hline Simetria & $\begin{array}{c}\omega \\
\left(\mathrm{cm}^{-1}\right)\end{array}$ & $\begin{array}{c}|\Sigma| \\
\left(\AA^{2}\right)\end{array}$ & $\begin{array}{c}\Delta \\
\left(\mathrm{cm}^{-1}\right)\end{array}$ & $\begin{array}{l}\xi \\
\left(\mathrm{cm}^{-1}\right)\end{array}$ \\
\hline \hline$A_{1 g}(\mathrm{RBM})$ & 326 & 0.3 & - & $\xi=326-326=0$ \\
& 326 & 0.6 & & $\xi=326-326=0$ \\
\hline$E_{2 g}(1)$ & 1440 & 0.6 & 2 & $\xi=1440-1450=-10$ \\
$E_{2 g}(2)$ & 1442 & 0.5 & & $\xi=1442-1450=-8$ \\
\hline$E_{1 g}(1)$ & 1513 & 0.4 & 8 & $\xi=1513-1527=-14$ \\
$E_{1 g}(2)$ & 1521 & 0.3 & & $\xi=1521-1527=-6$ \\
\hline$A_{1 g}$ & 1551 & 0.8 & - & $\xi=1551-1567=-16$ \\
\hline \hline
\end{tabular}

Tabela 4.14: Freqüuências $(\omega)$, Módulo das projeções $(|\Sigma|)$, "splittings" $(\Delta)$ e os "shifts" $(\xi)$ para o modo RBM e a banda G para o nanotubo $(8,0)$ com o defeito $3 \mathrm{NV}$. Os números em parênteses mostram a correspondência com o par degenerado do sistema puro

O modo RBM apresenta dois principais modos com perfis parecidos e degenerados, mas com projeções diferentes, como no sistema metálico. Contudo o pico permanece como no puro, sem desvios. Na banda G, o modo $E_{1 g}$ sofre grande acoplamento, como no tubo $(8,0)$ dopado com $1 \mathrm{~N}$, e apresenta splitting da ordem de $10 \mathrm{~cm}^{-1}$, como o faz a maioria dos defeitos. O outro modo degenerado, ou seja, o de simetria $E_{2 g}$ apresenta muito baixo splitting. Esses modos sofrem shifts negativos e da ordem de $10 \mathrm{~cm}^{-1}$. O modo $A_{1 g}$ é bem semelhante àquele do tubo $(8,0)$ puro, deslocando seu pico correspondente do espectro de $16 \mathrm{~cm}^{-1}$ para a região menos energética. Novamente, apesar de acoplados, ainda mantiveram projeções razoáveis quando comparados à projeção de modos não correspondentes. O modo de freqüência mais baixa de simetria $E_{2 g}$ desse defeito projetado no RBM do puro fornece $0.01 \AA^{2}$.

Os modos que melhor representaram o perfil dos sete Raman ativos mais fortes do tubo puro são representados na Figura 4.40. 

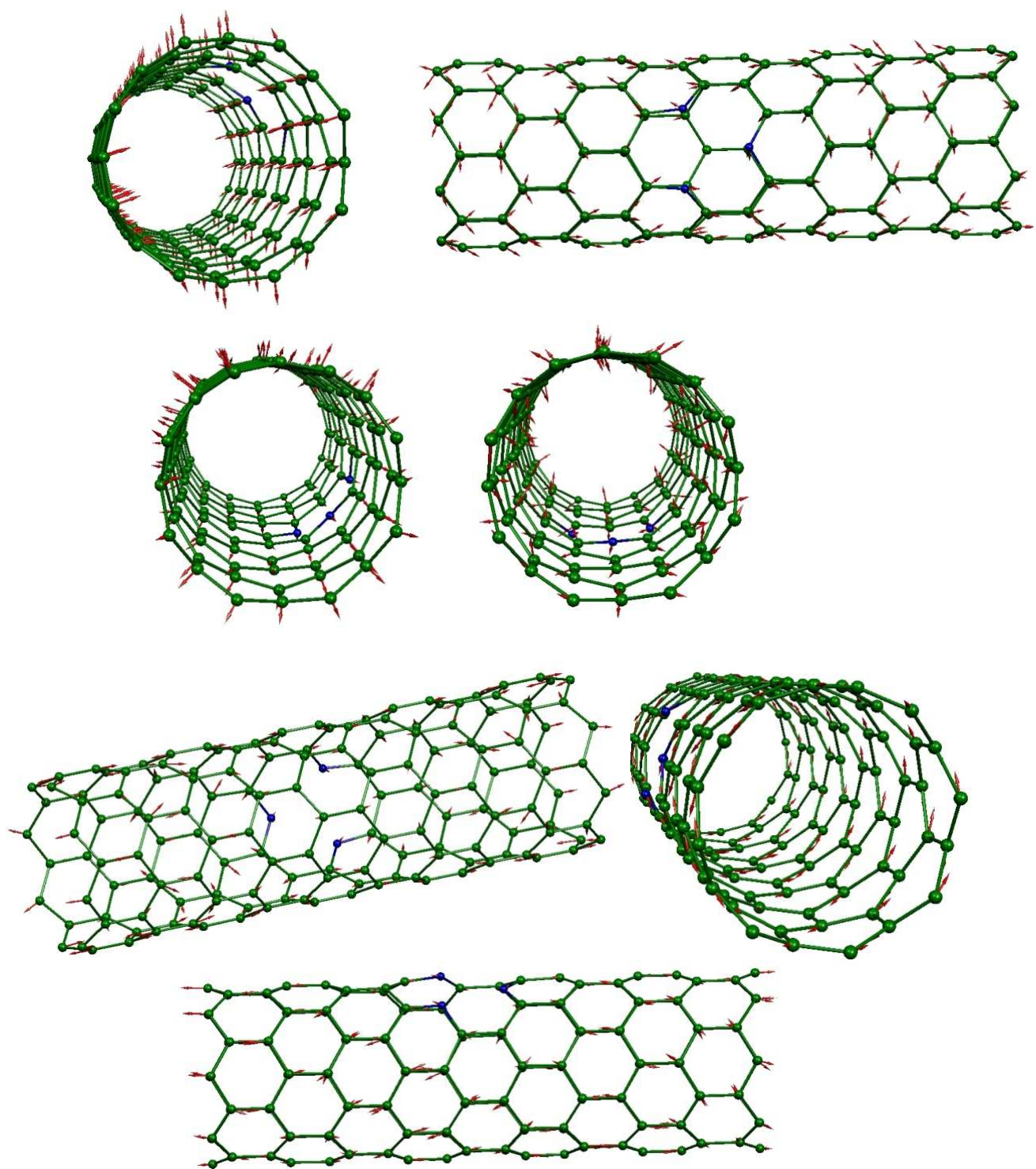

Figura 4.40: Modos vibracionais do nanotubo $(8,0)$ dopado com o defeito $3 \mathrm{NV}$ com perfis semelhantes aos sete Raman ativos do nanotubo puro.

A Figura 4.41 mostra novamente qualitativamente o efeito da Monovacância Rodeada por 3 Nitrogênios sobre os quatro principais modos do nanotubo semicondutor $(8,0)$. 
PICOS NO PURO

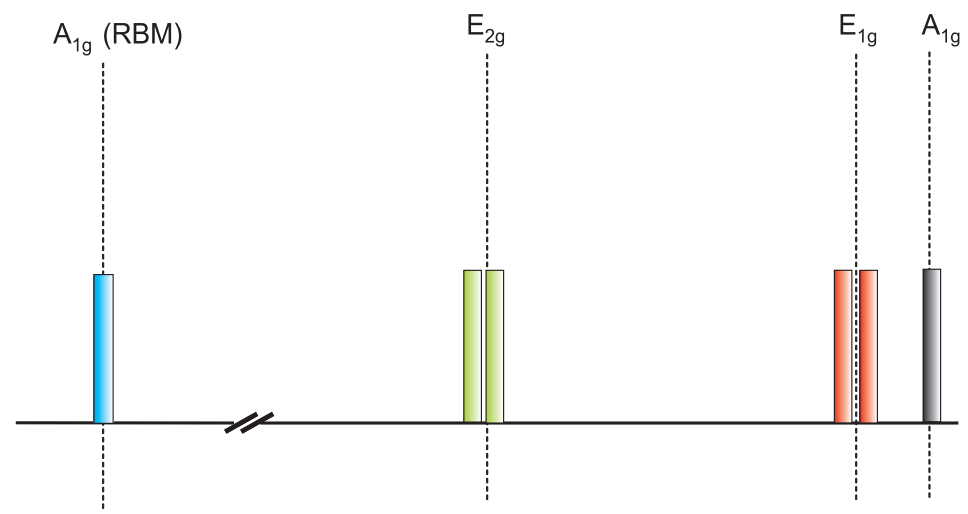

PICOS COM O DEFEITO

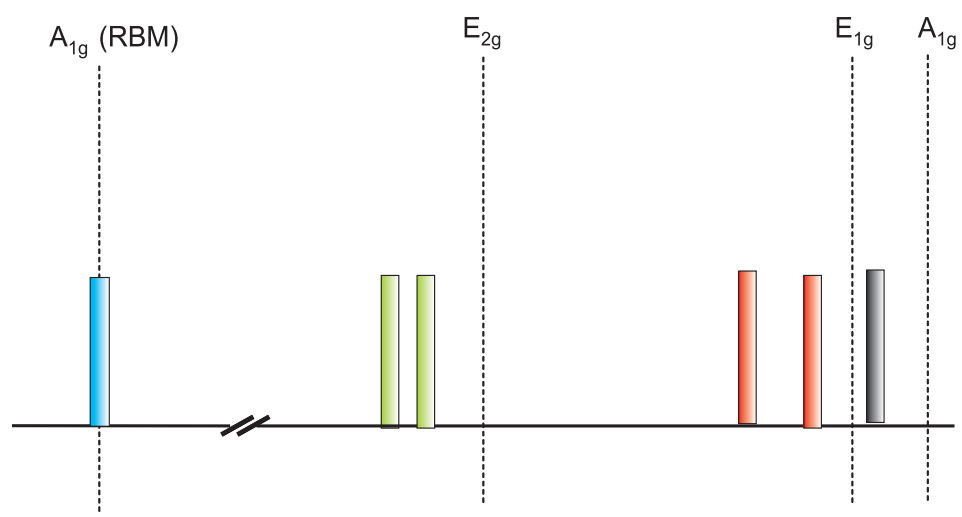

Figura 4.41: Representação qualitativa do que ocorre com as posições dos quatro mais importantes picos do puro quando se é introduzido o defeito $3 \mathrm{NV}$.

\subsubsection{Divacância Rodeada por 4 Nitrogênios - 4ND}

O último defeito analisado foi, como no sistema metálico, aquele proposto pelo nosso grupo. A estrutura da Divacância Rodeada por 4 Nitrogênios no nanotubo semicondutor está representada na Figura 4.42. 

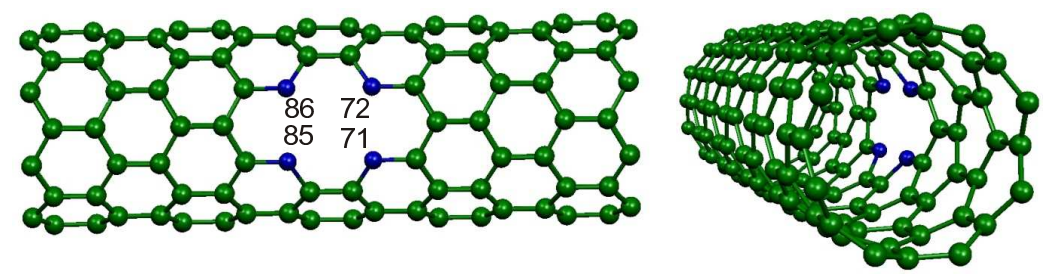

Figura 4.42: Estrutura da Divacância rodeada por quatro Nitrogênios no nanotubo $(8,0)$.

Novamente as densidades de estados do tubo puro e do sistema $154 C+$ $4 N$ foram superpostas na Figura 4.43, também com o mesmo alargamento anteriormente utilizado. Observe-se que a curva é parecida com aquela do defeito 3NV (essa semelhança entre esses defeitos na VDOS também ocorria no nanotubo metálico). Novos modos surgem exatamente nas mesmas regiões daquelas do sistema $156 C+3 N$.

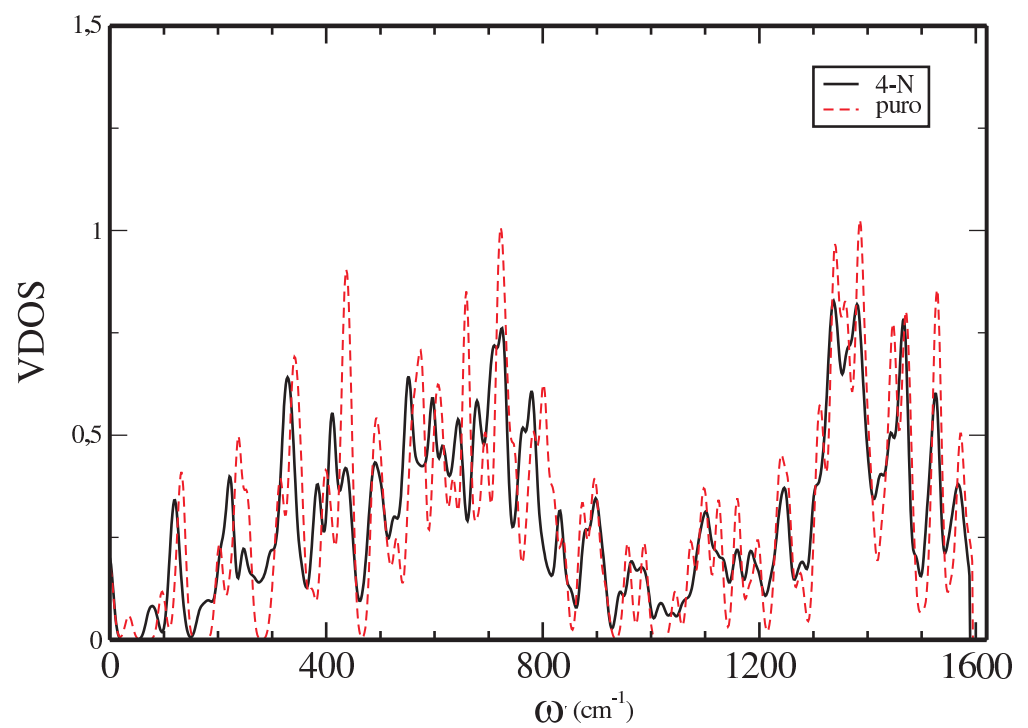

Figura 4.43: VDOS do sistema $154 C+4 N$ (linha cheia preta) comparada com aquela do puro (linha pontilhada e vermelha) para a Supercélula do nanotubo $(8,0)$ no ponto $\Gamma$. 
Analisando-se a PVDOS (Figura 4.44), vê-se que os átomos de nitrogênio nesse defeito contribuem de maneira considerável não somente para os modos de baixa freqüência (como todos os defeitos anteriores), como também para os modos de alta energia. Entretanto, na região da banda G, suas contribuições são desprezíveis. Os novos picos não correspondem a nenhum modo Raman ativo do puro. Como nos outros defeitos com vacância, os autovetores também tendem a preservar a simetria relativa à lacuna, vibrando de forma que suas direções mantenham alguma relação de simetria. Mas o elemento de simetria para o $4 \mathrm{ND}$ parece ser um espelho ao longo do tubo ${ }^{20}$.

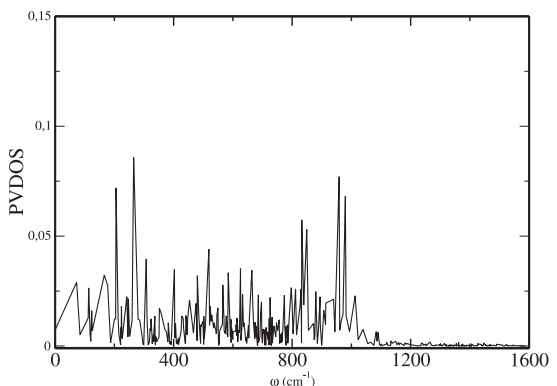

(a)

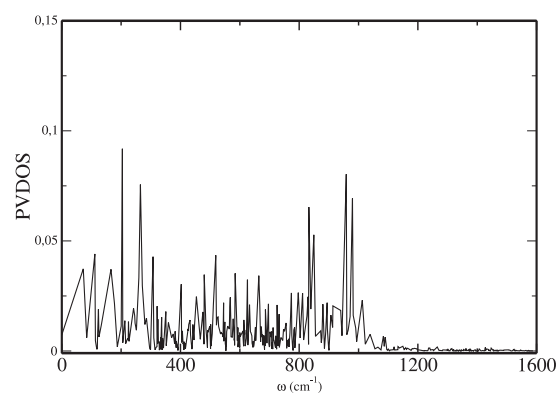

(c)

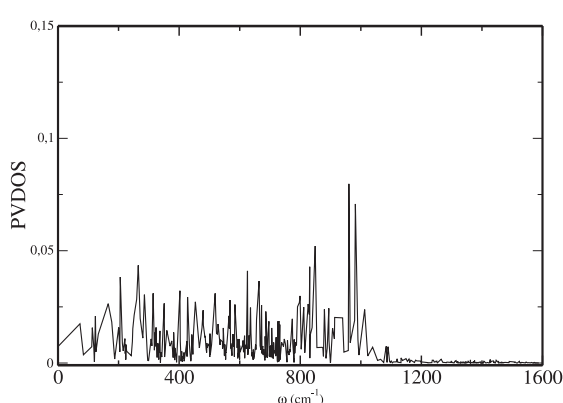

(b)

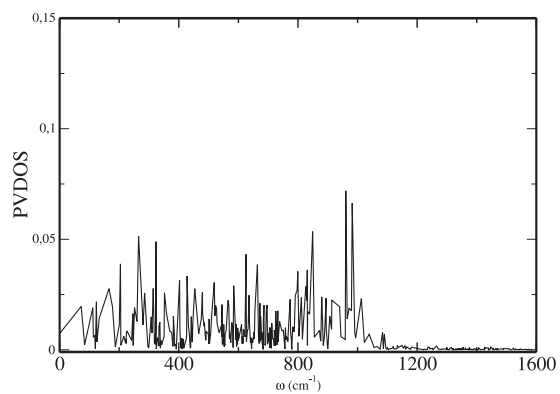

(d)

Figura 4.44: PVDOS para os 4 átomos de nitrogênio na Supercélula do nanotubo $(8,0)$ com a Divacância rodeada por 4 Nitrogênios no ponto $\Gamma$. (a) átomo 71 , (b) átomo 72 , (c) átomo 85 e (d) átomo 86, conforme Figura 4.37.

Como observado nos demais defeitos, a introdução de vacâncias produz uma maior desordem do sistema quanto aos autovetores, pois há um

\footnotetext{
${ }^{20}$ que também constitui um elemento de simetria do sistema $154 C+4 N$
} 
maior distanciamento da simetria original, portanto, os modos se acoplam muito. A Tabela 4.15 contém os resultados para os modos com caráter mais semelhante àqueles Raman ativos do tubo puro. A projeção entre modos não correspondentes ( $E_{2 g}$ de freqüência mais baixa do defeito no RBM do puro) resultou $0.002 \AA^{2}$.

\begin{tabular}{|c|c|c|c|}
\hline Simetria & $\begin{array}{c}\omega \\
\left(c m^{-1}\right)\end{array}$ & $\begin{array}{c}|\Sigma| \\
\left(\AA^{2}\right)\end{array}$ & $\begin{array}{l}\xi \\
\left(c m^{-1}\right)\end{array}$ \\
\hline \multirow{2}{*}{$E_{2 g}$} & 72 & - & $\xi=72-96=-24$ \\
\hline & 84 & - & $\xi=84-96=-12$ \\
\hline \multirow{3}{*}{$E_{1 g}$} & 212 & 0.7 & $\xi=212-222=-10$ \\
\hline & 222 & 0.5 & $\xi=222-222=0$ \\
\hline & 223 & 0.5 & $\xi=223-222=+1$ \\
\hline \multirow{2}{*}{$A_{1 g}$} & 318 & 0.5 & $\xi=318-326=-8$ \\
\hline & 327 & 0.4 & $\xi=327-326=+1$ \\
\hline \multirow{3}{*}{$E_{2 g}$} & 664 & - & $\xi=664-662=+2$ \\
\hline & 667 & 0.4 & $\xi=667-662=+5$ \\
\hline & 672 & 0.05 & $\xi=672-662=+10$ \\
\hline \multirow{2}{*}{$E_{2 g}$} & 1439 & 0.5 & $\xi=1439-1450=-11$ \\
\hline & 1444 & 0.5 & $\xi=1444-1450=-6$ \\
\hline & 1517 & 0.01 & $\xi=1517-1527=-10$ \\
\hline$E_{1 g}$ & 1518 & 0.7 & $\xi=1518-1527=-9$ \\
\hline$A_{1 g}$ & 1559 & 0.9 & $\xi=1559-1567=-8$ \\
\hline
\end{tabular}

Tabela 4.15: Freqüências ( $\omega)$, Módulo das projeções $(|\Sigma|)$ e os "shifts"( $\xi$ ) para os sete modos Raman ativos mais fortes para o nanotubo $(8,0)$ com o defeito 4 ND.

O comportamento dos shifts nesse defeito segue a tendência geral dos defeitos no nanotubo metálico, isto é, são negativos para a região de baixas energias, positivos para os modos intermediários e novamente negativos para os modos mais energéticos.

Como mostra a Tabela 4.16, o modo RBM também teve um acoplamento significativo com outros modos, portanto, o pico relativo a esse modo mostrará um alargamento (diferente do defeito $3 \mathrm{NV}$ para esse nanotubo $(8,0)$ ). 


\begin{tabular}{c|c|c|c|l}
\hline Simetria & $\begin{array}{c}\omega \\
\left(\mathrm{cm}^{-1}\right)\end{array}$ & $\begin{array}{c}|\Sigma| \\
\left(\AA^{2}\right)\end{array}$ & $\begin{array}{c}\Delta \\
\left(\mathrm{cm}^{-1}\right)\end{array}$ & $\begin{array}{l}\xi \\
\left(\mathrm{cm}^{-1}\right)\end{array}$ \\
\hline \hline$A_{1 g}(\mathrm{RBM})$ & 318 & 0.5 & - & $\xi=318-326=-8$ \\
& 327 & 0.4 & & $\xi=327-326=+1$ \\
\hline$E_{2 g}(1)$ & 1439 & 0.5 & 5 & $\xi=1439-1450=-11$ \\
$E_{2 g}(2)$ & 1444 & 0.5 & & $\xi=1444-1450=-6$ \\
\hline$E_{1 g}(1)$ & 1517 & 0.01 & 1 & $\xi=1517-1527=-10$ \\
$E_{1 g}(2)$ & 1518 & 0.7 & & $\xi=1518-1527=-9$ \\
\hline$A_{1 g}$ & 1559 & 0.9 & - & $\xi=1559-1567=-8$ \\
\hline \hline
\end{tabular}

Tabela 4.16: Freqüuências $(\omega)$, Módulo das projeções $(|\Sigma|)$, "splittings" $(\Delta)$ e os "shifts" $(\xi)$ para o modo RBM e a banda G para o nanotubo $(8,0)$ com o defeito 4ND. Os números em parênteses mostram a correspondência com o par degenerado do sistema puro

Os modos da região da banda $\mathrm{G}$ mantiveram os perfis correspondentes do tubo puro para esse defeito bem mais que no $3 \mathrm{NV}$. O modo de simetria $A_{1 g}$ acoplou muito pouco com outros modos e apresentou projeção de $0.9 \AA^{2}$ e apesar de possuir um shift também negativo como no $3 \mathrm{NV}$, possui uma diferença quanto à intensidade do desvio. No caso do 4ND ele é metade daquele observado na $3 N V$. Os modos de simetria $E_{1 g}$ não apresentam splitting e o modo $E_{2 g}$ apresenta $\Delta=5 \mathrm{~cm}^{-1}$. Os shifts desses modos são todos da ordem de $10 \mathrm{~cm}^{-1}$ e negativos.

A Figura 4.45 apresenta os modos mais semelhantes aos sete Raman ativos mais intensos no tubo puro $(8,0)$ para esse defeito. 

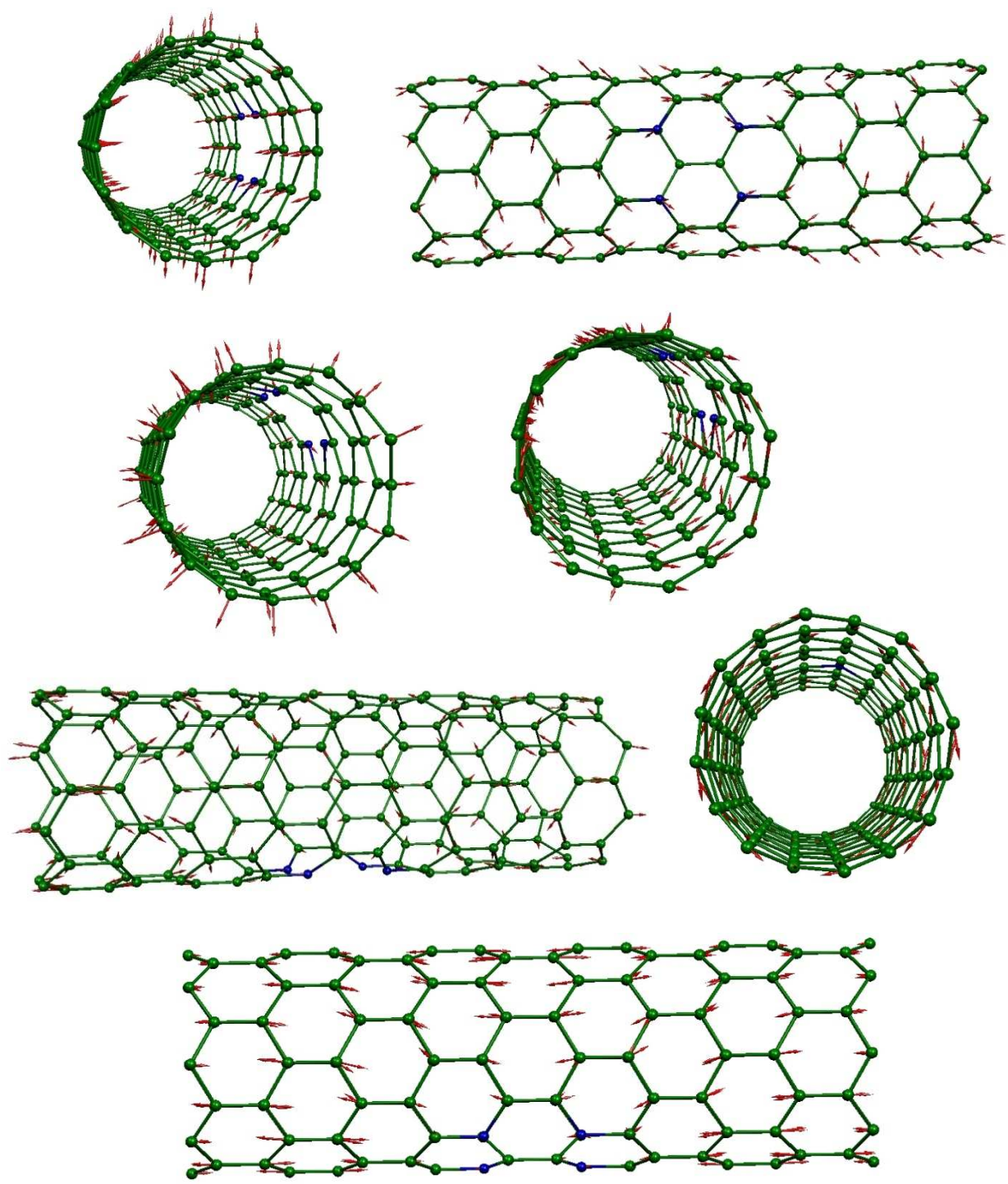

Figura 4.45: Modos vibracionais do nanotubo $(8,0)$ dopado com o defeito 4ND com perfis semelhantes aos sete Raman ativos do nanotubo puro.

Finalmente, a Figura 4.46 apresenta um esquema qualitativo para o efeito do defeito $4 \mathrm{ND}$ no nanotubo semicondutor $(8,0)$. 
PICOS NO PURO

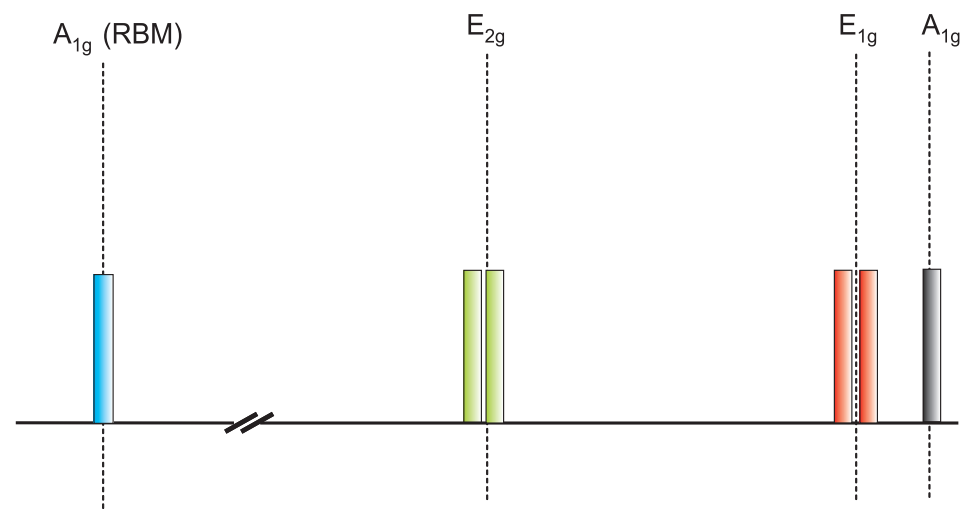

PICOS COM O DEFEITO

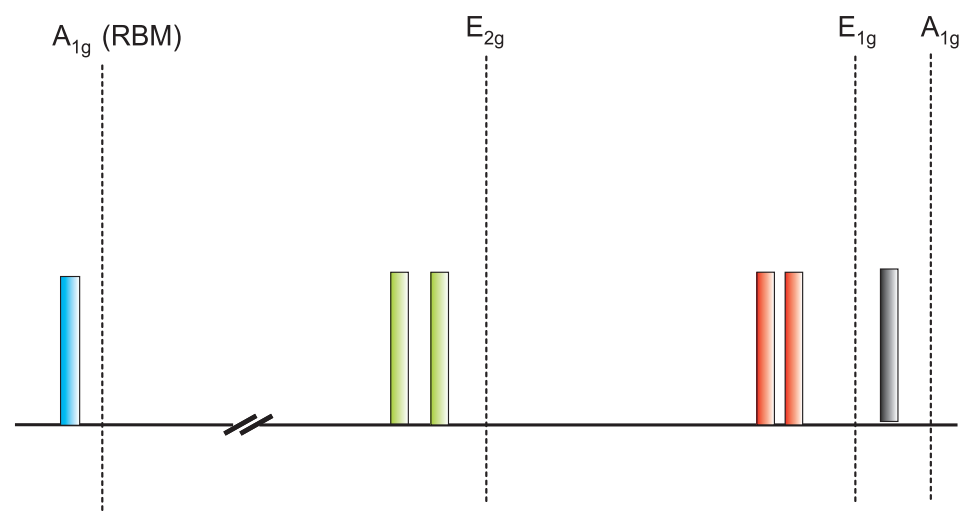

Figura 4.46: Representação qualitativa do que ocorre com as posições dos quatro mais importantes picos do puro quando se é introduzido o defeito 4ND.

\subsection{Resumo dos Resultados}

A seguir são mostrados esquemas ilustrativos que resumem os resultados obtidos. São feitas comparações entre os defeitos para cada sistema e no final um compração geral entre os sistemas metálico e semicondutor com as dopagens. Os modos analisados são somente os quatro modos principais mais detalhadamente discutidos ao longo do texto para todos os defeitos. 


\section{Nanotubo $(5,5)$}

A Figura 4.47 mostra uma comparação dos shifts do modo RBM no nanotubo $(5,5)$.

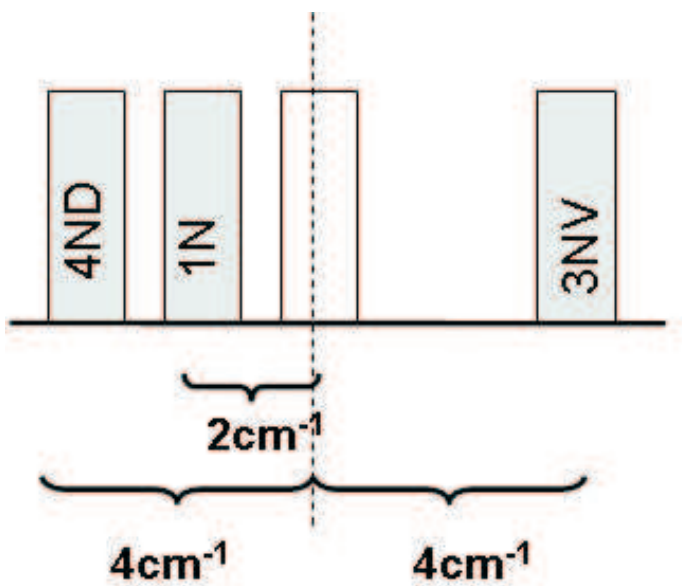

Figura 4.47: Comparação entre os "shifts"para os modos RBM dos defeitos introduzidos no nanotubo metálico. A barra branca representa a posição do pico no sistema puro.

Observe-se que uma diferença qualitativa é apresentada quanto ao sentido dos desvios. Para a Divacância há um desvio para a região menos energética e para a Monovacância para a região mais energética. O Nitrogênio Substitucional também apresenta shift para a região menos energética, mas de menor intensidade. Na banda $\mathrm{G}$, os modos degenerados no puro ( $E_{1 g}$ e $\left.E_{2 g}\right)$ apresentam splittings pequenos, tendo no máximo, um valor da ordem de $10 \mathrm{~cm}^{-1}$. Os shifts desses modos estão em média, também em torno do valor $10 \mathrm{~cm}^{-1}$. $\mathrm{O}$ modo de simetria $A_{1 g}$, contudo mostra um grande valor de shift para o $1 \mathrm{~N}$ e valores bem próximos para os demais defeitos (3NV e 4ND) assumindo para todos eles, valores negativos.

\section{Nanotubo $(8,0)$}

Na Figura 4.48 está a comparação entre os shifts do modo RBM no nanotubo $(8,0)$. 


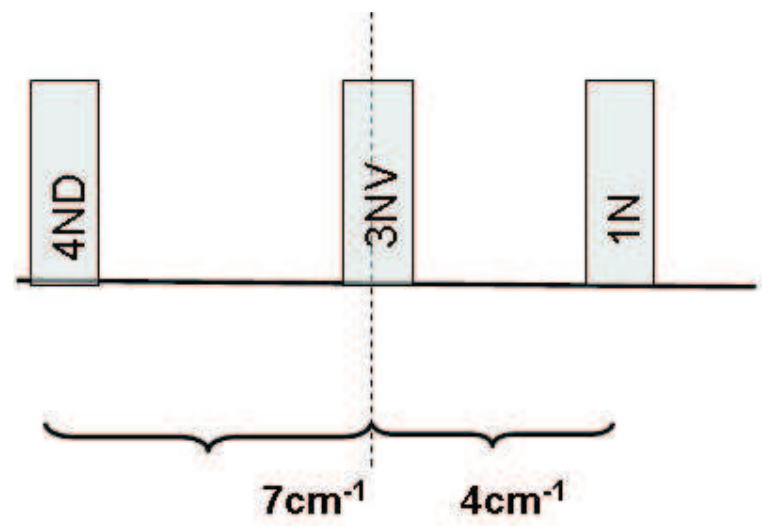

Figura 4.48: Comparação entre os "shifts"para os modos RBM dos defeitos introduzidos no nanotubo semicondutor. $\mathrm{O}$ modo $3 \mathrm{NV}$ não apresenta desvio relativo ao puro, portanto, está superposto ao pico do puro.

Para a Divacância nesse nanotubo, há um desvio novamente para a região menos energética, mas diferente da dopagem no nanotubo metálico, para a Monovacância não há desvio, ou seja, o shift é nulo e positivo para o Nitrogênio Substitucional. Na banda G, o comportamento geral é igual àquele no nanotubo metálico quanto aos splittings dos modos $E_{1 g}$ e $E_{2 g}$ apresentando também shifts negativos. Para o modo $A_{1 g}$ há o seguinte ordenamento relativo ao valor (intensidade) dos shifts: $\xi_{4 N D}<\xi_{1 N}<\xi_{3 N V}$.

\section{Sistemas Metálico e Semicondutor}

A Figura 4.49 apresenta um esquema resumido dos efeitos das dopagens para ambos os sistemas quanto aos quatro modos principis, isto é, o RBM e a banda G. As informações de splittings são iguais para ambos os sistemas, mas os shifts comportam-se de maneira peculiar para os sistemas metálico ou semicondutor. 


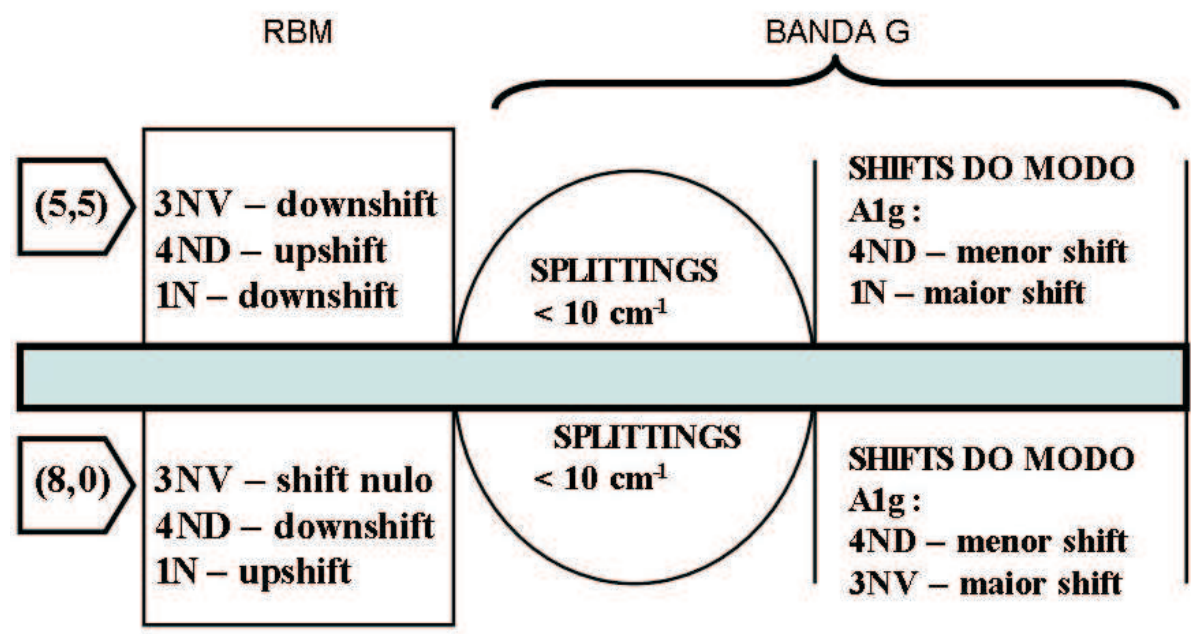

Figura 4.49: Comparação entre os sistemas metálico $(5,5)$ e semicondutor $(8,0)$. Os termos "downshift", "upshift"referem-se a "shift"negativo e positivo, respectivamente. 


\section{Capítulo 5}

\section{Conclusões}

Os muitos resultados experimentais em espectroscopia Raman de nanotubos $[19,44,45,62,63]$ mostraram que essa técnica é bastante rica em informações para caracterização dos tubos, não somente quanto ao seu diâmetro como também quanto ao seu caráter eletrônico (isto é, o fato de ser metálico ou semicondutor). Sabe-se que para os defeitos com nitrogênio, duas formas de nitrogênio estão presentes, a saber, em ligações $s p^{2}$ e tipo piridina possuindo, para este último vacância, ou vacâncias em sua vizinhança. Baseado no poder de caracterizção das técnicas espectroscópicas, esse trabalho investigou as propriedades vibracionais dos principais defeitos de nitrogênio em nanotubos de carbono, a fim de extrair propriedades que os diferenciassem, objetivando a identificação deles via espectro Raman, em especial a determinação de qual defeito tipo piridina de fato existe, entre aquele com uma vacância e aquele com duas.

Os picos mais notáveis no espectro Raman são o RBM e a banda G. O pico RBM do nanotubo $(5,5)$ apresenta comportamento diferenciado para os defeitos tipo piridina. O defeito $4 \mathrm{ND}$ move o pico para a região menos energética, enquanto que o $3 \mathrm{NV}$ para a região oposta mais energética. O defeito $1 \mathrm{~N}$ também move o pico para a região menos energética. Para o nanotubo $(8,0)$, o defeito 4ND move o pico RBM novamente para a região menos energética, mas agora o $1 \mathrm{~N}$ move para a região oposta mais energética. Não há shift para o defeito $3 \mathrm{NV}$. 
Para a banda $G$, no nanotubo $(5,5)$ há splittings da ordem $10 \mathrm{~cm}^{-1}$. O shift do pico $A_{1 g}$ para os defeitos tipo piridina são muito próximos e para o defeito $1 \mathrm{~N}$ apresenta um valor consideravelmente grande. Todos eles desviam-se para a região menos energética. No nanotubo $(8,0)$ o pico $A_{1 g}$ possui a seguinte ordem quanto aos shifts: $\xi_{4 N D}<\xi_{1 N}<\xi_{3 N V}$.

Assim, o RBM pode ser usado como ferramenta para a distinção entre os defeitos tipo piridina pelo comportamento qualitativo diferenciado que produzem quanto aos shifts. O pico $A_{1 g}$ da banda $\mathrm{G}$ também pode apresentar diferenças notáveis. Ao se dopar com $3 \mathrm{NV}$ o shift sofrido por ele $\left(-16 \mathrm{~cm}^{-1}\right)$ é o dobro da dopagem com o 4ND $\left(-8 \mathrm{~cm}^{-1}\right)$. O $1 \mathrm{~N}$ produz um shift intermediário de $-11 \mathrm{~cm}^{-1}$.

Ainda como característica comum a todos os defeitos observa-se uma tendência em produzir shifts negativos para as freqüências de baixa energia e para as de alta e shifts positivos para as freqüências intermediárias.

Em geral, os resultados sugerem que, apesar de os splitings e shifts não terem apresentado grandes diferenças entre os defeitos, o comportamento qualitativo diferenciado observado pelo RBM quanto aos shifts pode ser uma boa ferramenta de distinção entre esses defeitos através de espectroscopia vibracional. Contudo, uma perspectiva ainda seria um melhoramento do cálculo pela utilização de simetrias no cálculo das constantes de força, bem como o cálculo das intensidades Raman e uma análise mais detalhada dos efeitos da estrutura eletrônica sobre as vibrações, especialmente para o tubo metálico. Outras opções seriam a investigação teórica via imagens STM ou XPS (X-Ray Photoelectron Spectroscopy). 


\section{Apêndice A}

\section{Nanotubos de Carbono}

\section{A.1 Propriedades Estruturais}

Nanotubos de Carbono são vistos como folhas de grafeno enroladas, como discutido na Introdução, portanto, sua análise estrutural deve partir deste sistema. O grafeno forma uma rede de Bravais quando a célula unitária é um hexágono contendo dois átomos de carbono e vetores primitivos como na Figura $A .1$ abaixo, formando entre si um ângulo de $\frac{\pi}{3}$ :

$$
\begin{array}{r}
\left|\vec{a}_{1}\right|=\left|\vec{a}_{2}\right|=|\vec{a}|=a=2.46 \AA \\
\vec{a}_{1}=\left(\frac{\sqrt{3}}{2} a, \frac{1}{2} a\right) ; \vec{a}_{2}=\left(\frac{\sqrt{3}}{2} a,-\frac{1}{2} a\right) \\
a=\sqrt{3} a_{0}
\end{array}
$$

Observe-se que os átomos $A$ e $B$ não são equivalentes, porém o conjunto formado por ambos repete-se periodicamente. A área hexagonal hachurada é a célula unitária de Wigner-Seitz no espaço real. Os vetores da rede são portanto:

$$
\vec{R}=n_{1} \vec{a}_{1}+n_{2} \vec{a}_{2}
$$

No espaço recíproco, tem-se pela definição de rede recíproca [22]

$$
\vec{G}=m_{1} \vec{b}_{1}+m_{2} \vec{b}_{2} \text {. }
$$

com os vetores primitivos 


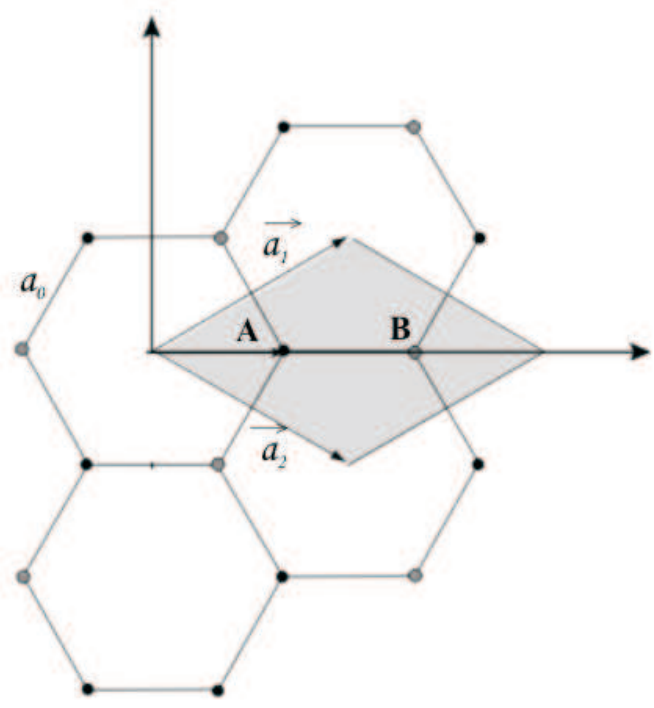

Figura A.1: Célula unitária do grafeno e seus vetores primitivos. $a_{0}=1.421 \AA$ é a distância $C-C$.

Figura A.2: Célula unitária de Wigner-Seitz no espaço recíproco (zona de Brillouin) do grafeno (região hachurada) e seus vetores primitivos. $O$ centro da zona é chamado ponto $\Gamma$ e os vértices da figura hachurada, ponto $K$. Também estão representados os vetores da rede direta (real).

$$
\begin{aligned}
& \vec{b}_{1}=2 \pi \frac{\vec{a}_{2} \times \vec{a}_{3}}{\vec{a}_{1} \cdot\left(\vec{a}_{2} \times \vec{a}_{3}\right)} \\
& \vec{b}_{2}=2 \pi \frac{\vec{a}_{3} \times \vec{a}_{1}}{\vec{a}_{1} \cdot\left(\vec{a}_{2} \times \vec{a}_{3}\right)}
\end{aligned}
$$

e $\vec{a}_{3}$ definido como um vetor na direção perpendicular ao plano.

Das equações acima tem-se para o grafeno os seguintes vetores primitivos que formam a célula de Wigner-Seitz na rede recíproca, ou seja, a zona de Brillouin, representada na Figura $A .2$ :

$$
\vec{b}_{1}=\left(\frac{2 \pi}{\sqrt{3} a}, \frac{2 \pi}{a}\right) ; \vec{b}_{2}=\left(\frac{2 \pi}{\sqrt{3} a},-\frac{2 \pi}{a}\right) .
$$

A Figura $A .3$ mostra a contrução do nanotubo. O enrolamento dá-se ao longo do vetor quiral (que formará a circunferência do tubo) e o comprimento 

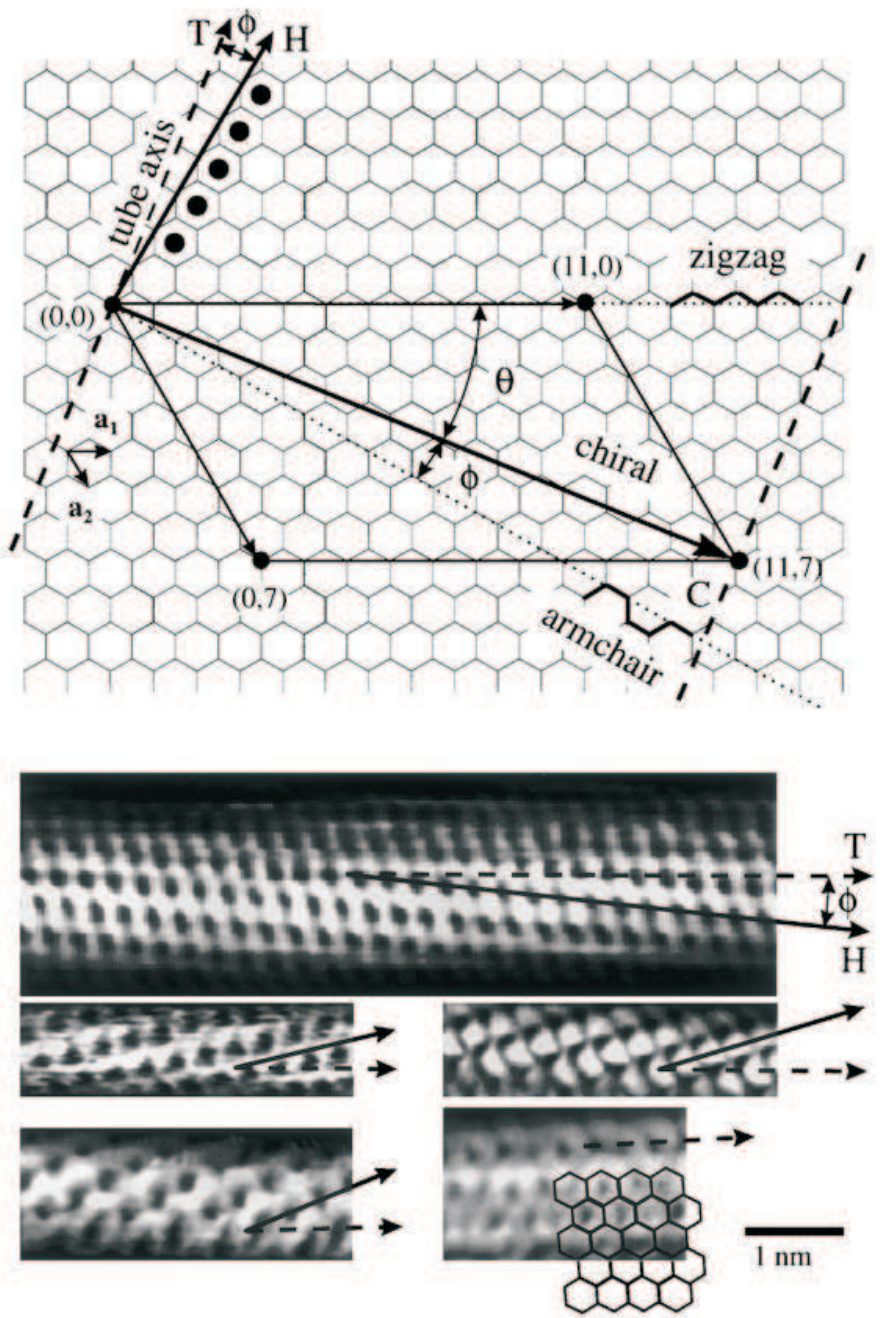

Figura A.3: Construção do nanotubo a partir da folha de grafeno. Chiral representa o vetor quiral e tube axis o eixo do tubo após o enrolamento, ou seja, a direção do vetor de translação. Na figura também são mostrados os vetores unitários do grafeno. Abaixo são mostradas imagens de STM de nanotubos de parede única, onde o vetor tracejado representa o vetor $\vec{T}$, enquanto que o outro, representa $\vec{H}$. Os dois últimos abaixo à esquerda tem-se um nanotubo armchair e à direita, zig-zag. Os restantes são quirais [64]. 
é dado pelo vetor perpendicular a este (linha tracejada na figura), o vetor de translação, que também define o eixo do nanotubo. Quando o vetor quiral coincide com as linhas pontilhadas, tem-se a formação de nanotubos aquirais (armchair ou zig-zag). Os demais são ditos nanotubos quirais. O ângulo entre $\vec{T} \mathrm{e}$ a direção dos hexágonos mais próximos (vetor $\vec{H}$ ) é o ângulo quiral $\phi$. Esse também é o ângulo entre o vetor quiral e a direção armchair. Às vezes, $\theta$, o ângulo entre o vetor quiral e a direção zig-zag é referido como o ângulo quiral. Contudo, lembrando que o ângulo entre os dois vetores unitários do grafeno (também mostrado na Figura A.3) é $\frac{\pi}{3}$, tem-se a relação entre $\phi$ e o ângulo $\theta$ entre o vetor quiral e a direção zig-zag: $\theta+\phi=\frac{\pi}{6}$. O vetor quiral é definido como:

$$
\vec{C}_{h}=n \vec{a}_{1}+m \vec{a}_{2}
$$

de onde vem a notação nanotubo $(n, m)$. O diâmetro do tubo é:

$$
d_{t}=\frac{\left|\overrightarrow{C_{h}}\right|}{\pi}
$$

e o vetor de translação

$$
\vec{T}=t_{1} \vec{a}_{1}+t_{2} \vec{a}_{2}
$$

com $t_{1}$ e $t_{2}$ números inteiros. Como $\vec{T}$ e $\vec{C}_{h}$ devem ser perpendiculares, $t_{1}$ e $t_{2}$ assumem os seguintes valores:

$$
t_{1}=\frac{(2 m+n)}{D} \quad t_{2}=\frac{-(2 n+m)}{D}
$$

sendo $D$ o máximo divisor comum entre $(2 m+n)$ e $-(2 n+m)$, para a célula unitária, que exige a menor periodicidade do vetor $\vec{T}$. Define-se também $N$, o número de células primitivas do grafeno na célula do nanotubo como:

$$
N=\frac{\text { Área }_{\text {nanotubo }}}{\text { Área }}=\frac{\left|\vec{C}_{h} \times \vec{T}\right|}{\left|\vec{a}_{1} \times \vec{a}_{2}\right|}
$$

A rede recíproca do nanotubo também é construída a partir daquela do grafeno. Sendo os vetores $\vec{K}_{1}$ e $\vec{K}_{2}$, correspondentes, respectivamente, aos vetores $\vec{C}_{h}$ e $\vec{T}$ da rede real, tem-se, novamente, da definição de rede recíproca [22], 


$$
\exp \left(i \vec{C}_{h} \cdot \vec{K}\right)=1
$$

onde $\vec{K}$ é qualquer vetor da rede recíproca e $\vec{R}$, da rede direta, as seguintes relações:

$$
\begin{aligned}
\vec{C}_{h} \cdot \vec{K}_{1}=2 \pi & \vec{C}_{h} \cdot \vec{K}_{2}=0 \\
\vec{T} \cdot \vec{K}_{1}=0 & \vec{T} \cdot \vec{K}_{2}=2 \pi
\end{aligned}
$$

Como anteriormente, para se calcular os inteiros de $\vec{T}$ devem-se explorar os produtos escalares [62]. Por fim, obtêm-se os vetores:

$$
\begin{array}{r}
\vec{K}_{1}=\frac{-t_{2} \vec{b}_{1}+t_{2} \vec{b}_{2}}{N} \\
\vec{K}_{2}=\frac{m \vec{b}_{1}-n \vec{b}_{2}}{N}
\end{array}
$$

com todos os parâmetros anteriormente definidos.

Contudo, $\left(-t_{2}\right) \vec{b}_{1}+\left(t_{1}\right) \vec{b}_{2}$ é um vetor da rede recíproca do grafeno, já que $t_{1}$ e $t_{2}$ são inteiros. Portanto, das relações acima, $N \vec{K}_{1}$ é um vetor recíproco do grafeno e haverá a cada $N \vec{K}_{1}$ uma repetição como os vetores recíprocos do grafeno, ou ainda, vetores que diferem de $N \vec{K}_{1}$, são equivalentes. Além disso, como $t_{1}$ e $t_{2}$ não possuem divisor comum, os vetores $N \vec{K}_{1}$ são os únicos pertencentes à rede recíproca do grafeno, ou seja, os outros $N-1$ vetores não são.

Devido à condição de equivalência entre os átomos na circunferência (cada ponto é equivalente àquele distante de $2 \pi R$ numa circunferência), temse condições de contorno sobre o vetor quiral que se refletem também no seu equivalente, o vetor $\vec{K}_{1}$. Portanto, somente determinados valores de vetores de onda $\vec{k}$ para ele serão permitidos, e são em número, igual a $N$. A zona de Brillouin do nanotubo é, então, composta por linhas espaçadas, onde haverá na direção $\vec{K}_{1}$ somente os pontos discretos permitidos e ao longo da direção $\vec{K}_{2}$ uma continuidade com periodicidade igual a $\frac{2 \pi}{\vec{T}}$, já que $\vec{T}$ é o seu equivalente na rede direta [62]. 
Figura A.4: Zona de Brillouin do nanotubo $(10,10)$ (linhas) e a zona do grafeno (hexágono).

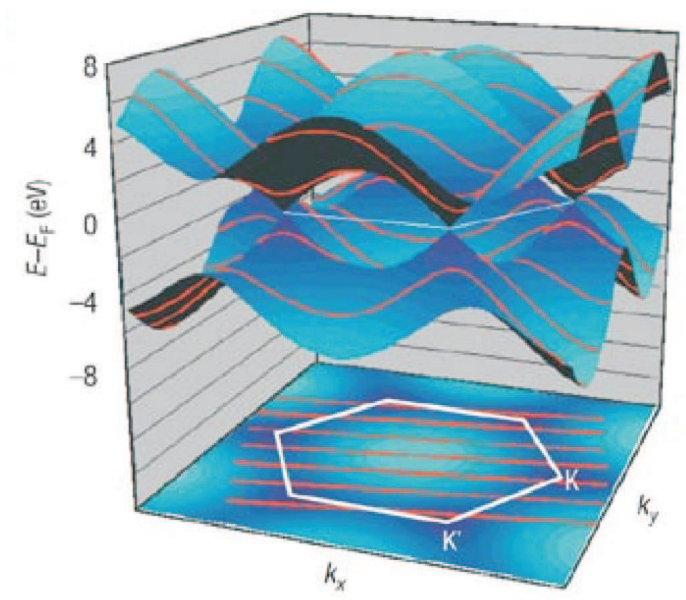

Figura A.5: Relação de dispersão das duas bandas $\pi$ do grafeno e rede recíproca de um nanotubo.

\section{A.2 Propriedades Energéticas}

O átomo de carbono possui quatro elétrons na camada de valência, dos quais três formam orbitais híbridos $s p^{2}$ e o último, pertencente a um orbital $p_{z}$ forma a chamada banda $\pi$. Na ligação entre dois carbonos no grafeno, portanto, há associados a esses orbitais $p$ perpendiculares à folha, dois elétrons e, ao mesmo tempo, haverá duas bandas $\pi$, a saber, $\pi \mathrm{e} \pi^{*}$. A relação de dispersão tridimensional para o grafeno e as linhas da rede recíproca de um nanotubo são mostradas na Figura A.5. Observe-se que para esse nanotubo as linhas não cruzam o vértice $\mathrm{K}$ da rede recíproca do grafeno, o que implica que o comportamento de gap nulo típico do gafeno não é refletido neste nanotubo, que, portanto, não é metálico.

Como discutido acima, a rede recíproca do nanotubo corresponde a linhas que cruzam a rede recíproca do grafeno, portanto, a relação de dispersão do nanotubo será um arranjo unidimensional composto das $N$ bandas (correspondentes aos $\mathrm{N}$ vetores permitidos) repetindo-se continuamente num período de $\frac{2 \pi}{\vec{T}}$, como na Figura $A .5$ (Observe-se as linhas ao longo superfície 


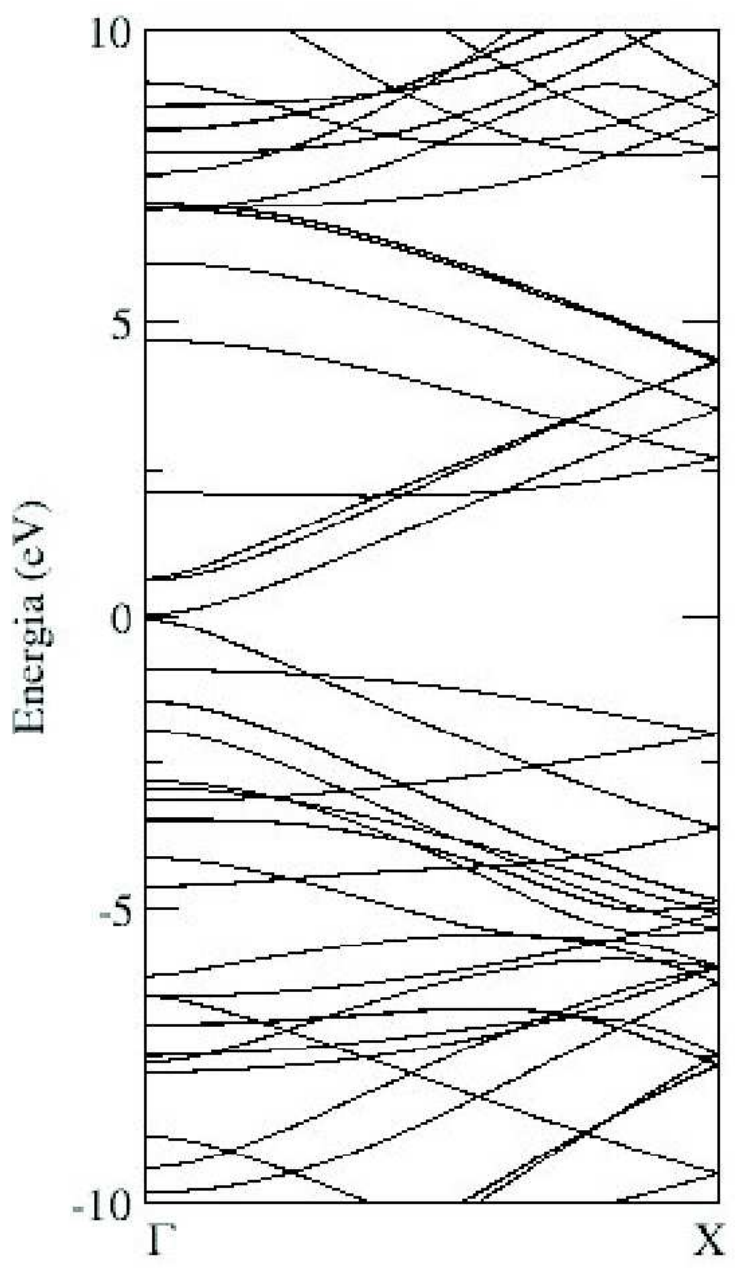

Figura A.6: Relação de dispersão do nanotubo de carbono (7,0). A energia de Fermi está no nível zero. Observe o gap presente na estrutura.

de energia). Na Figura $A .6$ está representada a relação de dispersão de um nanotubo.

Como comentado acima, o caráter eletrônico de um nanotubo, ou seja, ser semicondutor ou metálico é determinado pelo cruzamento da zona de Brillouin do nanotubo com os vértices do hexágono da rede recíproca do grafeno, onde o gap é nulo para esse último. Se há cruzamento, o nanotubo será metálico, caso contrário, será semicondutor. Uma condição que satisfaz isso é que $(n-m)$ seja múltiplo de 3 [62]. 


\section{Referências Bibliográficas}

[1] Retirado do Dicionário Livre de Geociências:

(http : //www.dicionario.pro.br/dicionario/index.php/Grafita).

[2] Retirado do Dicionário Livre de Geociências:

(http : //www.dicionario.pro.br/dicionario/index.php?title = Diamante).

[3] H. W. Kroto, J. R. Heath, S. C. O'Brien, R. F. Curl, R. E. Smalley, Nature 318, 162 (1985).

[4] S. Iijima, Nature (London) 354, 56 (1991).

[5] R. T. Yang, Carbon 38 (2000), 623.

[6] S. Chopra, A. Pham, J. Gaillard, A. Parker, and A. M. Rao, Applied Physics Letters, v. 80, no. 24, 4632 (2002).

[7] Edição da Figura original:

(http ://en.wikipedia.org/wiki/Carbon_nanotube).

[8] L. A. Silva, S. C. Guerini, V. Lemos, J. M. Filho, IEEE Transactions on Nanotechnology, v. 5, 517-522 (2006).

[9] Y. Miyamoto, A. Rubio, M. L. Cohen, S. G. Louie, Phys. Rev. B, 50, 7 (1994).

[10] Y. Miyamoto, M. L. Cohen, and S. G. Louie, Solid State Comm. 102, 8 (1997) 605608.

[11] S. M. C. Vieira, O. Stéphan, D. L. Carroll, J. Mater. Res. v. 21, 12 (2006).

[12] M. C. Rossi, Estudo Teórico de sensores baseados em nanotubos $C N_{x}$ utilizando cálculos ab initio, Dissertação (Mestrado) São Paulo (2007).

[13] M. He, S. Zhou, J. Zhang, Z. Liu, C. Robinson, J. Phys. Chem. B 109 (2005), 92759279. 
[14] M. Terrones, P. M. Ajayan, F. Banhart, et al., Applied Physics A 74, 355 (2002).

[15] D. S. Bethune, C. H. Klang, M. S. de Vries, G. Gorman, R. Savoy, J. Vazquez, R. Beyers, Nature 363, 605-607 (1993).

[16] Nanotubes in space - David Salt, ScienceWise, v. 4, no. 3, (2007).

[17] F. Villalpando-Paez, A. H. Romero, E. Muñoz-Sandoval, et al., Chem. Phys. Lett. 386, 137 (2004).

[18] Edição das Figuras encontradas nas páginas: http://www.fortunecity.com/tattooine/excession/177/ap_org1_v99b.html e http://www.meta-synthesis.com/webbook/45_vsepr/VSEPR.html.

[19] A. Jorio, M. A. Pimenta, A. G. Souza Filho, R. Saito, G. Dresselhaus, M. S. Dresselhaus, New Journal of Physics, Alemanha, v. 5, 139.1-139.17 (2003).

[20] M. Born, R. Oppenheimer, Annalen der Physik, v. 84, 457-484 (1927).

[21] J. Kohanoff, Eletronic Structure Calculations for Solids and Molecules: Theory and Computational Methods, Cambridge University Press (2006).

[22] N. W. Ashcroft, N. D. Mermin, Solid State Physics (Holt, Rinehart, and Winston, New York, 1976), 1st ed.

[23] A. R. B. de Castro e R. C. C. Leite, Física do Estado Sólido (Ed. UNICAMP e Edgard Blücher, Campinas, 1978).

[24] J. C. Slater, Phys. Rev.,81, 385 (1951)

[25] P. W. Atkins, R. S. Friedman, Molecular Quantum Mechanics (3rd ed.), Oxford University Press, Oxford (1997)

[26] P. Hohenberg, W. Kohn, Phys. Rev. 136, B864 (1964).

[27] J. Kohanoff, N. I. Gidopoulos, Density Functional Theory: Basics, New Trends and Applications. In: S. Wilson, Editor, Handbook of Molecular Physics and Quantum Chemistry, John Wiley and Sons, Ltd., Chichester (2003).

[28] M. Levy, Proc. Natl. Acad. Sci. U.S.A. 76, 6062 (1979).

[29] K. Capelle, A bird's-eye view of density-functional theory, Available from: arXiv:cond-mat/0211443. 
[30] M. E. Casida et al., The Journal of Chemical Physics, 11, v. 108, 4439 (1998).

[31] G. P. Srivastava, The Physics of Phonons, Adam Hilger, Bristol, UK (1990).

[32] R. O. Jones, O. Gunnarsson, The density functional formalism, its applications and prospects, Rev. Mod. Phys. 61, 689-746 (1989).

[33] W. Ku, A. G. Eguiluz, Phys. Rev. Lett. 89, 126401 (2002).

[34] W. Kohn, Review of Modern Physics 71, 1253 (1999).

[35] J. P. Perdew, A. Zunger, Phys. Rev. B 23, 5048 (1981).

[36] R. Biwas, D. R. Hamann, Phys. Rev. B 36.

[37] P. Giannozzi, S. de Gironcoli, P. Pavone, S. Baroni, Phys. Rev. B 43, 7231 (1991).

[38] S. Baroni, S. de Gironcoli, A. Dal Corso, P. Giannozzi, Rev. Mod. Phys. 73, 515 (2001).

[39] R. Heid et al, Phys. Rev. B 57, no. 13, 7407 (1998).

[40] P. Bruesch, J. Bernasconi, U. T. Hochli, L. Pietronero, Phonons: Theory and Experiments III - Phenomena Related to Phonons (Springer-Verlag), Springer Series in Solid-State Sciences, v. 34, Berlin (1987).

[41] R. A. Ando, Espectroscopia vibracional, Raman ressonante e eltrônica de nitroderivados em sistemas conjugados, Dissertação (Mestrado) São Paulo (2005).

[42] A. M. Rao et al., Science, 275, 187 (1997).

[43] Retirado de: (http : //www.cheaptubes.com/SWNTs.htm\#swnts_90s_raman_spectra).

[44] A. Jorio, M. A. Pimenta, C. Fantini, M. Souza, A. G. Souza Filho, Ge. G. Samsonidze, G. Dresselhaus, M. S. Dresselhaus, R. Saito, Carbon 42 (2004), 1067.

[45] A. Jorio et al., Phys. Rev. B 65, 155412 (2002).

[46] A. Jorio, R. Saito, G. Dresselhaus, and M. S. Dresselhaus, Phil. Trans. R. Soc. A 362, 2311 (2004).

[47] L. Kleinman, D. M. Bylander, Phys. Rev. Lett. 48, 1425-1428 (1982).

[48] P. Ordejón, Computational Materials Science, 12, no. 3, 157-191 (1998). 
[49] O. F. Sankey, D. J. Nikleswki, Phys. Rev. B, 40, 3979 (1989).

[50] P. Ordejón, Physica Status Solidi (b), 217, 335-356 (2000).

[51] J. P. Perdew, K. Burke, M. Ernzerhof, Phys. Rev. Lett., 77, 3865-3868 (1996).

[52] N. Troullier, J. L. Martins, Physical Review B, 43, 1993-2006 (1991).

[53] H. J. Monkhorst, J. D. Pack, Phys. Rev. B, 13, 5188 (1976).

[54] Ihm et al., J. Phys. C: Solid State Phys., 12 (1979).

[55] D. Sánchez-Portal, P. Ordejón, E. Artacho, J. M. Soler, International Journal of Quantum Chemistry, 65, 453-461 (1997).

[56] D. Sanchez-Portal, E. Artacho, J. M. Solar, A. Rubio, P. Ordejon, Phys. Rev. B 59, $19,12678-12688$ (1999).

[57] N. Mounet, Structural, vibrational and thermodynamic properties of carbon allotropes from first-principles: diamond, graphite, ans nanotubes, Dissertação (Mestrado) Massachusetts Institute of Technology (2005).

[58] S. Piscanec et al., Phys. Rev. Lett. 93, 185503 (2004).

[59] S. Reich, Carbon nanotubes: Vibrational and electronic properties ab initio, Tese (Doutorado) Berlim (2002).

[60] A. M. Rao, P. C. Eklund, hunji Bandow, A. Thess, R. E. Smalley, Nature 388, 257259 (1997).

[61] A. Das, A. K. Sood, A. Govindaraj, A. M. Saitta, M. Lazzeri, F. Mauri, C. N. R. Rao, arXiv:0709.0727v1 [cond-mat.mes-hall].

[62] R. Saito, G. Dresselhaus, M. S. Dresselhaus, Properties Properties of Carbon Nanotubes, Imperial College Press, (2005).

[63] M. S. Dresselhaus, P. C. Eklund, Phonons in carbon nanotubes, Advances in Physics $49,705(2000)$

[64] J. W. G. Wilder, L. C. Venema, A. G. Rinzler, R. E. Smalley, C. Dekker, Nature 391, 59-62 (1998).

[65] M. Damnjanović, I. Milošević, T. Vuković, R. Sredanović, Phys. Rev. B, 60, 2728 (1999). 
[66] J. Zimmerman, Vibrational Modes of Carbon Nanotubes: A Force-ConstantModel Approach, Tese (Doutorado) Regensburg (2006).

[67] J. M. Soler, E. Artacho, J. D. Gale, A. Garcia, J. Junquera, P. Ordejon, D. SanchezPortal, J. Physics: Condensed Matter 14, 2745-2779 (2002).

[68] P. Ayala, A. Grüneis, C. Kramberger, M. H. Rümmeli, I. G. Solórzano, Jr. F. L. Freire, T. Pichler, J. Chem Phys., 127(18), 184709 (2007).

[69] P. T. Araújo et. al, Phys. Rev. B, 77, 241403 (2008).

[70] J. Maultzsch, S. Reich, C. Thomsen, Phys. Rev. B, 65, 233402 (2002). 